\title{
Money, Growth, and Welfare in a Schumpeterian Model with the Spirit of Capitalism*
}

\author{
Qichun $\mathrm{He}^{\dagger} \quad$ Yulei Luo ${ }^{\ddagger} \quad$ Jun $\mathrm{Nie}^{\S} \quad$ Heng-fu Zou $\mathbb{I}$
}

October 23, 2021

\begin{abstract}
According to Schumpeter (1934), entrepreneurs are driven to innovate not just for the fruits of success but also for success itself. This description of entrepreneurship echoes Weber's (190405, German; 1958) description of the "spirit of capitalism," which states that people enjoy the accumulation of wealth regardless of its effect on smoothing consumption. This paper explores the implications of the spirit of capitalism on monetary policy, growth, and welfare in a Schumpeterian growth model. Different from the existing literature, we show that money is not superneutral in the long run and it could promote economic growth when the spirit of capitalism is strong. Furthermore, we show the optimal nominal interest rate decreases with the strength of the spirit of capitalism, potentially supporting a negative interest rate.
\end{abstract}

JEL Classification Numbers: E52 O42 O47.

Keywords: spirit of capitalism; cash-in-advance; Schumpeterian model; monetary policy; growth and welfare

${ }^{*}$ We thank the Editor and the Reviewers for their thoughtful comments and constructive suggestions. The views expressed here are the opinions of the authors only and do not necessarily represent those of the Federal Reserve Bank of Kansas City or the Federal Reserve System. All remaining errors are our responsibility.

${ }^{\dagger}$ He: China Economics and Management Academy, Central University of Finance and Economics, Beijing, China. Email: qichunhe@gmail.com.

${ }^{\ddagger}$ Luo: Faculty of Business and Economics, University of Hong Kong, Hong Kong. Email: yulei.luo@gmail.com.

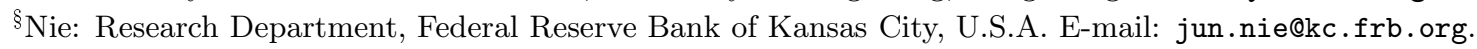

IZou: China Economics and Management Academy, Central University of Finance and Economics, Beijing, China. Email: hzoucema@gmail.com. 


\section{Introduction}

Since the pioneering work by Aghion and Howitt (1992), Schumpeterian growth theory has developed into a key framework for understanding long-run economic growth. This theory formulates Schumpeter's (1942) notion of "creative destruction" - the process by which new innovations replace old technologies - and shows that innovations resulting from entrepreneurial investments are crucial to long-run economic growth.

But what drives entrepreneurs to innovate? Schumpeter (1934) refutes the traditional and hedonistic assumption that defines entrepreneurs' utility on consumption and instead emphasizes the "psychology of entrepreneurs": the entrepreneur is strongly motivated by the "dream and the will to found a private kingdom, usually, though not necessarily, also a dynasty."

"Then there is the will to conquer, the impulse to fight, to prove oneself superior to others, to succeed for the sake, not of the fruits of success, but of success itself, from this aspect, economic action becomes akin to sport.... The financial result is a secondary consideration, or, at all events, mainly valued as an index of success and as a symptom of victory, the displaying of which very often is more important as a motive of large expenditure than the wish for the consumers' goods themselves." (p.93)

This description of entrepreneurship is very similar to Max Weber's description of the "spirit of capitalism" 1

"In fact, the summum bonum of his ethic, the earning of more and more money, combined with the strict avoidance of all spontaneous enjoyment of life, is above all completely devoid of any eudaemonistic, not to say hedonistic, admixture. It is thought of so purely as an end in itself, that from the point of view of the happiness of, or utility to, the single individual, it appears entirely transcendental and absolutely irrational. Man is dominated by the making of money, by acquisition as the ultimate purpose of his life. Economic acquisition is no longer subordinated to man as the means for the satisfaction of his material needs. This reversal of what we should call the natural relationship, so irrational from a naive point of view, is evidently as definitely a leading principle of capitalism as it is foreign to all peoples not under capitalistic influence."(p.53)

The theoretical literature on the spirit of capitalism - enjoying the accumulation of wealth regardless of its effect on consumption smoothing — shows that it has important implications on

\footnotetext{
${ }^{1}$ See Weber (1958). The German edition was published in 1904-05.
} 
economic growth and asset pricing in non-Schumpetarian growth frameworks (Zou 1994; Bakshi and Chen 1996). These findings are consistent with the empirical evidence provided by Barro (2004) and McCleary and Barro (2006, 2019) which show beliefs and religion do matter for economic activity. However, little research has explored how the spirit of capitalism would influence innovation and long-run growth in a Schumpeterian growth model.

More importantly, incorporating the spirit of capitalism could also have significant implications for the effects of monetary policy on growth and welfare. In a Schumpeterian model with money, Chu and Cozzi (2014) show that an increase in the nominal interest rate reduces both R\&D and economic growth, and that the optimal monetary policy features a positive nominal interest rate (thereby violating the Friedman rule (Friedman 1969), which says the optimal non-negative nominal interest rate is zero). The key intuition behind their results is that a higher interest rate raises the borrowing cost of entrepreneurial investment that is subject to a cash-in-advance (CIA) constraint, which helps mitigate the possible overinvestment issue in Schumpeterian models (see Aghion and Howitt 1992, 1998) 2 However, the spirit of capitalism introduces a new channel for monetary policy to influence R\&D investment, labor allocation, and consumption-leisure decisions; therefore, whether these new findings on monetary policy still hold requires a careful analysis.

To fill these gaps in the literature, we formalize Schumpeter's idea of the "psychology of entrepreneurs" by introducing the spirit of capitalism into a stylized Schumpeterian model with money based on the work of Aghion et al. (2013) and Chu and Cozzi (2014). Specifically, we model the spirit of capitalism through a direct preference for wealth. See Luo et al. (2020) for a detailed review of a long line of sociological and economic literature to justify why this modeling strategy is consistent with Weber's original work on the spirit of capitalism. To the best of our knowledge, this is the first paper to provide a unified framework to investigate (both theoretically and quantitatively) the implications of the spirit of capitalism for the effects of monetary policy on long-run growth and welfare.

Our analysis delivers three main findings. First, we show that introducing the spirit of capitalism into the Schumpeterian growth framework yields novel insights into the effects of monetary policy on long-run growth. Specifically, we theoretically prove that money is not superneutral in this framework and that the effect of higher nominal interest rates on long-run growth depends on the strength of the spirit of capitalism in an economy. When the spirit of capitalism is small or absent, a higher interest rate reduces growth. However, when the spirit of capitalism is strong

\footnotetext{
${ }^{2}$ As explained in Aghion and Howitt (1992), due to the "business-stealing" effect (i.e., the private business does not internalize the loss to the previous monopolist caused by an innovation), economic growth could be excessive relative to the optimal level (in which case the social planner takes into account the loss to the previous monopolist caused by an innovation).
} 
enough (relative to the elasticity of labor and taste for leisure), higher nominal interest rates could promote growth.

The key intuitions of this finding are as follows. Without the spirit of capitalism, an increase in the nominal interest rate reduces long-run growth through two channels. The first channel is that, due to an elastic labor supply and the CIA constraint on consumption, higher nominal interest rates encourage households to choose leisure over consumption, leading to lower labor supply in the R\&D sector and therefore lower long-run growth (this is the market size effect highlighted in Aghion et al. 2013). The second channel is that, due to the CIA constraint on R\&D, higher nominal interest rates also increase borrowing costs for entrepreneurs, shifting labor away from R\&D toward manufacturing and reducing long-run growth (a negative labor reallocation effect) 3

In contrast, with the spirit of capitalism, an increase in the nominal interest rate could promote long-run growth. Specifically, in the presence of the spirit of capitalism, a higher nominal interest rate induces consumers (who have a direct preference for wealth) to increase their savings, thereby lowering the real interest rate and raising the value of innovations for entrepreneurs 4 We show that a stronger degree of the spirit of capitalism could amplify this positive effect of a higher nominal interest rate on $\mathrm{R} \& \mathrm{D} 5$ Therefore, when the spirit of capitalism is strong enough, the positive effect could dominate the two negative effects described in the previous paragraph, causing long-run growth to increase with the nominal interest rate.

Second, we theoretically and quantitatively show that the optimal nominal interest rate decreases with the degree of the spirit of capitalism, suggesting the Friedman rule-that the optimal non-negative interest rate is zero-is likely to be valid. This finding is in contrast to the main finding in Chu and Cozzi (2014) which shows that the optimal nominal interest rate is positive in a similar Schumpeterian growth model. It also provides theoretical support for negative interest rates, which have been discussed intensively in recent years.

Third, we calibrate our model to the U.S. economy and quantify the contribution of the spirit of capitalism to long-run growth. Our analysis suggests that the spirit of capitalism explains onethird of long-run growth in the U.S. (0.6 percent out of 1.8 percent annually), which is substantial. To the best of our knowledge, this is the first study to quantify the growth contribution of the spirit of capitalism. In this sense, our analysis enriches Aghion and Howitt (1992) and provides a more complete view of Schumpeterian growth models in understanding long-run growth.

\footnotetext{
${ }^{3}$ As the second channel works in the same direction as the first channel, it is not required for generating our key finding. We include it in our quantitative analysis to be comparable with the literature.

${ }^{4}$ The value of innovation is higher or the opportunity cost of innovation is lower when the real interest rate is lower. This will be more clear when we derive the innovation process in section 2.4

${ }^{5}$ This will be more clear after we derive the consumption Euler equation which shows the nominal interest rate interacts with the marginal rate of substitution between wealth and consumption in determining saving decision.
} 
Our paper contributes to a large literature studying the implications of the spirit of capitalism or the quest for status on economic growth (Zou 1994; Futagami and Shibata 1998; Smith 1999; Corneo and Jeanne 2001), savings (Cole, Malaith and Postlewaite 1992; Zou 1995; Carroll 2000; Luo et al. 2009), asset pricing (Bakshi and Chen 1996; Smith 2001; Gong and Zou 2002), wealth distribution (Luo and Young, 2009; Corneo and Jeanne, 2001), business cycles (Karnizova 2010; Michaillat and Saez 2015, 2019), secular stagnation (Michau 2018; Ono and Yamada 2018), money (Gong and Zou 2001), taxation (Saez and Stantcheva 2018), comparison with recursive utility (Alaoui and Sandroni 2018), expansion of variety (Hof and Prettner 2019), and industrialization (Chu et al. 2020). Different from the existing literature, our paper investigates the wealth and long-run growth implications of the spirit of capitalism for monetary policy. In addition, in contrast with most of these studies which focus on the theory side, we conduct quantitative analysis based on a calibrated model and also provide empirical evidence to support the key mechanism.

Our paper also adds to the literature on the effect of monetary policy on long-run growth and welfare (Sidrauski 1967; Stockman 1981; Gomme 1993; Akerlof, Dickens and Perry 1996; Dotsey and Sarte 2000; Akyol 2004; Benigno and Ricci 2011; Brunnermeire and Sannikov 2016; Arawatari et al. 2018; Chu et al. 2019; Eyster et al. 2020). Challenging the seminar work by Sidrauski (1967) which argues for superneutrality of money in the long run (i.e., changes in the inflation rate or nominal interest rate have no effects on long-run growth), most recent studies show money could influence long-run output growth or steady-state levels through various channels. For example, Jones and Manuelli (1994) adopt an endogenous growth model with human capital and Marquis and Reffett (1994), Funk and Kromen (2010), and Chu and Cozzi (2014) focus on R\&D-driven growth models. A recent paper by Eyster et al. (2020) introduces customers' concerns for pricing fairness to the New Keynesian model, and shows that monetary policy is not neutral in the long run. Most of these studies show a negative relationship between the inflation rate and growth in the long run 6 The novel contribution of our paper is to show that the relationship between the inflation rate (or the nominal interest rate) and growth depends on the strength of the spirit of capitalism.

The remainder of this paper is organized as follows. Section 2 describes the monetary Schumpeterian model with the spirit of capitalism. Section 3 presents theoretical results and intuitions. Section 4 conducts quantitative analysis. Section 5 provides general discussions. Section 6 concludes.

\footnotetext{
${ }^{6}$ One exception is Eyster et al. (2020) which shows a positive correlation between the inflation rate and the stead-state employment level in the long run. But they do not directly study the implications of monetary policy on long-run growth.
} 


\section{A Monetary Schumpeterian Model with the Spirit of Capital- ism}

We introduce the spirit of capitalism (henceforth the SOC) - a direct preference for wealth - into a Schumpeterian growth model with money. In particular, we introduce money demand via CIA constraints on both consumption (Clower, 1967; Lucas, 1980) and R\&D (Chu and Cozzi, 2014). We employ a standard framework which combines Aghion et al. (2013) and Chu and Cozzi (2014) to study the SOC effects.

\subsection{Households}

We assume there is a unit continuum of identical households in the economy. The population size of each household is fixed at $L$. Each household has a lifetime utility function as follows:

$$
U=\int_{0}^{\infty} e^{-\rho t}\left[\ln \left(c_{t}\right)+\theta \ln \left(a_{t}\right)-\eta \frac{l_{t}^{1+1 / \sigma}}{1+1 / \sigma}\right] d t
$$

where $c_{t}$ is per capita real consumption of final goods at time $t, a_{t}$ is per capita wealth, $l_{t}$ is per capita labor supply at time $t$, and $\rho$ is the discount rate. Furthermore, we follow Aghion et al. (2013) to use $\eta$ to denote the disutility of labor and $\sigma$ to measure the Frisch elasticity of labor supply. A larger $\eta$ means that the agent has a stronger preference for leisure, while a larger $\sigma$ means a lower elasticity of labor supply or people are less responsive to wage changes 7

$\theta \geq 0$ captures the preference for wealth or the strength of the SOC. A larger $\theta$ refers to a stronger preference for wealth or a stronger SOC 8 Notice that in a representative-agent framework, introducing the SOC in the household sector can be considered as a general way to model the "psychology of entrepreneurs" described by Schumpeter's entrepreneurship. This can be rationalized by assuming internal division of labor within households - some household members specialize in making consumption/savings decisions, while the rest are responsible for entrepreneurial decisions (Angeletos and Panousi, 2009).

\footnotetext{
${ }^{7}$ As a comparison, Chu and Cozzi (2014) focuses on the taste for leisure (similar to the $\eta$ parameter in our specification) but assume a log-utility form on leisure. In Online Appendix F, we show that our main predictions hold when we use an alternative utility function $U=\int_{0}^{\infty} e^{-\rho t}\left[\ln \left(c_{t}\right)+\theta \ln \left(a_{t}\right)+\eta \frac{\left(1-l_{t}\right)^{1-\sigma}}{1-\sigma}\right] d t$ that nests Chu and Cozzi (2014) as a special case with $\sigma=1$ (and $\theta=0$ ).

${ }^{8}$ Wealth in utility can also be used to study other motivations such as bequests and inter vivos. See Kaplow (2009) for a discussion. We use absolute wealth in the utility to measure the spirit of capitalism. Using relative wealth (such as $a_{i t} / \bar{a}_{t}$ where $i$ refers to individual wealth and $\bar{a}_{t}$ is the average wealth in the economy) in the utility does not change our main results as the log utility will treat the average wealth level as a constant and thus does not alter the optimal decisions.
} 
Each household maximizes its lifetime utility given in equation (11) subject to the following asset-accumulation equation:

$$
\dot{e}_{t}+\dot{m}_{t}=r_{t} e_{t}+w_{t} l_{t}-c_{t}-\pi_{t} m_{t}+i_{t} b_{t}+\tau_{t}
$$

where $e_{t}$ is the real value of assets (i.e., the real value of equity shares in monopolistic intermediategoods firms), $r_{t}$ and $w_{t}$ are the rates of real interest and the wage, respectively, $m_{t}$ is the real money balance holding, $\pi_{t}$ is the cost of holding money (or the inflation rate), and $b_{t}$ refers to the cash borrowed by entrepreneurs to finance the wage bill of $R \& D$ workers which incurs an interest payment, $i_{t} b_{t}$. Following the standard literature, we assume households receive a lumpsum transfer of seigniorage revenue, $\tau_{t}$ (which will be defined below).

Given the budget constraint, we define wealth $a_{t}$ as the sum of the real equity value and the real money balance: $a_{t} \equiv e_{t}+m_{t}$. The CIA constraint is given by $c_{t}+b_{t} \leq m_{t} 9$ Using the Hamiltonian function, the first-order condition for consumption can be written as:

$$
\frac{1}{c_{t}}=\mu_{t}\left(1+i_{t}\right)
$$

where $\mu_{t}$ is the Hamiltonian co-state variable on (2). (See Appendix 7.1 for the derivation.) The optimal condition for labor supply is:

$$
\eta l_{t}^{1 / \sigma}=w_{t} \mu_{t}
$$

Combining (3) and (44) leads to the optimal condition for labor supply:

$$
l_{t}=\left(\frac{w_{t}}{\eta c_{t}\left(1+i_{t}\right)}\right)^{\sigma}
$$

which shows that a higher nominal interest rate or a stronger taste for leisure reduces labor supply.

The Euler equation for real assets $\left(e_{t}\right)$ is:

$$
-\frac{\dot{\mu_{t}}}{\mu_{t}}=r_{t}-\rho+\frac{\theta}{\mu_{t} a_{t}} .
$$

Combining (3) and (6) yields the following consumption Euler equation:

$$
\frac{\dot{c}_{t}}{c_{t}}=r_{t}-\rho+\theta\left(1+i_{t}\right) \frac{c_{t}}{a_{t}}
$$

Note that $\theta=0$ gives the monetary Schumpeterian model without the SOC, which says that a higher real interest rate would lead to more savings and less consumption (i.e., leading to higher

\footnotetext{
${ }^{9}$ We include the CIA constraint on both consumption and R\&D borrowing so our model results can be directly compared to Chu and Cozzi (2014). But as we will explain in later, our key results do not rely on the CIA constraint on R\&D.
} 
marginal utility of consumption); in contrast, when the discount rate $(\rho)$ is higher, it encourages more consumption (i.e., leading to lower marginal utility of consumption). When $\theta>0$, the preference for wealth accumulation tends to lower consumption by introducing a third term on the right side of equation (77). In general, this equation shows that, when people have the SOC, consumption-savings choices depend not only on the real return on wealth, $r_{t}-\rho$, but also on the marginal rate of substitution between wealth and consumption. In other words, similar to the discussion in Michaillat and Saez (2019), people become less forward-looking and future interest rates have less impact on today's consumption than in the standard model. The modification of the Euler equation due to wealth in the utility in equation (77) has also been pointed out by a few other recent studies including Michaillat and Saez (2015, 2019), Michau (2018), Michau et al. (2018), and Ono and Yamada (2018) 10

\subsection{Monetary Authority}

Let the nominal money stock at the beginning of time $t$ be $M_{t}$. For convenience, we assume that the monetary authority controls the nominal interest rate $i_{t}$ (through controlling the growth rate of money stock $M_{t} / M_{t}$ ) and rebates the seigniorage revenue back to households. The per capita seigniorage revenue is $\tau_{t}=\dot{M}_{t} /\left(P_{t} L\right)$. The per capita real money balance is $m_{t}=M_{t} /\left(P_{t} L\right)$, where $P_{t}$ is the price level of the final goods and the inflation rate is given by $\dot{P}_{t} / P_{t}=\pi_{t}$. Thus, $\dot{m}_{t} / m_{t}=\dot{M}_{t} / M_{t}-\pi_{t}$ and $\tau_{t}=\left(\dot{m}_{t} / m_{t}+\pi_{t}\right) m_{t}=\dot{m}_{t}+\pi_{t} m_{t}$.

If we substitute the Fisher equation $i_{t}=\pi_{t}+r_{t}$, the equilibrium result $\dot{m}_{t} / m_{t}=\dot{c}_{t} / c_{t}$, and $\dot{M}_{t} / M_{t}=\dot{m}_{t} / m_{t}+\pi_{t}$ into the consumption Euler equation (17), we have:

$$
\frac{\dot{M_{t}}}{M_{t}}=i_{t}-\rho+\theta\left(1+i_{t}\right) \frac{c_{t}}{a_{t}}
$$

The existence of the SOC slightly complicates the relationship between the nominal interest rate $i_{t}$ and the money supply growth rate $\dot{M}_{t} / M_{t}$ by introducing an extra term on the right side of (8) . Fixing the consumption-to-wealth ratio $c_{t} / a_{t}$, it is easy to see higher nominal interest rates also lead to higher money supply growth. However, as we will derive later, the consumption-to-wealth ratio is also a function of nominal interest rate. In Online Appendix C, we numerically confirm that the positive relationship is well maintained in the presence of the SOC.

As a note, our model is designed to focus on long-run growth and not about studying exogenous shocks during business cycles or government countercyclical/stabilization policies. In our model,

\footnotetext{
${ }^{10}$ If we assume no CIA on consumption and only a CIA constraint on R\&D, the nominal interest rate could still influence households' saving decision through influencing the consumption-wealth ratio. We have shown this in Online Appendix A.
} 
the nominal interest rate is deterministically controlled by the government and we are interested in how it affects the long-run growth and welfare of the economy. In addition, it makes no difference whether the inflation or the nominal interest rate (or the nominal money growth rate) is chosen as the policy instrument in our deterministic model. We use the nominal interest rate as the math notations are simpler and the model is easier to solve analytically.

\subsection{Production Side}

We follow Chu and Cozzi (2014) who rewrite the Schumpeterian model of Aghion and Howitt (1992) to remove the scale effect (explained later). First, there is a perfectly competitive final goods sector in which the final-goods sector which has the following production function:

$$
y_{t}=\exp \left(\int_{0}^{1} \ln x_{t}(\epsilon) d \epsilon\right)
$$

where $x_{t}(\epsilon)$ denotes differentiated intermediate goods $\epsilon \in[0,1]$. Perfect competition means firms take the price of each intermediate good $\epsilon, p_{t}(\epsilon)$, as given. Firms' profit maximization leads to the demand function for $x_{t}(\epsilon)$ :

$$
x_{t}(\epsilon)=y_{t} / p_{t}(\epsilon) .
$$

Second, there is a monopolistic intermediate goods sector, with a unit continuum of manufacturing industries producing differentiated intermediate goods. Each industry produces one intermediate good for the final goods sector. Within each monopolistic industry $\epsilon$, an industry leader with the highest level of productivity dominates and produces intermediate good $\epsilon$ with labor as the only input:

$$
x_{t}(\epsilon)=\gamma^{N_{t}(\epsilon)} L_{x, t}(\epsilon)
$$

where $L_{x, t}(\epsilon)$ is the production labor in industry $\epsilon, \gamma>1$ is the step size of innovation, and $N_{t}(\epsilon)$ is the number of innovations that have occurred in industry $\epsilon$ as of time $t$.

The marginal cost of production for the leader in industry $\epsilon$ is $m c_{t}(\epsilon)=w_{t} / \gamma^{N_{t}(\epsilon)} . \gamma>1$ means each vertical innovation allows a worker to produce one unit of intermediate good with less time. When the next innovation arrives, its owner has a lower marginal cost: $m c_{t}(\epsilon) / \gamma$. Bertrand price competition leads to a profit-maximizing price $p_{t}(\epsilon)$ equal to the marginal cost of the previous innovation $w_{t} / \gamma^{N_{t}(\epsilon)-1}$, which is a markup $\gamma$ over its own marginal cost. Therefore, the labor income from the manufacturing sector is:

$$
w_{t} L_{x, t}(\epsilon)=\left(\frac{1}{\gamma}\right) p_{t}(\epsilon) x_{t}(\epsilon)=\left(\frac{1}{\gamma}\right) y_{t}
$$


and the monopolistic profit of each industry's leader is given by:

$$
\Pi_{t}(\epsilon)=\left(1-\frac{1}{\gamma}\right) p_{t}(\epsilon) x_{t}(\epsilon)=\left(\frac{\gamma-1}{\gamma}\right) y_{t} .
$$

\subsection{Innovation Process}

Within each industry $\epsilon$, there is a unit continuum of $\mathrm{R} \& \mathrm{D}$ firms $j \in[0,1]$ that conduct innovations to achieve the positive monopolistic profit given in (13). The value of each innovation (i.e., the value of the monopolistic firm in industry $\epsilon$ ) is denoted $v_{t}(\epsilon)$. In a symmetric equilibrium, $v_{t}(\epsilon)=v_{t} 11$ There is free entry into R\&D which means free labor mobility - the cost of innovation equals the foregone wage rate.

To capture the strength of the CIA on $R \& D$, we assume that entrepreneurs borrow cash to finance $\beta \in[0,1]$ fraction of the wage bills of $\mathrm{R} \& \mathrm{D}$ workers. So the total cost of R\&D for firm $j$ would be $(1-\beta) w_{t} L_{r, t}(j)+\beta\left(1+i_{t}\right) w_{t} L_{r, t}(j)=\left(1+\beta i_{t}\right) w_{t} L_{r, t}(j)$, and the zero-expected-profit condition of R\&D firm $j$ in each industry is:

$$
\lambda_{t}(j) v_{t}=\left(1+\beta i_{t}\right) w_{t} L_{r, t}(j)
$$

where $L_{r, t}(j)$ is the amount of labor hired by $\mathrm{R} \& \mathrm{D}$ firm $j$, and $\lambda_{t}(j)$ is the firm-level innovation rate per unit time: $\lambda_{t}(j)=\varphi\left(L_{r, t}(j) / L\right)$, where $\varphi$ is a constant which measures the productivity of R\&D labor in conducting innovation activities. Note that $\lambda_{t}(j)$ is scaled by total population $L$, which eliminates the scale effects to yield the scale-invariant model as the labor share rather than total population matter for growth. (See Laincz and Peretto (2006) and Segerstrom (1998) for discussions on the scale effect.)

The aggregate arrival rate of innovation can be written as:

$$
\lambda_{t}=\int_{0}^{1} \lambda_{t}(j) d j=\frac{\varphi}{L} L_{r, t}=\varphi l_{r, t},
$$

where $l_{r, t}$ is the share of labor employed in the R\&D sector. Similarly, the share of labor in production/manufacturing is $l_{x, t}=L_{x, t} / L$. The no-arbitrage condition for $v_{t}$ is:

$$
v_{t}=\frac{\Pi_{t}+\dot{v}_{t}-\lambda_{t} v_{t}}{r_{t}}
$$

which means that the value of an innovation equals the discounted value of the sum of the flow profit of innovation $\left(\Pi_{t}\right)$ and potential capital gain $\left(\dot{v}_{t}\right)$ less the expected capital loss $\left(\lambda_{t} v_{t}\right)\left(\lambda_{t}\right.$ is the arrival rate of the next innovation). Another way to understand this equation is that the opportunity cost $r_{t} v_{t}$ of holding an innovation equals the sum of the flow profit of innovation $\left(\Pi_{t}\right)$ and potential capital gain $\left(\dot{v}_{t}\right)$ less the expected capital loss $\left(\lambda_{t} v_{t}\right)$. In either explanation, a decline in $r_{t}$ increases the value of innovation.

\footnotetext{
${ }^{11}$ See the justifications provided in Cozzi et al.(2007) for this equilibrium.
} 


\subsection{Labor Market and the Final Goods Market Clearing Condition}

Labor is used in both manufacturing (producing intermediate goods) and R\&D activities. The labor market clearing condition is:

$$
L_{x, t}+L_{r, t}=l_{t} L
$$

where $L_{x, t}$ and $L_{r, t}$ are the total employment in manufacturing and $\mathrm{R} \& \mathrm{D}$, respectively.

To derive the final goods market clearing condition, we first plug $\tau_{t}=\left(\dot{m}_{t}+\pi_{t} m_{t}\right)$ into (2) which yields the resource constraint of the economy: $\dot{e}_{t}=r_{t} e_{t}+w_{t} l_{t}-c_{t}+i_{t} b_{t}$. Then, using $v_{t}=e_{t} L$ and $l_{t}=l_{x, t}+l_{r, t}$, we can rewrite the resource constraint as $\dot{v}_{t} / L=r_{t} v_{t} / L+w_{t}\left(l_{x, t}+l_{r, t}\right)-c_{t}+i_{t} b_{t}$. Since the amount of cash borrowed by entrepreneurs satisfies $b_{t} L=\beta w_{t} L_{r, t}$, we have $\dot{v}_{t} / L=$ $r_{t} v_{t} / L+w_{t} l_{x, t}+(1+\beta i) w_{t} l_{r, t}-c_{t}$. Finally, using (12) to replace $w_{t} l_{x, t}$ and substituting (13), (14), and (16) into the previous equation to replace $(1+\beta i) w_{t} l_{r, t}$, we get

$$
\frac{\dot{v_{t}}}{L}=\frac{r_{t} v_{t}}{L}+\frac{y_{t}}{\gamma L}+\frac{(1-1 / \gamma) y_{t}+\dot{v}_{t}-r_{t} v_{t}}{L}-c_{t}
$$

which implies that the final goods market clearing condition is $c_{t}=y_{t} / L$.

\subsection{Equilibrium Balanced Growth}

Plugging equation (63) into (9), we have:

$$
y_{t}=\exp \left(\int_{0}^{1} N_{t}(\epsilon) d \epsilon \ln \gamma\right) L_{x}=\exp \left(\int_{0}^{t} \lambda_{v} d v \ln \gamma\right) L_{x} \equiv Z_{t} L_{x}
$$

where the law of large numbers has been applied and $Z_{t} \equiv \exp \left(\int_{0}^{t} \lambda_{v} d v \ln \gamma\right)$ is the level of aggregate technology. The growth rate of $Z_{t}$ is then:

$$
g_{z}=\lambda_{t} \ln \gamma=\varphi l_{r, t} \ln \gamma
$$

The general equilibrium for our model is defined as follows:

Definition Given a nominal interest rate $i_{t}$ and an initial condition $Z_{0}$, a dynamic equilibrium for the model is a time path of prices $\left\{p_{t}(\epsilon), r_{t}, w_{t}, i_{t}, \pi_{t}, v_{t}\right\}$ and allocations $\left\{c_{t}, e_{t}, m_{t}, y_{t}, x_{t}(\epsilon)\right.$, $\left.L_{x, t}(\epsilon), L_{r, t}(j)\right\}$ such that: given prices, the households maximize utility, competitive final-goods firms maximize profit, monopolistic intermediate-goods firms choose $\left\{L_{x, t}(\epsilon), p_{t}(\epsilon)\right\}$ to maximize profit, and $R \xi D$ firms choose $\left\{L_{r, t}(j)\right\}$ to maximize expected profit; all markets clear, that is, the labor market clears $\left(L_{x, t}+L_{r, t}=l_{t} L\right)$, and the final goods market clears $\left(y_{t}=c_{t} L\right)$; the $C I A$ constraint binds: $c_{t}+b_{t}=m_{t}$, and the amount of cash borrowed by entrepreneurs satisfies $b_{t} L=\beta w_{t} L_{r, t}$; the value of monopolistic firms adds up to the value of households' assets (i.e., $\left.v_{t}=e_{t} L\right)$. 
As shown in Kurz (1968), multiple steady-state equilibria will emerge when capital enters the utility function. In our model, we find that the dynamics of the model remains similar to that in Chu and Cozzi (2014) 12 That is, the economy immediately jumps to a unique and saddle-point stable balanced-growth path on which each variable grows at a constant rate, as summarized in Proposition 1 below.

Proposition 1 Given a nominal interest rate (i.e., $i_{t}=i$ ), the dynamics of the economy is that the economy immediately jumps to unique and saddle-point stable balanced growth path on which each variable grows at a constant rate.

Proof. See Appendix 7.2 for the derivation.

On the balanced growth path, the output market clearing condition implies that $c_{t}$ and $y_{t}$ must grow at the same rate: $g_{c}=g_{y}$ (we use $g$ to denote the growth rate). Equation (18) yields $g_{y}=g_{z}$. The binding CIA constraint delivers $g_{c}=g_{m}$. Therefore, the balanced growth rate $g_{t}$ (the growth rate of per capita consumption or output) is the one given in (19).

Because the balanced growth rate is uniquely pinned down by the share of labor employed by $\mathrm{R} \& \mathrm{D}$ firms, we solve for the equilibrium labor allocation at the nominal interest rate $i$. Using equations (7) and (12)-(15), we can derive the following two equations regarding optimal labor allocation and the consumption-wealth ratio, respectively (see Appendix 7.3 for details):

$$
\begin{gathered}
(\gamma-1) l_{x, t}=(1+\beta i)\left(l_{r, t}+\rho / \varphi-\frac{\theta(1+i) c_{t}}{\varphi a_{t}}\right), \\
\frac{c_{t}}{a_{t}}=\frac{\gamma w_{t} L_{x, t}}{(1+\beta i) w_{t} L_{r, t} / \lambda+\gamma w_{t} L_{x, t}+\beta w_{t} L_{r, t}}=\frac{\gamma l_{x, t}}{(1+\beta i) / \varphi+\gamma l_{x, t}+\beta l_{r, t}} .
\end{gathered}
$$

Combining $c_{t}=y_{t} / L$ with (12), we have $c_{t}=\gamma w_{t} l_{x, t}$. Now the labor market clearing condition becomes:

$$
l_{r, t}+l_{x, t}=l_{t}=\left(\frac{1}{\eta \gamma l_{x, t}(1+i)}\right)^{\sigma} .
$$

Using (21) to substitute out the consumption wealth ratio in (20), we have

$$
(\gamma-1) l_{x, t}=(1+\beta i)\left(l_{r, t}+\rho / \varphi-\frac{\theta(1+i) \gamma l_{x, t}}{(1+\beta i)+\varphi \gamma l_{x, t}+\varphi \beta l_{r, t}}\right) .
$$

For a given $i$, the labor market clearing condition (22) and the free labor mobility condition (23) pin down the stationary equilibrium labor allocation $\left\{l_{r}, l_{x}\right\}$ on a balanced growth path.

\footnotetext{
${ }^{12}$ Hof and Prettner (2019) also show that there exists a unique saddle-point stable balanced growth path in a Romer-type expanding varieties model (Romer, 1990) with capital accumulation.
} 


\section{Main Theoretical Results and Intuitions}

We provide two propositions regarding the effects of the SOC on long-run growth and welfare in this section. As the key mechanism does not rely on the CIA constraint on the R\&D, we assume the CIA constraint only applies to consumption in this section, which allows us to more clearly explain the key intuitions using our analytical results. In the next section, we include the CIA constraint on the $\mathrm{R} \& \mathrm{D}$ when presenting the quantitative analysis to better compare with recent findings in the literature.

\subsection{Growth}

The following proposition summarizes our key result on growth which shows monetary policy's effects on growth (including both the size and the direction) crucially depend on the strength of the SOC:

Proposition 2 With the CIA constraint on consumption and elastic labor supply (i.e., $\eta>0)$, if $[\eta \gamma(1+i)]^{-\sigma /(1+\sigma)} \leq 1$, whether a higher nominal interest rate leads to higher long-run economic growth depends on the relative sizes of the elasticity of labor supply $(\sigma)$ and the taste for leisure $(\eta)$ versus the degree of the $S O C(\theta)$. In particular, when the degree of the SOC is strong enough, higher nominal interest rates promote growth; when the elasticity of labor supply or the taste for leisure is large enough, higher nominal interest rates reduce growth.

Proof. See Appendix 7.4 for the derivation.

As Proposition 2 presents the main results of our model, we provide some explanations to help understand the results. First, the optimal labor allocation between the production sector and the R\&D sector plays a crucial role in understanding this proposition. Like in Chu and Cozzi(2014), on the balanced growth path, the growth rate of the economy in our model is a linear function of the R\&D labor share given in (19). Two conditions pin down the equilibrium labor allocation in our model: (i) the labor market clearing condition described by (22) which gives the total amount of labor resource, and (ii) the free labor mobility condition described by (23) which determines the optimal labor allocation between production and R\&D by equating the wage rates between the two sectors. Graphically, putting manufacturing labor $l_{x, t}$ on the horizontal axis, (22) is a downward-sloping curve (the $L$ curve in Figure 1), while (23) is an upward-sloping curve (the $M$ curve in Figure 1). The intersection of the two lines shows the equilibrium labor allocation 13

\footnotetext{
${ }^{13}$ Note that a larger $\eta$ means the agent has a stronger preference for leisure which decreases labor supply. Similarly, a lower elasticity of labor supply (a larger $\sigma$ ) means people are less responsive to wage changes which also tends to decrease total labor supply. In Figure 1, a larger $\eta$ or $\sigma$ tends to shift the $L$ curve leftward and reduce the
} 
Second, let's explain the key mechanisms for monetary policy to affect growth with and without the SOC. Without the SOC, an increase in the nominal interest rate reduces total labor supply $l_{t}$ and therefore lowers both manufacturing and R\&D labor, leading to lower long-run growth (we can name it the consumption-leisure choice effect). Graphically, an increase in the nominal rate leads the $L$ curve to shift downward but does not change the $M$ curve 14

In contrast, the presence of the SOC creates a new channel - the labor reallocation channelfor monetary policy to positively affect the optimal R\&D labor input and long-run growth. This channel operates through altering the saving behavior of households which affects the real interest rate $r_{t}$. We can see this in two ways. The first way is to compare the Euler equations with and without the SOC:

$$
\begin{aligned}
& \frac{\dot{c}_{t}}{c_{t}}=r_{t}-\rho+\theta\left(1+i_{t}\right) \frac{c_{t}}{a_{t}}, \text { with the SOC, } \\
& \frac{\dot{c}_{t}}{c_{t}}=r_{t}-\rho, \text { without the SOC. }
\end{aligned}
$$

It is clear from (24) that an increase in the nominal interest rate will amplify the effect of marginal rate of substitution between wealth and consumption $\left(\frac{c_{t}}{a_{t}}\right)$ on consumption-saving decision, which increases savings and thus leads to a decline in the real interest rate $\left(r_{t}\right)$. This raises the value of innovations which attracts more labor in the R\&D sector (we therefore call this effect the labor reallocation effect). Thus, with the SOC, an increase in the nominal interest rate generates a positive effect on R\&D labor and long-run growth through the labor reallocation effect. Without the SOC, this effect does not exist as shown by equation (25).

We can also use Figure 1 to provide a graphical explanation. An increase in the nominal interest rate shifts the $M$ curve upward and a stronger SOC tends to amplify the upward shift. Without the SOC, an increase in the nominal interest rate cannot shift the $M$ curve (also seen from the free labor mobility condition (23) under $\beta=0$ and $\theta=0$ ). Thus, the existence of the SOC creates a new channel for monetary policy to positively affect R\&D labor and thereby long-run growth. In particular, when the degree of the SOC is large enough, the positive labor reallocation effect (i.e., the upward shift in the $M$ curve) may outweigh the negative consumptionleisure choice effect (i.e., the downward shift in the $L$ curve), leading the equilibrium R\&D labor to increase in response to a rise in the nominal interest rate. In contrast, without the SOC, R\&D labor will always fall when the nominal interest rate rises because the positive labor reallocation channel does not exist.

equilibrium level of labor input in the $\mathrm{R} \& \mathrm{D}$ sector and thus the long-run growth rate.

${ }^{14}$ This can be seen by equation (23) when $\beta=0$ and $\theta=0$. Notice that a larger Frisch elasticity of labor supply $(\sigma)$ or a stronger taste for leisure $(\eta)$ would strengthen the negative consumption-leisure choice effect, as shown by equation (22). 
Corollary 1 Under the assumptions of an elastic labor supply and a CIA constraint on consumption only, the consumption-wealth ratio is a decreasing function of the nominal interest rate and the strength of the SOC.

Proof. The consumption to wealth ratio in (21) shows that it is increasing in the manufacturing labor $l_{x}$ when the CIA on R\&D is absent (i.e., $\beta=0$ ). Based on Proposition 2 and its proof, we have

$$
\frac{\partial\left(c_{t} / a_{t}\right)}{\partial i}=\frac{\partial\left(c_{t} / a_{t}\right)}{\partial l_{x}} \frac{\partial l_{x}}{\partial i}<0 \text { and } \frac{\partial\left(c_{t} / a_{t}\right)}{\partial \theta}=\frac{\partial\left(c_{t} / a_{t}\right)}{\partial l_{x}} \frac{\partial l_{x}}{\partial \theta}<0
$$

\subsection{Welfare}

Before we show our key proposition on welfare implications, we first derive our welfare function. As Proposition 1 shows, given a change in the nominal interest rate, the economy will jump immediately to a new balanced growth path. This makes welfare comparison easier as we only need to focus on the initial levels (of consumption and wealth) and the balanced growth rate. Let's denote a variable with a subscript 0 , such as $l_{x, 0}, l_{r, 0}$, to be its initial value when the economy reaches the balanced growth path. Then, we can explicitly derive a welfare function based on (1) on the balanced growth path:

$$
\begin{aligned}
U & =\frac{1}{\rho}\left[\ln \left(c_{0}\right)+\theta \ln \left(a_{0}\right)+\frac{(1+\theta) g}{\rho}-\eta \frac{l_{0}^{1+1 / \sigma}}{1+1 / \sigma}\right] \\
& =\frac{1}{\rho}\left[(1+\theta) \ln \left(c_{0}\right)-\theta \ln \left(\frac{c_{0}}{a_{0}}\right)+\frac{(1+\theta) g}{\rho}-\eta \frac{l_{0}^{1+1 / \sigma}}{1+1 / \sigma}\right] \\
& =\frac{1}{\rho}\left[(1+\theta) \ln \left(Z_{0} l_{x, 0}\right)-\theta \ln \left(\frac{\gamma l_{x, 0}}{1 / \varphi+\gamma l_{x, 0}}\right)+\frac{(1+\theta) g}{\rho}-\eta \frac{l_{0}^{1+1 / \sigma}}{1+1 / \sigma}\right] \\
& =\frac{1}{\rho}\left[\ln \left(l_{x, 0}\right)+\theta \ln \left(\frac{1}{\varphi}+\gamma l_{x, 0}\right)+\frac{(1+\theta) g}{\rho}-\eta \frac{l_{0}^{1+1 / \sigma}}{1+1 / \sigma}-\theta \ln \gamma\right],
\end{aligned}
$$

where $l_{0}=l_{x, 0}+l_{r, 0}$, and $g=\varphi l_{r, 0} \ln \gamma$. Note that the second to the last equality uses the final goods market clearing condition to replace $c_{0}$ and the consumption-wealth ratio in (21) (imposing $\beta=0$ ) to replace $c_{0} / a_{0}$; the last equality normalizes $Z_{0}$ (the aggregate technology at time 0 ) to 1.

Expression (26) shows that welfare depends on growth (which is a linear function of the R\&D labor $l_{r}$ ), manufacturing labor $l_{x, 0}$ (which drives the initial level of consumption and wealth on the balanced growth path), and labor supply $l_{0}$ (or leisure $1-l_{0}$ ). The following proposition provides a general characterization of the effect of the SOC on optimal monetary policy: 
Proposition 3 When the $S O C$ is relatively low, the optimal nominal interest rate is a decreasing function of the degree of the $S O C$.

Proof. See Appendix 7.5 for the derivation.

Note the condition "the SOC is relatively low" is to ensure that higher nominal interest rates reduce growth (based on Proposition 2). The intuition behind Proposition 3 is as follows. According to (26), the effect of a higher nominal interest rate on welfare can be decomposed in two parts:

$$
\frac{\partial U(\theta)}{\partial i}=\frac{1}{\rho}[\underbrace{\left(\frac{1}{l_{x, 0}}+\frac{\varphi \gamma \theta}{1+\varphi \gamma l_{x, 0}}\right) \frac{\partial l_{x, 0}}{\partial i}+\frac{(1+\theta)}{\rho} \frac{\partial g}{\partial i}}_{\mathrm{MWL}} \underbrace{-\eta l_{0}^{1 / \sigma} \frac{\partial l_{0}}{\partial i}}_{\mathrm{MWG}}]
$$

The first part of (27) represents the marginal welfare loss (MWL) from a higher nominal interest rate which includes the negative effect on consumption and wealth (the first term) and the negative effect on growth (the second term). Note that we have used the result (in Proposition 2) that when the SOC is relatively low, a higher nominal interest rate reduces growth. The second part represents the marginal welfare gain (MWG) from a higher nominal interest rate due to an increase in leisure (or a decline in labor supply).

When the SOC increases, it will immediately increase the absolute value of the MWL (i.e., making it more negative) while it doesn't move the MWG 15 To force the MWL to equal to the MWG, the nominal interest rate needs to decline which reduces the absolute value of the MWL while increasing the MWG. Therefore, the optimal nominal interest rate is a decreasing function of the SOC.

It's worth noting that the condition "when the SOC is relatively low" is a sufficient condition but not a necessary condition for Proposition 3 to hold. When the SOC is high, the effect of a higher nominal interest rate on growth becomes positive, making the overall effect of SOC on the MWL ambiguous and therefore it's more difficult to prove this result theoretically. However, our quantitative analysis based on the calibrated model in the next section suggests that Proposition 3 could still hold even when the SOC is strong (such that a higher nominal interest rate promotes growth). The reason is that, even when a higher SOC promotes growth, it lowers optimal labor input and output in the manufacturing sector. Thus, when the second effect dominates the first one, a higher SOC still increases the absolute value of the MWL and therefore still requires the nominal interest rate to reduce to equalize the MWL to the MWG.

\footnotetext{
${ }^{15}$ The unchanged MWG can also be seen from Figure 1 That is, an increase in $\theta$ will only shift the M curve but does not change the $\mathrm{L}$ curve. The result is a re-allocation of labor (between the manufacturing sector and the R\&D sector) while leaving the total labor supply unchanged.
} 


\section{Quantitative Analysis and Empirical Evidence}

In this section, we use a calibrated version of the model to quantitatively show how monetary policy's effect on long-run growth and welfare could crucially depend on the strength of the SOC. There are three purposes of such a quantitative analysis. First, this numerical example complements the theoretical results by providing results with the CIA constraint also applying to R\&D. This also allows us to directly compare the results with Chu and Cozzi (2014) and show that the presence of the SOC could alter the main results in Chu and Cozzi (2014). Second, the calibration provides an opportunity to numerically examine if the condition in Proposition 2 holds under the calibrated parameter values. We also use the calibrated model to show the results can hold under more general conditions (as we comment in the discussion of Proposition 2). Third, we can also use the calibrated model to quantify the contribution of the SOC to long-run growth, which is missing in the literature on the growth effects of the SOC.

\subsection{Calibration}

We calibrate the model in two steps. In the first step, we pin down a few parameters' values directly from the data or the values commonly used in the literature. Our first group consists of 3 parameters. We set the labor elasticity parameter $\sigma=0.5$ according to the macro literature (see Aghion et al. 2013). We set the discount rate $\rho=0.04$, a standard value used in the literature. We set the parameter on the CIA constraint $\beta=0.05$ which means $5 \%$ of $\mathrm{R} \& \mathrm{D}$ investment faces the CIA constraint 16

In the second step, we jointly calibrate other key parameters (which are difficult to directly assign values) to match a few key moments. This consists of 4 parameters: the degree of the $\operatorname{SOC}(\theta)$, the taste of leisure parameter $(\eta)$, and the two innovation parameters $(\varphi, \gamma)$. As these parameters are difficult to directly measure, we jointly calibrate them to four data moments: (1) U.S. long-run economic growth (from the FOMC's published long-run growth projection); (2) the consumption to wealth ratio 17 (3) the real interest rate 18 and (4) total labor supply $l=1 / 3$

\footnotetext{
${ }^{16}$ We provide sensitive analysis in Section 4.2.4 and show this parameter has little effects on our calibration results.

${ }^{17}$ The aggregate consumption to wealth ratio is constructed based on its formula $c / a=c /(e+m)=$ $(c / y) /(y /(e+c))$ where we used $m=c$ as in the model. $c / / y$ is measured by the U.S. consumption-GDP ratio and $e / y$ is measured by the U.S. market-cap to GDP ratio (https://www.longtermtrends.net/market-cap-to-gdp/).

${ }^{18}$ The real interest rate is calculated by subtracting inflation from the nominal interest rate. The normal interest rate is based on the average level of 1-year Treasury yield in 1960-2019, which is 5.04\%. We use core PCE inflation (the measure used by the Federal Reserve to set monetary policy) as our measure of inflation and set $\pi=3.25 \%$ which is the average level in 1960 - 2019. As report in Table 1 the resulting real interest rate is $1.79 \%$.
} 
(i.e., 8 hours out of 24 hours). Parameter values are reported in Table 1, It is worth noting that our calibrated value of the degree of the SOC (0.09) is slightly smaller but comparable to that obtained in Bakshi and Chen (1996). In a model with the SOC and CRRA preferences, they find that when the relative weight of the degree of the SOC compared to the degree of risk aversion to consumption is about $1 / 3-1 / 2$, the model can explain the joint behavior of aggregate consumption and the equity return observed in the U.S. economy. As we will show in the next section, using a larger value of $\theta$ will strengthen our new findings.

Under these parameter values, we can first check if the condition in Proposition $2[\eta \gamma(1+i)]^{-\sigma /(1+\sigma)} \leq$ 1 is satisfied. Indeed, plugging in the parameter values, $[\eta \gamma(1+i)]^{-\sigma /(1+\sigma)}=0.32<1$. In general, as $\sigma>0$, we only need $\eta \gamma \geq 1 /(1+i)$ to satisfy $[\eta \gamma(1+i)]^{-\sigma /(1+\sigma)} \leq 1$. As the key data moment to pin down the labor supply elasticity $\eta$ is fixed at $1 / 3$ (i.e., eight hours per day), our calibration suggests that the value of $\eta$ is around 25 and therefore this condition is likely to hold quite generally.

\subsection{Quantitative Results}

We present three sets of results on implications of the SOC on monetary policy, growth, and welfare.

\subsubsection{Growth Implications}

We revisit Proposition 2 using our calibrated model which assumes the CIA constraint applies to both consumption and R\&D. Figure 2 shows how growth changes with the nominal interest rate at different degrees of the SOC. The solid line is based on our calibrated value of $\theta$. It shows that monetary policy has very little effect on long-run growth as the flatness of the curve suggests (the slope is only slightly negative). When the SOC is absent, this curve (the blue dashed line) is more downward sloping, meaning that an increase in the nominal interest rate reduces growth. This is consistent with the finding in Chu and Cozzi (2014). However, when the degree of the SOC increases, the slope could become positive, such as the two green dashed and dotted lines show. This suggests that an increase in the nominal interest rate could promote long-run economic growth when the degree of the SOC is strong.

This finding is important as the degree of the SOC could differ significantly across countries. Weber (1958) uses the emergence of the SOC in western countries to explain why capitalism developed in western countries rather than in China. Weber refutes the fact that only westerners love accumulating wealth by arguing that people in ancient China also loved accumulating wealth. The difference, according to our understanding, is that the Protestant Reformation tries to instill 
the SOC into every secular person such as through the intergenerational transmission and shaping of children's religious preference by their parents (as highlighted in Doepke and Zilibotti, 2008). Therefore, unlike ancient China where the preference for wealth was not spread to the majority of the population, western countries have the SOC in secular Protestants who account for a large fraction of total population. From this point of view, the influences of different religions/culture may lead to the differences in the SOC across countries.

The different effects of monetary policy on growth are mainly through the labor-allocation channel. As the top left panel in Figure 3 shows, the relationship between R\&D labor $\left(l_{r}\right)$ and the nominal interest rate displays the same pattern as the relationship between growth and the nominal interest rate: when there is no SOC, it is a downward sloping curve; but, when the SOC is strong enough it becomes an upward sloping curve. The change in the relationship between nominal interest rate and $R \& D$ labor is a result of three competing forces. Specifically, there are two forces producing negative effects of nominal interest rates on R\&D labor: (a) higher nominal interest rates reduce total labor supply via the consumption-leisure choice, which reduces both R\&D labor and manufacturing labor; and (b) higher nominal interest rates also increase the borrowing cost of entrepreneurs through the CIA constraint on $\mathrm{R} \& \mathrm{D}$, thereby reducing demand for R\&D labor. On the other hand, the presence of the SOC also leads to a positive effect. Specifically, (c) higher nominal interest rates increase savings (see household's Euler equation (77) ) and thus lowers the real interest rate $(r)$, leading to lower borrowing costs for entrepreneurs. This raises the value of innovations, as seen from the no-arbitrage condition, (16), and thus attracts more labor into the R\&D sector (which can be seen in (14)). Overall, the positive effect becomes larger when the SOC is stronger and could dominate the two negative effects, causing the total effect to be positive on $R \& D$ labor. That is exactly what we see in the top left panel in Figure 3 .

Decomposing the effects of the nominal interest rate on labor into the above three effects also helps us to understand the role of the CIA constraint on the R\&D activity. Specifically, the effect of the CIA constraint on R\&D is mainly through (b). In other words, the presence of the CIA constraint magnifies the negative forces of nominal interest rates on $R \& D$ labor, but it does not materially influence the positive channel (c). Therefore, our key result that the SOC could change the effect of a higher nominal interest rate on growth from negative to positive does not rely on the assumption of the CIA constraint on R\&D. This also explains why Proposition 2 captures the key mechanisms of our new findings. 


\subsubsection{Welfare Implications}

Figure 4 shows that the SOC also has important implications for optimal monetary policy. Specifically, as the figure shows, the optimal nominal interest rate (represented by circles on each line) shifts to the left as the degree of the SOC increases. For example, the optimal nominal interest rate is positive in a model without the SOC (blue dashed line). However, in our calibrated model (the blue solid line), the optimal nominal interest rate is either zero (if we set zero as a lower bound for the nominal rate) or negative (if we allow the nominal rate to fall into the negative territory).

These findings generate two implications. First, it suggests that the existence of the SOC could make the Friedman rule more likely as the optimal. That is, a zero inflation rate could maximize welfare due to the existence of the SOC, altering the recent finding by Chu and Cozzi (2014). Second, if we allow the nominal interest rate to fall into the negative territory, such as what several advanced countries are using now, the existence of the SOC provides a possible justification on why a negative interest rate could be the optimal one. This result echoes the finding in Michaillat and Saez $(2015,2019)$ which shows that (in a New Keynesian model) the natural rate of interest decreases with the marginal utility of wealth and therefore the natural interest rate can be negative in steady state.

It's important to note that the optimal nominal interest rate that maximizes welfare may not be the one that maximizes the long-run growth, which is a typical result in the Schumpeterian growth framework, including our model and Chu and Cozzi (2014). Let's explain why this is the case in our model using the welfare expression (26). In general, the welfare depends on long-run growth, initial level of consumption and wealth, and labor supply. There is generally a trade-off between the balanced-growth rate and the initial consumption level (when reaching the balanced growth path) 19 For example, when the nominal interest rate increases growth, it raises labor input in the $\mathrm{R} \& \mathrm{D}$ sector but reduces manufacturing labor $l_{x, 0}$, leading to lower initial consumption. Therefore, whether a higher nominal interest that raises growth will improve welfare is ambiguous. In addition, a higher nominal interest rate also reduces total labor supply, leading to higher leisure which improves welfare. So, the overall effect of the nominal interest rate on welfare is not necessarily in line with the effect on growth. This helps explains why under a stronger SOC, higher nominal interest rates promote growth while the optimal nominal interest rate also decreases with the SOC.

\footnotetext{
${ }^{19}$ The initial consumption level positively depend on manufacturing labor (or final output).
} 


\subsubsection{Quantifying the Overall Growth Effect of the SOC}

Figure 2 shows that a stronger SOC leads to higher long-run growth, which is consistent with the existing findings in the literature (Zou 1994; Futagami and Shibata, 1998; Smith, 1999; Corneo and Jeanne, 2001; Hof and Prettner, 2019). Further adding to this literature, we use our calibrated model to quantify the contribution of the SOC to the US long-run growth. Table 2 reports growth rates and other key variables in our model economy (which is calibrated to the US economy) and in an economy without the SOC. As the first column of Table 2 shows, the long-run growth would decline from 1.8 percent to 1.2 percent if the SOC is absent. In other words, the presence of the SOC helps explain about one-third of US long-run growth.

The decline in growth can be explained by the decline in R\&D labor as the second column of Table 2 shows. In particular, $l_{r}$ is about one-third lower in the economy without the SOC than in the calibrated economy. Though labor in the production sector $\left(l_{x}\right)$ increases $3.7 \%$, total labor supply still drops $1.8 \%$.

\subsubsection{Sensitivity Analysis}

In the calibration, we have assumed $\beta=0.05$ for the CIA constraint on R\&D. We conduct robustness checks to show our calibration results are not sensitive to this value. In particular, we set two alternative values for $\beta, 0.1$ and 0.2 , and recalibrate our model. We find that the calibration results are very close to our benchmark economy. In addition, the key patterns in Figures 2,4 do not change, which are shown in Figures [5.9. These comparisons also uncover one finding that, as the CIA constraint on $\mathrm{R} \& \mathrm{D}$ becomes tighter (i.e., a larger $\beta$ ), the optimal nominal interest rate shifts to the right and therefore is more likely to be positive. As discussed, the welfare function depends on long-run growth, initial levels of consumption and wealth, and labor supply, generating a trade-off between long-run growth and initial consumption. When the nominal interest rate increases, it shifts more labor from $R \& D$ to manufacturing under a larger $\beta$, leading to lower growth but higher initial consumption. The welfare gain from higher initial consumption dominates the welfare loss from lower growth on the balanced growth path when the CIA constraint on R\&D becomes tighter, leading to a higher optimal nominal interest.

\section{General Discussions}

Our model shows that the SOC provides a new channel through which monetary policy can promote long-run growth in a Schumpeterian model. The key channel relies on the interaction between the nominal interest rate and the SOC which drives the real interest rate and long-run 
R\&D. In this section, we provide discussions on the real effects of monetary policy, the relationship between the nominal and the real interest rates, and the robustness of the results in alternative growth models.

\subsection{Real Effects of Monetary Policy}

Our paper connects with the literature on the real effect of monetary policy. In discussing the real effects of monetary policy, it's useful to distinguish two strands of separate but also related literature: the research focusing on the short-run fluctuations and the research focusing on longrun growth or levels. Our paper contributes to the second group of the literature but also sheds light on the first group of research.

There is a long debate regarding whether monetary policy has real effects in the long run. Most of early studies show money does not influence long-run growth. The debate goes back to the seminal studies by Sidrauski (1967) and Lucas (1972) which argue that monetary policy has no real effects in the long run. Sidrauski (1967) introduces money to the Ramsey capital accumulation model by assuming money in the utility function and shows money growth doesn't alter either long-run capital stock or consumption (this is called "superneutrality" of money). Lucas (1972) introduces money to an overlapping generation model where money is required for transaction of goods between the old generation and the young generation and shows that an increase in money supply only results in increases in prices while leaving real variables unchanged (this is called "neutrality" of money). Stockman (1981) introduces money to the Ramsey capital accumulation model through CIA constraints and shows that the superneutrality result holds when the CIA constraint only applies to consumption, while it could generate real effects on output if the CIA constraint is applied to investment. Dotsey and Sarte (2000) show that money is superneutral with a CIA constraint on consumption in the AK growth model 20 Overall, the reason for why monetary policy in these models cannot generate long-run real effects is because a money expansion causes one-for-one change in the price level, leaving the real interest rate unchanged. The balanced growth in these models is determined by the standard consumption Euler equation $\frac{\dot{c_{t}}}{c_{t}}=r_{t}-\rho$ while the real interest rate $r_{t}$ is not influenced by monetary policy 21 That is, in the long-run $\frac{\dot{M}_{t}}{M_{t}}=\pi_{t}$, and there is a one-for-one relationship between the nominal interest rate and inflation based on the Fisher equation $i_{t}=r_{t}+\pi_{t}$.

Introducing money to R\&D-based endogenous-growth models based on either Romer (1990) or

\footnotetext{
${ }^{20}$ They also show that the presence of inflation uncertainty could reduce long-run growth. But this is through the uncertainty channel.

${ }^{21}$ Notice that in the Ramsey capital accumulation model long-run growth is zero in which cases monetary policy does not influence long-run output levels.
} 
Aghion and Howitt (1992) enables monetary policy to have real effects on long-run growth, though most models show that monetary policy has a negative impact on long-run growth. Marquis and Reffett (1994) introduce money (with a CIA constraint) to the Romer growth model with a transaction-service sector and shows that monetary expansion causes factor inputs to reallocate from R\&D and production to transaction services, reducing long-run growth. Funk and Kromen (2010) incorporate sticky prices into a R\&D-based Schumpeterian model and find that inflation has growth effects in the short-run. As we have mentioned earlier, Chu and Cozzi (2014) introduce money to a Schumpeterian model and show a higher nominal interest reduces long-run growth through both the CIA on consumption that reduces labor supply and the CIA on R\&D investment that shifts labor away from $R \& D$ to production.

Relative to the above models emphasizing long-run effects of monetary policy, we introduce a new channel which can generate a positive growth effect of monetary policy. Our key innovation is introducing the SOC to a Schumpeterian model which alters households' consumption Euler equation. In particular, the SOC brings the marginal rate of substitution between wealth and consumption to the consumption Euler equation and allows the nominal interest rate to interact with it. In this way, a higher nominal interest rate could amplify the SOC effect on encouraging savings and reducing the real interest rate which in turn promotes R\&D and long-run growth. Though we are the first to investigate this mechanism's new implications of monetary policy on long-run growth, a similar approach (i.e., wealth in utility) has been taken by Michaillat and Saez $(2015,2019)$ to study business cycles in New Keynesian models. Michaillat and Saez (2019) show that the modified Euler equation due to wealth in the utility function can help to resolve a few anomalies in the New Keynesian model. Michaillat and Saez (2015) further show that, with the modified Euler equation, unconventional monetary and fiscal policy (such as a helicopter drop of money, a wealth tax, or budget-balanced government purchases) can stabilize the economy in a liquidity trap. These papers suggest the new channel brought by the SOC could be applied to different models as its mechanism is through altering the agent's consumption Euler equation.

Turning more generally to the literature focusing on monetary policy's effects on short-run fluctuations, such as the widely used DSGE models, these models naturally generate real effects of monetary policy in the short run by incorporating nominal rigidities. That is, if prices cannot adjust fully in the short run, a monetary expansion could drive up demand and stimulate economic activity. The mechanism here is straightforward, just like what Sidrauski (1967, p. 544) explains: "In the short run, an increase in the rate of monetary expansion is equivalent to a rise in government transfers to the private sector. It therefore results in an increase in consumption and a fall in the rate of capital accumulation." However, the existence of nominal rigidities in the short run also leads to a positive correlation between the nominal interest rate and the real 
interest rate which can be seen by the Fisher equation $(i=r+\pi)$ - when prices are rigid in the short run, an increase in nominal interest rate tends to raise the real interest rate as inflation adjusts slowly. This is not necessarily true in the long run, as we will explain in the next section.

\subsection{Relationship between Nominal and Real Interest Rates}

As discussed in the previous section, our paper suggests monetary policy can influence long-run growth through interacting with the SOC. This theory's new channel shows that a higher nominal interest rate could raise long-run growth by pushing down real interest rate and promoting R\&D activity. This suggests a negative correlation between the nominal and the real interest rates in the long run. This seems to be different from what we observe in the short run 22 We thus provide more discussions on this relationship from both theoretical and empirical perspectives in this section.

Theoretically, similar to our model, most endogenous-growth models which generate negative impact of monetary policy on long-run growth (e.g., Marquis and Reffett, 1994; Chu and Cozzi, 2014) lead to a negative correlation between the nominal and the real interest rates. This is a result of two facts. First, in these models, the long-run growth rate is positively correlated with the real interest rate, which can be seen by a typical consumption Euler equation. Second, in the long run, higher money growth means higher nominal interest rates 23 These two together suggest that, if a higher nominal interest rate reduces long-run growth, it must lead to a negative correlation between nominal and real interest rates. So, our model's prediction regarding the negative correlation between the nominal and the real interest rates is consistent with that obtained in the above papers. What's different is that our model shows that a higher nominal interest rate could promote long-run growth if the SOC is sufficiently strong. In other words, our model does not necessarily imply a positive correlation between long-run growth and the real interest rate though the model is consistent with previous paper in generating a negative correlation between the nominal and the real interest rates 24

Empirically, the relationship between the nominal and the real interest rates could differ in the short run and in the longer run. In the short run, due to nominal rigidities, prices adjust

\footnotetext{
${ }^{22}$ It's worth noting the short-run relationship has also changed over time. As Mishkin (1981) pointed out, the correlation between nominal and real interest rates was negative in the US during 1953-1979 (see also Summers, 1982), whereas it has changed to be positive after October 1979 (see Huizinga and Mishkin, 1984).

${ }^{23}$ In this literature, monetary authority either controls money growth or sets nominal interest rates, which are equivalent.

${ }^{24}$ Specifically, when the SOC is strong and a higher nominal interest rate promotes long-run growth, long-run growth and the real interest rate is negatively correlated; when the SOC is low and a higher nominal interest rate reduces long-run growth, long-run growth and the real interest rate is positively correlated.
} 
gradually following an increase in money supply, causing inflation to move slowly and thus the nominal interest rate moves in the same direction of the real interest rate (which can be seen from the Fisher equation). In the long run, as inflation could increase with higher money growth, the correlation between nominal and real interest rate could be negative.

To empirically examine this relationship, we estimate the accumulative impulse response of real interest rate to a positive monetary shock (i.e., an exogenous increase in the federal funds rate) using the local projection method (Jordà, 2005; Olea and Plagborg-Møller, 2021). In particular, the accumulative impulse of the real interest rate to the monetary policy shock is estimated through the following regression:

$$
\Delta r_{t, h}=\alpha(h)+\beta(h) \cdot r_{t-1}+\gamma(h) \cdot \text { mpshock }_{t}+\epsilon_{t}(h),
$$

where $\Delta r_{t, h} \equiv r_{t+h}-r_{t}$ is the $h$-month ahead accumulative change in the real interest rate and mpshock $k_{t}$ is the Romer-Romer monetary policy shock in month $t 25$ We control the lag of the real interest rate, $r_{t-1}$, in the regression equation as Olea and Plagborg-Møller (2021) show that lag-augmented local projections are more robust. As Figure11] shows, the estimated accumulative impulse response is positive and statistically significant in the short run (i.e., within the first two years) while becoming negative and statistically significant in the longer run (e.g., after eight years), suggesting that the correlation between the nominal and the real interest rates tends to change from positive in the short run to negative in the long run. This is consistent with our model's prediction and also reconciles the positive correlation between nominal and real interest rates implied by the short-run business cycle models and the negative correlation implied by the long-run growth models (including the current paper).

\subsection{Robustness of the Results in Alternative Growth Models}

Our study may beg the question of whether our results are unique to the Schumpeterian model. In this section, we explain why our key results do not hinge on the unique feature of the Schumpeterian model. To help illustrate this, in Appendix 17.6, we replace the Schumpeterian model with a Romer (1990) type variety-expanding growth model, which is a competing growth framework of the Schumpetrian R\&D growth model, and shows the key results still hold 26

The driving forces behind these findings can be summarized as follows. Under the CIA constraint on $\mathrm{R} \& \mathrm{D}$, higher nominal interest raise the borrowing cost of entrepreneurs, which tends to reduce $R \& D$ and growth. However, with the CIA constraint on consumption, the positive effect

\footnotetext{
${ }^{25}$ We take the monthly Romer-Romer monetary policy shocks estimated in Wileland and Yang (2020) which extends the original estimation in Romer and Romer (2004) to include more recent years.

${ }^{26}$ In Online Appendix E, we also show the key results hold in an AK growth model.
} 
due the existence of the SOC still works through the consumption Euler equation, which causes a higher nominal interest rate to increase savings and push down the real interest rate, spurring R\&D and growth 27 Thus, when the positive growth-promoting effect through the channel of the SOC dominates the negative growth effect due to the CIA on R\&D, higher nominal interest rates would raise long-run growth.

In general, our results could be robust to alternative model specifications because the key mechanism still works. First of all, the existence of the SOC always increases savings and lowers the real interest rate, which may generate positive growth effects (in $\mathrm{R} \& \mathrm{D}$ growth models). This growth-enhancing effect of the SOC arises from the household-side of the economy. The varietyexpanding model of Romer (1990) and the Schumpeterian quality-ladder model of Aghion and Howitt (1992) differ in the production-side of the economy. In other words, the existence of the SOC tends to promote growth in both models. The negative effect of higher nominal interest rates on growth in the R\&D-based models of either Romer (1990) or Aghion and Howitt (1992) could come from different channels. It could come from decreasing labor supply (due to the consumption-leisure choice effect from the elastic labor supply) under the CIA on consumption. It could also come from dampened R\&D incentives due to the CIA on R\&D.

Other specifications on the CIA constraint can also be analyzed. For instance, when the CIA constraint applies to the manufacturing sector in Romer's model, higher nominal interest rates will also have an additional negative effect on long-run growth. When the CIA constraint applies to the manufacturing sector in Aghion and Howitt's Schumpeterian model, monetary expansion will have an additional positive effect on growth by shifting labor away from manufacturing to R\&D. We can also introduce money through the money-in-the-utility-function (MIUF) approach, an alternative approach to introduce money in the long-run growth models, and show the key mechanism still exists (see Online Appendix G for an example).

To summarize, the positive growth-enhancing effect due to the SOC always exists in these models, while the negative effects of monetary expansion could come from many sources. Therefore, when the degree of the SOC is small or absent, the negative effects dominate the positive effect, and thus higher interest rates reduce growth; when the SOC is strong enough, the positive effect dominates the negative effects, and thus higher interest rates promote growth.

\footnotetext{
${ }^{27}$ Please note that the CIA on consumption is crucial in this version of the Romer model. Under the CIA on consumption, the positive consumption-portfolio effect increases with the nominal interest rate. By contrast, in the Schumpeterian model, even without the CIA on consumption, higher nominal interest rates still generate the positive labor reallocation effect through the CIA on $R \& D$.
} 


\section{Conclusions}

In this paper we formalize Schumpeter's idea of "psychology of entrepreneurs" — entrepreneurs innovate for the sake of success itself, not only for the fruits of success - by introducing the spirit of capitalism (or a direct preference on wealth) into a Schumpeterian growth model with money. We show that the existence of the spirit of capitalism creates a new channel for monetary policy to impact growth and welfare and generates new implications for monetary policy. In particular, unlike recent research which shows that higher nominal interest rates always lead to lower long-run growth, we show a higher nominal interest rate could promote long-run growth when the spirit of capitalism is strong.

In addition, we show that a stronger SOC also pushes the optimal nominal interest rate lower, making the Friedman rule (the optimal non-negative nominal interest rate is zero) more likely to hold, contrasting with the finding in a recent paper study by Chu and Cozzi (2014) which uses a similar Schumpeterian model to demonstrate that the optimal nominal interest rate is positive. This finding also provides support to the adoption of a negative interest rate which has been intensively discussed by policymakers in recent years. Finally, when calibrating the model to the US economy, we show the SOC can help explain a substantial part (about one-third) of long-run growth in the US.

Finally, our model is designed to focus on long-run growth and not about studying exogenous shocks during business cycles or government countercyclical/stabilization policies such as inflation targeting. In our model, the nominal interest rate and inflation are deterministically controlled by the government. However, it is very interesting for future research to consider exogenous shocks

(such as inflation shocks) in a stochastic model and discuss the role of inflation targeting under the presence of the SOC and R\&D (please see the New Keynesian model with the SOC but without R\&D in Michaillat and Saez, 2015; 2019).

\section{Appendix}

\subsection{Solving the Household's Optimization Problem}

The household's Hamiltonian function can be written as:

$$
H_{t}=\ln c_{t}+\theta \ln \left(a_{t}\right)-\eta \frac{l_{t}^{1+1 / \sigma}}{1+1 / \sigma}+\mu_{t}\left(r_{t} e_{t}+w_{t} l_{t}-c_{t}-\pi_{t} m_{t}+i_{t} b_{t}+\tau_{t}\right)+\xi_{t}\left(m_{t}-c_{t}-b_{t}\right),
$$

where $\mu_{t}$ is the co-state variable on (2), $\xi_{t}$ is the Lagrangian multiplier for the CIA constraint, and $a_{t}=e_{t}+m_{t}$. 
The first-order conditions are:

$$
\begin{aligned}
& \frac{\partial H_{t}}{\partial c_{t}}=\frac{1}{c_{t}}-\mu_{t}-\xi_{t}=0, \\
& \frac{\partial H_{t}}{\partial l_{t}}=-\eta l_{t}^{1 / \sigma}+\mu_{t} w_{t}=0, \\
& \frac{\partial H_{t}}{\partial b_{t}}=\mu_{t} i_{t}-\xi_{t}=0, \\
& \frac{\partial H_{t}}{\partial e_{t}}=\frac{\theta}{a_{t}}+\mu_{t} r_{t}=\rho \mu_{t}-\dot{\mu}_{t}, \\
& \frac{\partial H_{t}}{\partial m_{t}}=\frac{\theta}{a_{t}}-\mu_{t} \pi_{t}+\xi_{t}=\rho \mu_{t}-\dot{\mu}_{t} .
\end{aligned}
$$

Combining (32) and (33) yields $\xi_{t}=\mu_{t}\left(r_{t}+\pi_{t}\right)$. Further combining with (31) yields $i_{t}=r_{t}+\pi_{t}$. Plugging this condition into (29) yields:

$$
\frac{1}{c_{t}}=\mu_{t}\left(1+i_{t}\right)
$$

which is (3) in the main text. Rewriting (30) we get the optimal condition for labor supply:

$$
\eta l_{t}^{1 / \sigma}=w_{t} \mu_{t}
$$

which is (4) in the main text. Rewriting (32) as:

$$
-\frac{\dot{\mu_{t}}}{\mu_{t}}=r_{t}-\rho+\frac{\theta}{\mu_{t} a_{t}}
$$

yields the intertemporal optimality condition (6) in the main text.

\subsection{Proof of Proposition 1}

For convenience, we define the ratio of final output to the value of the monopolistic firms $y_{t} / v_{t}$ as a new variable $\Theta_{t}$ (i.e., $\Theta_{t}=y_{t} / v_{t}$ ). The law of motion of $\Theta_{t}$ is:

$$
\frac{\dot{\Theta_{t}}}{\Theta_{t}}=\frac{\dot{y_{t}}}{y_{t}}-\frac{\dot{v_{t}}}{v_{t}}
$$

Given a fixed nominal interest rate $i$, combining (57) and (58) yields $\dot{c}_{t} / c_{t}=r_{t}-\rho+\theta(1+i) c_{t} / a_{t}$. From the final goods market clearing condition $c_{t}=y_{t} / L$, we then have $\dot{y}_{t} / y_{t}=\dot{c}_{t} / c_{t}$.

Equation (16) gives $\dot{v}_{t} / v_{t}=r_{t}+\lambda_{t}-\Pi_{t} / v_{t}$. Equation (15) delivers $\lambda_{t}=\varphi l_{r, t}$. Using (13), we have $\Pi_{t} / v_{t}=[(\gamma-1) / \gamma] \Theta_{t}$. Plugging these into (37), we have:

$$
\frac{\dot{\Theta_{t}}}{\Theta_{t}}=\frac{(\gamma-1)}{\gamma} \Theta_{t}-\varphi l_{r, t}-\rho+\frac{\theta(1+i) c_{t}}{a_{t}}
$$


Combining (12), (14) and (15) yields $l_{x, t}=(1+\beta i) \Theta_{t} /(\varphi \gamma)$. From (22), we have $l_{r, t}+l_{x, t}=l_{t}=$ $\left[\eta \gamma l_{x, t}(1+i)\right]^{-\sigma}$. Therefore,

$$
l_{r, t}=\left(\frac{\varphi}{\eta \Theta_{t}(1+\beta i)(1+i)}\right)^{\sigma}-\frac{(1+\beta i) \Theta_{t}}{\varphi \gamma} .
$$

Plugging the above expression of $l_{x, t}$ into (21) yields:

$$
\frac{c_{t}}{a_{t}}=\frac{(1+\beta i) \Theta_{t}}{(1+\beta i)\left(1+\Theta_{t}\right)+\varphi \beta\left[\left(\frac{\varphi}{\eta \Theta_{t}(1+\beta i)(1+i)}\right)^{\sigma}-\frac{(1+\beta i) \Theta_{t}}{\varphi \gamma}\right]} .
$$

Plugging these results into (38), we have:

$$
\frac{\dot{\Theta_{t}}}{\Theta_{t}}=\left[\begin{array}{c}
1-\left(\frac{1}{\eta(1+\beta i)(1+i)}\right)^{\sigma}\left(\frac{\varphi}{\Theta_{t}}\right)^{1+\sigma}+\frac{\beta i}{\varphi \gamma} \\
+\frac{\theta(1+i)(1+\beta i)}{(1+\beta i)\left(1+\Theta_{t}\right)+\varphi \beta\left[\left(\frac{\varphi}{\eta \Theta_{t}(1+\beta i)\left(1+i_{t}\right)}\right)^{\sigma}-\frac{(1+\beta i) \Theta_{t}}{\varphi \gamma}\right]}
\end{array}\right] \Theta_{t}-\rho .
$$

Because $\Theta_{t}>0$, equation (39) shows that $\Theta_{t}$ is saddle-point stable, meaning that $\Theta_{t}$ jumps immediately to its interior steady state given by the univariate equation:

$\frac{\rho}{\Theta_{t}}=1+\frac{\beta i}{\varphi \gamma}-\left(\frac{1}{\eta(1+\beta i)(1+i)}\right)^{\sigma}\left(\frac{\varphi}{\Theta_{t}}\right)^{1+\sigma}+\frac{\theta(1+i)(1+\beta i)}{(1+\beta i)\left(1+\Theta_{t}\right)+\varphi \beta\left[\left(\frac{\varphi}{\eta \Theta_{t}(1+\beta i)(1+i)}\right)^{\sigma}-\frac{(1+\beta i) \Theta_{t}}{\varphi \gamma}\right]}$.

This equation can be rewritten as:

$$
\begin{aligned}
& \left(\frac{1}{\eta(1+\beta i)(1+i)}\right)^{\sigma}\left(\frac{\varphi}{\Theta_{t}}\right)^{1+\sigma}=\frac{\varphi \gamma+\beta i}{\varphi \gamma} \\
& +\frac{\theta(1+i)(1+\beta i)}{(1+\beta i)\left[1+(1-\beta / \gamma) \Theta_{t}\right]+\beta \varphi^{1+\sigma} \Theta_{t}^{-\sigma} /[\eta(1+\beta i)(1+i)]^{\sigma}}-\frac{\rho}{\Theta_{t}} .
\end{aligned}
$$

With $\Theta_{t}>0$ and $\Theta_{t}$ on the horizontal axis, the LHS (left-hand-side) of (40) is a downwardsloping curve with the vertical and horizontal axes as the asymptotes. The RHS is a hyperbola with the vertical asymptote as the vertical axis, and the horizontal asymptote is $y=(\varphi \gamma+\beta i) / \varphi \gamma$ when $\theta$ is small (we are considering reasonable values of $\theta$; it is clear this holds when $\theta=0$ ). Therefore, the two lines intersect once at $\Theta_{t}^{*}$. When $\Theta_{t}>\Theta_{t}^{*}, \Theta_{t}>0$; when $\Theta_{t}<\Theta_{t}^{*}, \Theta_{t}<0$. Therefore, given a fixed nominal interest rate $i$, the dynamics of $\Theta_{t}$ show saddle-point stability: $\Theta_{t}$ jumps immediately to its interior steady state that is stationary and unique. Given $l_{x, t}=$ $(1+\beta i) \Theta_{t} /(\varphi \gamma)$ and $l_{r, t}=\left(\varphi /\left[\eta \Theta_{t}(1+\beta i)(1+i)\right]\right)^{\sigma}-l_{x, t}$, we know that $l_{r}, l_{x}$ and $l$ must be stationary and unique as well.

\subsection{Derivation of Equations (20) and (21)}

Dividing both sides of equation (16) by $v_{t}$, we have $r_{t}=\Pi_{t} / v_{t}+g_{t}-\lambda_{t}$, where we have used $\dot{v}_{t} / v_{t}=g_{t}$. We rewrite this equation as $\Pi_{t}=\left(r_{t}+\lambda_{t}-g_{t}\right) v_{t}$, which is equivalent to

$$
\lambda_{t} \Pi_{t}=\left(r_{t}+\lambda_{t}-g_{t}\right) \lambda_{t} v_{t} .
$$


Using the Euler equation (77), we have $g_{t}=r_{t}-\rho+\theta\left(1+i_{t}\right)\left(c_{t} / a_{t}\right)$, which gives $r_{t}-g_{t}=$ $\rho-\theta\left(1+i_{t}\right)\left(c_{t} / a_{t}\right)$. The free entry condition (14) can be written as $\lambda_{t} v_{t}=\left(1+\beta i_{t}\right) w_{t} L_{r, t}$. Plugging these two conditions into (41) to replace $\left(r_{t}-g_{t}\right)$ and $\lambda_{t} v_{t}$, we have:

$$
\lambda_{t} \Pi_{t}=\left[\rho+\lambda_{t}-\theta(1+i) c_{t} / a_{t}\right]\left(1+\beta i_{t}\right) w_{t} L_{r, t} .
$$

Using (12) and (13), we have $\Pi_{t}=(\gamma-1) w_{t} L_{x, t}$. Plugging this condition into (42) to replace $\Pi_{t}$ yields:

$$
\lambda_{t}(\gamma-1) l_{x, t}=\left[\rho+\lambda_{t}-\theta(1+i)\left(c_{t} / a_{t}\right)\right]\left(1+\beta i_{t}\right) l_{r, t},
$$

where we have used $l_{x, t}=L_{x, t} / L$ and $l_{r, t}=L_{r, t} / L$. Using (15), (43) becomes:

$$
(\gamma-1) l_{x, t}=\left(\frac{\rho}{\varphi}+\frac{\lambda_{t}}{\varphi}-\frac{\theta(1+i) c_{t}}{\varphi a_{t}}\right)\left(1+\beta i_{t}\right)
$$

Using $\lambda_{t}=\varphi l_{r, t}$, we obtain equation (20) in the main text.

The derivation for equation (21) is as follows:

$$
\frac{c_{t}}{a_{t}}=\frac{c_{t} L}{a_{t} L}=\frac{y_{t}}{e_{t} L+m_{t} L},
$$

where we have used the output market clearing condition $c_{t}=y_{t} / L$ and $a_{t}=e_{t}+m_{t}$.

The CIA constraint binds: $c_{t}+b_{t}=m_{t}$, where $b_{t} L=\beta w_{t} L_{r, t}$. We also have $e_{t}=v_{t} / L$. Therefore, (44) can be written as:

$$
\frac{c_{t}}{a_{t}}=\frac{y_{t}}{v_{t}+c_{t} L+b_{t} L}=\frac{y_{t}}{v_{t}+y_{t}+\beta w_{t} L_{r, t}} .
$$

Using (12), we have $y_{t}=\gamma w_{t} L_{x, t}$. Combining (14) and (15), we have $v_{t}=\left(1+\beta i_{t}\right) w_{t} L_{r, t} / \varphi l_{r, t}=$ $\left(1+\beta i_{t}\right) w_{t} L / \varphi$, where we have used $l_{r, t}=L_{r, t} / L$. Therefore, (45) can be rewritten as:

$$
\frac{c_{t}}{a_{t}}=\frac{\gamma w_{t} L_{x, t}}{(1+\beta i) w_{t} L / \varphi+\gamma w_{t} L_{x, t}+\beta w_{t} L_{r, t}}=\frac{\gamma l_{x, t}}{(1+\beta i) / \varphi+\gamma l_{x, t}+\beta l_{r, t}},
$$

which is equation (21) in the main text.

\subsection{Proof of Proposition 2}

We resort to the graphical proof presented in Aghion and Howitt (1998, ch. 2). Two conditions pin down the equilibrium labor allocation: the labor market clearing condition in (22) and the free labor mobility condition in (23). We rewrite the labor market clearing condition (22) as:

$$
l_{r, t}=\left[\eta \gamma\left(1+i_{t}\right)\right]^{-\sigma} l_{x, t}^{-\sigma}-l_{x, t} .
$$


We have the constraint $l_{r, t}+l_{x, t}=l_{t} \leq 1$ and $\lim _{l_{x, t} \rightarrow 0} l_{r, t}=\infty$. Therefore, the labor market clearing condition becomes $l_{r, t}+l_{x, t}=1$ when $l_{x, t}$ is smaller than a threshold $\underline{l_{x}}$. We also have $l_{x, t}=[\eta \gamma(1+i)]^{-\sigma /(1+\sigma)}$ when $l_{r, t}=0$. Therefore, we impose the restriction on the parameters: $[\eta \gamma(1+i)]^{-\sigma /(1+\sigma)} \leq 1$. Using (47), we have:

$$
\begin{aligned}
\frac{\partial l_{r, t}}{\partial l_{x, t}} & =-\sigma\left(\frac{1}{\eta \gamma\left(1+i_{t}\right)}\right)^{\sigma} l_{x, t}^{-\sigma-1}-1<0, \\
\frac{\partial^{2} l_{r, t}}{\partial l_{x, t}^{2}} & =\sigma(\sigma+1)\left(\frac{1}{\eta \gamma\left(1+i_{t}\right)}\right)^{\sigma} l_{x, t}^{-\sigma-2}>0 .
\end{aligned}
$$

Therefore, the labor market clearing condition shows that, with the manufacturing labor $\left(l_{x, t}\right)$ on the horizontal axis, the R\&D labor share $\left(l_{r, t}\right)$ is a downward-sloping convex function of $l_{x, t}$ when $l_{x, t} \in\left[\underline{l_{x}}, 1\right]$. We denote this curve as the $L$ curve in Figure 1 , Imposing $\beta=0$, we rewrite the free labor mobility (23) as:

$$
l_{r}=(\gamma-1) l_{x}-\rho / \varphi+\frac{\theta(1+i) \gamma l_{x}}{1+\varphi \gamma l_{x}}
$$

We have $l_{r, t}=-\rho / \varphi$ when $l_{x, t}=0$. Taking derivatives, we have

$$
\begin{aligned}
\frac{\partial l_{r, t}}{\partial l_{x, t}} & =(\gamma-1)+\frac{\theta(1+i) \gamma}{\left(1+\varphi \gamma l_{x}\right)^{2}}>0, \\
\frac{\partial^{2} l_{r, t}}{\partial l_{x, t}^{2}} & =-\frac{2 \theta \varphi(1+i) \gamma^{2} l_{x}}{\left(1+\varphi \gamma l_{x}\right)^{3}}<0 .
\end{aligned}
$$

Thus, the free labor mobility condition shows that $l_{r, t}$ is an upward-sloping concave function of manufacturing labor $l_{x, t}$ (with $l_{x, t}$ on the horizontal axis). We denote this curve as the $M$ curve in Figure 1 .

The two lines intersect once, meaning there is a unique solution (a unique balanced growth path). Two properties follow. First, the SOC only shifts the $M$ curve, with an increase in $\theta$ rotating the $M$ curve counter-clockwise around $(0,-\rho / \varphi)$, thereby leading to higher R\&D labor $l_{r}$ and lower manufacturing labor $l_{x}$, all else equal. Thus, a stronger degree of the SOC raises the balanced growth rate, all else equal (i.e., the equilibrium would move from $O$ to $A$ ). Second, both the taste for leisure $\eta$ and the Frisch elasticity of labor supply $\sigma$ only shift the $L$ curve, with a larger $\eta$ or $\sigma$ shifting the $L$ curve leftward, thereby decreasing both R\&D labor $l_{r}$ and manufacturing labor $l_{x}$, all else equal. So, either an increase in the taste for leisure $\eta$ or an increase in the Frisch elasticity of labor supply $\sigma$ would decrease the balanced growth rate (i.e., the equilibrium would move from $O$ to $B$ ), all else equal.

Using (47) and (50), an increase in the nominal interest rate shifts both curves: it rotates the $M$ curve counter-clockwise around $(0,-\rho / \varphi)$, and the degree of rotation depends on the size 
of $\theta$. Additionally, it shifts the $L$ curve to the left with the size of the shift depending on the magnitudes of both $\eta$ and $\sigma$ (i.e., the equilibrium would move from $O$ to $E$ ). Therefore, as the nominal interest rate increases, when growth-enhancing effect of the SOC dominates (i.e., with a relatively large $\theta$ ), the $M$ curve shifts more than the $L$ curve does, yielding a larger R\&D labor $l_{r}$ and thereby higher long-run growth; when the growth-reducing effects of the taste for leisure $\eta$ or the Frisch elasticity of labor supply $\sigma$ dominate (it is more likely with a larger $\eta$ or $\sigma$ ), the $L$ curve shifts more than the $M$ curve does, producing a smaller R\&D labor $l_{r}$ and thereby lower long-run growth.

By contrast, without the $\operatorname{SOC}(\theta=0)$, an increase in the nominal interest rate shifts the $L$ curve to the left. The new equilibrium will move along the $M$ curve (i.e., the equilibrium would move from $O$ to $B$ ), yielding a lower R\&D labor $l_{r}$ and thereby lower long-run growth.

\subsection{Proof of Proposition 3}

Using Figure 1 and the proof of Proposition 2, we have

$$
\frac{\partial l_{x, 0}}{\partial i}<0, \frac{\partial l_{0}}{\partial i}<0, \text { and } \frac{\partial l_{r, 0}}{\partial i} \lesseqgtr 0 \Longleftrightarrow \frac{\partial g}{\partial i} \lesseqgtr 0,
$$

where $l_{x, 0}, l_{r, 0}$, and $l_{0}$ refer to the initial values of labor inputs in the manufacturing sector, the R\&D sector, and the whole economy when the economy reaches the balanced growth path.

For a given $\theta_{1}>0$, let $i^{*}$ be the optimal nominal interest rate. Denote $i^{* *}$ to be the optimal interest rate under $\theta_{2}=\theta_{1}+\Delta \delta$, where $\Delta \delta$ is very small. We will show that $i^{* *}<i^{*}$. Taking the derivative of $U$ in (26) with respect to $i$, we have

$$
\frac{\partial U}{\partial i}=\frac{1}{\rho}\left[\left(\frac{1}{l_{x, 0}}+\frac{\varphi \gamma \theta}{1+\varphi \gamma l_{x, 0}}\right) \frac{\partial l_{x, 0}}{\partial i}+\frac{(1+\theta)}{\rho} \frac{\partial g}{\partial i}-\eta l_{0}^{1 / \sigma} \frac{\partial l_{0}}{\partial i}\right] .
$$

Evaluating (53) at $i^{*}$ and using the definition of $i^{*}$, we have

$$
\left.\frac{\partial U\left(\theta_{1}\right)}{\partial i}\right|_{i=i^{*}}=\frac{1}{\rho}[\underbrace{\frac{\varphi \gamma \theta_{1}}{1+\varphi \gamma l_{x, 0}} \frac{\partial l_{x, 0}}{\partial i}+\frac{\theta_{1}}{\rho} \frac{\partial g}{\partial i}}_{\text {Part } A}+\underbrace{\frac{1}{l_{x, 0}} \frac{\partial l_{x, 0}}{\partial i}+\frac{1}{\rho} \frac{\partial g}{\partial i}-\eta l_{0}^{1 / \sigma} \frac{\partial l_{0}}{\partial i}}_{\text {Part } B}]=0 .
$$

Note that when $\theta$ is small, we have $\partial l_{x, 0} / \partial i<0$ and $\partial g / \partial i<0$ (which are from Proposition 2). Therefore, when $\theta_{1}$ increases by a sufficiently small level $\Delta \delta$, Part $A$ declines (i.e., becomes more negative) while Part $B$ does not change. In other words, starting from an economy with $\left(\theta_{1}, i^{*}\right)$, when $\theta_{1}$ starts to increase, Part $A$ starts to decline while Part $B$ does not change. Thus we have

$$
\left.\frac{\partial U\left(\theta_{2}\right)}{\partial i}\right|_{i=i^{*}}<\left.\frac{\partial U\left(\theta_{1}\right)}{\partial i}\right|_{i=i^{*}}=0=\left.\frac{\partial U\left(\theta_{2}\right)}{\partial i}\right|_{i=i^{* *}}
$$


Therefore, we have $i^{* *}<i^{*}$. In other words, both $i^{*}$ and $i^{* *}$ are on the right side of a concave function 28

\subsection{The Romer (1990) Model with the SOC}

We incorporate the SOC into the Romer (1990) variety-expanding model 29 In the variety expanding model, each innovation represents a new variety that corresponds to an intermediate good. The economy consists of a final goods sector, an intermediate goods sector, households, and a monetary authority. Entrepreneurs conduct innovations, and the cost of each innovation (the cost of R\&D) is a fixed amount ( $\eta$ units of final goods). Each innovation is owned by a monopolistic entrepreneur, and there is free-entry into R\&D.

Households. As the key results do not rely on the labor-supply choice, here we assume that labor supply is inelastic. The population size of each household is fixed at $L$ and each household has a lifetime utility function as follows:

$$
U=\int_{0}^{\infty} e^{-\rho t}\left[\ln \left(c_{t}\right)+\theta \ln \left(a_{t}\right)\right] d t
$$

where the notations are defined in the same way as in the benchmark model. Each household maximizes its lifetime utility given in equation (56) subject to the asset-accumulation equation (2).

The policy instrument of the monetary authority is assumed to be the nominal interest rate $i_{t}$. The monetary authority rebates the seigniorage revenue $\tau_{t}=\dot{m}_{t}+\pi_{t} m_{t}$ to households as a lump-sum transfer. The CIA constraint is given by $c_{t}+b_{t} \leq m_{t}$, where $b_{t}$ is the amount of money borrowed from each member of households by entrepreneurs to finance $R \& D$ (i.e., $\eta$ ), and its return is $i_{t}$.

We rewrite the optimality condition for consumption and Euler equations as follows:

$$
\begin{gathered}
\frac{1}{c_{t}}=\mu_{t}\left(1+i_{t}\right), \\
-\frac{\dot{\mu_{t}}}{\mu_{t}}=r_{t}-\rho+\frac{\theta}{\mu_{t} a_{t}} . \\
\frac{\dot{c_{t}}}{c_{t}}=r_{t}-\rho+\theta \frac{c_{t}\left(1+i_{t}\right)}{a_{t}} .
\end{gathered}
$$

\footnotetext{
${ }^{28}$ Here we assume the welfare function is well-behaved and leads to unique optimal interest rate. Indeed, our calibrated model confirms this, which can also be seen in the previous studies that use the Schumpeterian framework, such as Aghion, Akcigit, and Fernández-Villaverde, 2013, and Chu and Cozzi, 2014).

${ }^{29}$ See Barro and Sala-i-Martin (2004, ch. 6).
} 
Note that these equations come from the household's optimal decisions, which hold in both the Schumpeterian model and the Romer-type model. Therefore, the consumption-portfolio effect due to a higher nominal interest rate that tends to increase growth is present in either type of R\&D-based models.

The Final Goods. There is a competitive final goods sector. A representative final good firm $i$ has the following production function:

$$
y_{i}=\sum_{j=1}^{N} X_{i j}^{\alpha} L_{i}^{1-\alpha}
$$

where $X_{i j}$ is the amount of the input of intermediate good $j, L_{i}$ is the amount of labor used by final good firm $i$, and $N$ is the number of intermediate goods (innovations/varieties).

Perfect competition means that final goods firms take the wage rate $\left(w_{t}\right)$ and prices of intermediate goods $\left(P_{j}\right)$ as given when maximizing their profits. Using the first-order condition associated with $X_{i j}$, we obtain the aggregate demand for the $j$-th intermediate good $X_{j}$ :

$$
X_{j}=\sum_{i} X_{i j}=L\left(\frac{\alpha}{P_{j}}\right)^{1 /(1-\alpha)} .
$$

The optimal condition for labor demand of final goods firms yields: $w_{t}=(1-\alpha)(Y / L)$, where $Y=\sum_{i} y_{i}$ is the total amount of final output.

The Intermediate Goods. Intermediate goods firms transform one unit of final goods into one unit of intermediate goods. We have normalized final goods' price to unity. The marginal/unit cost for the intermediate good firm (i.e., the manufacturing firm) would be 1 . When an entrepreneur obtains a patent on one intermediate good (one variety), he would be the monopolistic supplier to the final goods sector. Therefore, the $j$-th intermediate good firm's optimizing problem can be written as:

$$
\max _{P_{j}} \Pi_{j}=\left(P_{j}-1\right) X_{j}=\left(P_{j}-1\right) L\left(\frac{\alpha}{P_{j}}\right)^{1 /(1-\alpha)}
$$

where the last equality uses (61). The optimal price of the $j$-th intermediate goods is $P_{j}=1 / \alpha$. Therefore, $X_{j}=\alpha^{2 /(1-\alpha)} L$ and the monopoly profit of the $j$-th intermediate goods firm is:

$$
\Pi_{j}=\left(\frac{1}{\alpha}-1\right) \alpha^{2 /(1-\alpha)} L
$$

Research Arbitrage. We denote $v_{t}(j)$ as the value of the monopolistic firm specializing in intermediate good $j$. In this version of the monetary Romer model, the R\&D sector uses final goods as the factor input (i.e., the lab-equipment $R \& D$ process). Because entrepreneurs have to borrow cash from households to finance the R\&D expenditure, the cost of $\mathrm{R} \& \mathrm{D}$ becomes $\eta\left(1+i_{t}\right)$. 
Free-entry into R\&D yields an expected profit of zero for entrepreneurs:

$$
v_{t}(j)=\eta\left(1+i_{t}\right)
$$

The asset equation for $v_{t}(j)$ is:

$$
r_{t} v_{t}(j)=\Pi_{j}+v_{t}(j)
$$

The equilibrium can be defined in a similar way as in the benchmark model:

Definition Given the nominal interest rate $i_{t}$, a dynamic equilibrium for the model is a time path of prices $\left\{P_{j}, r_{t}, w_{t}, i_{t}\right\}$ and allocations $\left\{c_{t}, e_{t}, b_{t}, m_{t}, y_{t}, X_{j}\right\}$ such that given prices, the households maximize utility, competitive final-goods firms maximize profit, monopolistic intermediategoods firms choose $\left\{P_{j}\right\}$ to maximize profit; the final goods market clears (i.e., $Y_{t}=c_{t} L+$ $\left.\eta \dot{N}+\sum_{j} X_{j}\right)$; the value of monopolistic firms adds up to the value of households' assets (i.e., $\left.v N=\eta(1+i) N=e_{t} L\right)$; the amount of cash borrowed by entrepreneurs is $b_{t} L=\eta \dot{N}$.

We focus on the balanced growth path along which allocation variables such as $c_{t}, m_{t}, Y_{t}$, and $N$ all grow at the same constant rate. In equilibrium, we have $v_{t}(j)=v_{t}$ and $\dot{v}_{t}=0$. Therefore, using (58), (599), (64), and (65), the balanced growth rate $g$ can be written as:

$$
g=\frac{\Pi_{j}}{\eta\left(1+i_{t}\right)}-\rho+\theta \frac{c_{t}\left(1+i_{t}\right)}{a_{t}} .
$$

The Growth Effect of Monetary Policy. Substituting out $\Pi_{j}$ using (63) in (66) , we obtain

$$
g=\frac{(1 / \alpha-1) \alpha^{2 /(1-\alpha)} L}{\eta\left(1+i_{t}\right)}+\frac{\theta c_{t}\left(1+i_{t}\right)}{a_{t}}-\rho,
$$

where the consumption-wealth ratio is solved as follows. Under symmetry, we have

$$
c_{t} L=Y_{t}-\eta \dot{N}-N X_{j}=N\left[\alpha^{2 \alpha /(1-\alpha)}\left(1-\alpha^{2}\right) L-g \eta\right],
$$

where $g=\dot{N} / N$. Using $m_{t} L=c_{t} L+b_{t} L=c_{t} L+\eta \dot{N}$, we have $a_{t} L=e_{t} L+m_{t} L=\eta(1+i) N+$ $c_{t} L+\eta \dot{N}$. Using the final goods market clearing condition, we have $c_{t} L+\eta \dot{N}=Y_{t}-N X_{j}=$ $N\left[\alpha^{2 \alpha /(1-\alpha)}\left(1-\alpha^{2}\right) L\right]$. Therefore, the consumption-wealth ratio is:

$$
\frac{c_{t}}{a_{t}}=\frac{\alpha^{2 \alpha /(1-\alpha)}\left(1-\alpha^{2}\right) L-g \eta}{\alpha^{2 \alpha /(1-\alpha)}\left(1-\alpha^{2}\right) L+(1+i) \eta} .
$$

Proposition 4 The balanced growth rate is a decreasing function of the nominal interest rate when there is no SOC (i.e., $\theta=0$ ). The balanced growth rate could be an increasing function of the nominal interest rate when the $S O C$ is strong. 
Proof: Differentiating the balanced growth rate in (67) with respect to $i$ yields:

$$
\frac{\partial g}{\partial i}=-\frac{(1 / \alpha-1) \alpha^{2 /(1-\alpha)} L}{\eta\left(1+i_{t}\right)^{2}}+\frac{\theta c_{t}}{a_{t}}+\theta\left(1+i_{t}\right)\left[\frac{\partial\left(c_{t} / a_{t}\right)}{\partial g} \frac{\partial g}{\partial i}+\frac{\partial\left(c_{t} / a_{t}\right)}{\partial i}\right]
$$

Using (68), we have $\partial\left(c_{t} / a_{t}\right) / \partial g=-\eta /\left[\alpha^{2 \alpha /(1-\alpha)}\left(1-\alpha^{2}\right) L+\eta\right]$. Therefore, we have

$$
\begin{gathered}
\left(1+\frac{\eta \theta\left(1+i_{t}\right)}{\alpha^{2 \alpha /(1-\alpha)}\left(1-\alpha^{2}\right) L+\eta}\right) \frac{\partial g}{\partial i}=\frac{\theta c_{t}}{a_{t}}\left(1-\frac{\left(1+i_{t}\right) \eta}{a_{t}}\right)-\frac{(1 / \alpha-1) \alpha^{2 /(1-\alpha)} L}{\eta\left(1+i_{t}\right)^{2}} \\
=\frac{\theta c_{t}}{a_{t}}\left[1+\alpha^{2 \alpha /(1-\alpha)}\left(1-\alpha^{2}\right) \frac{L}{a_{t}}-\frac{L}{N_{t}}\right]-\frac{(1 / \alpha-1) \alpha^{2 /(1-\alpha)} L}{\eta\left(1+i_{t}\right)^{2}}
\end{gathered}
$$

where we have used $\left(1+i_{t}\right) \eta / a_{t}=L / N_{t}-\alpha^{2 \alpha /(1-\alpha)}\left(1-\alpha^{2}\right)\left(L / a_{t}\right)$.

When there is no SOC (i.e., $\theta=0)$, (170) shows that $\partial g / \partial i=-(1 / \alpha-1) \alpha^{2 /(1-\alpha)} L /\left[\eta\left(1+i_{t}\right)^{2}\right]<$ 0 . When $\theta$ is large, it is possible that the right-hand-side (RHS) of (70) is positive. Given $g=N_{t} / N_{t}>0$, the number of varieties will approach infinity as time goes by. Therefore, we have $\partial g / \partial i>0$ if $\theta\left(c_{t} / a_{t}\right)\left[1+\alpha^{2 \alpha /(1-\alpha)}\left(1-\alpha^{2}\right)\left(L / a_{t}\right)-L / N_{t}\right]>(1 / \alpha-1) \alpha^{2 /(1-\alpha)} L /\left[\eta\left(1+i_{t}\right)^{2}\right]$, which is more likely to hold when $\theta$ is larger.

\section{References}

[1] Aghion, P., Akcigit, U. and Fernández-Villaverde, J. 2013. "Optimal Capital versus Labor Taxation with Innovation-Led Growth.” NBER Working Paper No. 19086.

[2] Aghion, P., and Howitt, P., 1992. "A Model of Growth through Creative Destruction." Econometrica $60,323-351$.

[3] Aghion, P., and Howitt, P. 1998. Endogenous Growth Theory, Cambridge, MA, MIT Press.

[4] Akerlof, G., Dickens, W., and Perry, G., 1996. "Low Inflation or No Inflation: Should the Federal Reserve Pursue Complete Price Stability?" Challenge 39(5), 11-17.

[5] Akyol, A., 2004. "Optimal Monetary Policy in an Economy with Incomplete Markets and Idiosyncratic risk." Journal of Monetary Economics 51, 1245-1269.

[6] Alaoui, L., and Sandroni, A. 2018. "Predestination and the Protestant Ethic." Journal of the European Economic Association 16(1), 45-76.

[7] Angeletos, George-Marios and Panousi, Vasia, 2009. "Revisiting the Supply Side Effects of Government Spending." Journal of Monetary Economics 56(2), 137-153. 
[8] Arawatari, R., Hori, T., and Mino, K., 2018. "On the Nonlinear Relationship between Inflation and Growth: A Theoretical Exposition." Journal of Monetary Economics 94, 79-93.

[9] Bakshi, G., and Chen, Z., 1996. "The Spirit of Capitalism and Stock-Market Prices." American Economic Review 86(1), 133-157.

[10] Barro, Robert J., 2004, "Spirit of Capitalism — Religion and Economic Development," Harvard International Review 25(4), 64-67.

[11] Barro, R. and X. Sala-i-Martin, 2004. "Economic Growth (2nd edition), " Cambridge, MA: the MIT Press

[12] Benigno, P., and Ricci, L.A., 2011. "The inflation-output trade-off with downward wage rigidities," American Economic Review 101(4), 1436-66.

[13] Brunnermeier, M., and Sannikov, Y., 2016. "On the Optimal Inflation Rate." American Economic Review 106(5), 484-89.

[14] Carroll, C. 2000. "Why Do the Rich Save So Much?" in Does Atlas Shrug? The Economic Consequences of Taxing the Rich (editor Slemrod, J.B.) Harvard University Press.

[15] Chu, A., and Cozzi, G., 2014. "R\&D and Economic Growth in a Cash-in-Advance Economy." International Economic Review, 55: 507-524.

[16] Chu, A., Cozzi, G., Fan, H., Furukawa, Y., and Liao, C.H., 2019. "Innovation and Inequality in a Monetary Schumpeterian Model with Heterogeneous Households and Firms." Review of Economic Dynamics 34, 141-164.

[17] Chu, A., Fan, H., and Wang, X., 2020. "Status-Seeking Culture and Development of Capitalism." Journal of Economic Behavior and Organization 180, 275-290.

[18] Cole, H., Mailath, G., and Postlewaite, A. 1992. "Social Norms, Savings Behavior, and Growth." Journal of Political Economy 100, 1092-1125.

[19] Corneo, G., and Jeanne, O., 2001. "Status, the Distribution of Wealth, and Growth." The Scandinavian Journal of Economics 103, 283-293.

[20] Cozzi, G., Giordani, P., and Zamparelli, L., 2007. "The Refoundation of the Symmetric Equilibrium in Schumpeterian Growth Models." Journal of Economic Theory 136, 788-797.

[21] Doepke, M., and Zilibotti, F., 2008. "Occupational Choice and the Spirit of Capitalism." The Quarterly Journal of Economics 123(2), 747-793. 
[22] Dotsey, M., and Sarte, P., 2000. "Inflation Uncertainty and Growth in a Cash-in-Advance Economy." Journal of Monetary Economics 45, 631-655.

[23] Eyster, E., Madarász, K., and Michaillat, P., 2020. "Pricing Under Fairness Concerns." Journal of the European Economic Association, forthcoming.

[24] Friedman, M., 1969. The Optimum Quantity of Money. Macmillan.

[25] Funk, P., and Kromen, B., 2010. "Inflation and Innovation-driven Growth." B.E. Journal of Macroeconomics, 10(1), 1-52.

[26] Futagami, K., and Shibata, A., 1998. "Keeping One Step ahead of the Joneses: Status, the Distribution of Wealth, and Long-run Growth." Journal of Economic Behavior and Organization 36, 109-126.

[27] Gomme, P., 1993. "Money and Growth: Revisited," Journal of Monetary Economics, 32, 51-77.

[28] Gong, L., and Zou, H., 2001. "Money, Social Status, and Capital Accumulation in a Cashin-Advance Model." Journal of Money, Credit and Banking 33(2), 284-293.

[29] Gong, L., and Zou, H., 2002. "Direct Preferences for Wealth, the Risk Premium Puzzle, Growth, and Policy Effectiveness." Journal of Economic Dynamics and Control 26(2), 247270.

[30] Hof, F.X., and Prettner, K., 2019. "The Quest for Status and R\&D-based Growth." Journal of Economic Behavior and Organization 162(C), 290-307.

[31] Jones, L., and Manuelli, R., 1995. "Growth and the Effects of Inflation." Journal of Economic Dynamics and Control 19(8), 1405-1428.

[32] Jordà, Ò. "Estimation and Inference of Impulse Responses by Local Projections." American Economic Review 95(1), 161-182.

[33] Kaplow, Louis, 2009. "Utility from Accumulation." NBER Working Paper, NO. 15595.

[34] Karnizova, L., 2010. "The Spirit of Capitalism and Expectation-driven Business Cycles." Journal of Monetary Economics 57(6), 739-752.

[35] Kurz, M., 1968. "Optimal Economic Growth and Wealth Effects." International Economic Review 9, 348-357. 
[36] Laincz, C., and Peretto, P., 2006. "Scale Effects in Endogenous Growth Theory: An Error of Aggregation Not Specification." Journal of Economic Growth 11(3), 263-88.

[37] Lucas, R.E., 1972. "Expectations and the Neutrality of Money." Journal of Economic Theory 4, 103-124.

[38] Luo, Y., Nie, J., and Zou, H., 2020. "The Spirit of Capitalism and Consumption Inequality." CEMA Working Paper, No. 616.

[39] Luo, Y., Smith, W., and Zou, H., 2009. "The Spirit of Capitalism, Precautionary Savings, and Consumption." Journal of Money, Credit and Banking 41(2-3), 543-554.

[40] Luo, Y., and Young, E., 2009. "The Wealth Distribution and The Demand For Status," Macroeconomic Dynamics 13(S1), 1-30.

[41] Marquis, M., and Reffett, K., 1994. "New Technology Spillovers into the Payment System." Economic Journal 104, 1123-1138.

[42] McCleary, R., and Barro R., 2006. "Religion and Economy," Journal of Economic Perspectives 20(2), 49-72.

[43] McCleary, R., and Barro R., 2019. The Wealth of Religion, Princeton University Press.

[44] Michaillat, P., and Saez, E., 2015. "An Economical Business-Cycle Model.” NBER Working Paper No. 19777.

[45] Michaillat, P., and Saez, E., 2019. "Resolving New Keynesian Anomalies with Wealth in the Utility Function." Review of Economics and Statistics (forthcoming).

[46] Michau, J.B., 2018., "Secular Stagnation: Theory and Remedies?" Journal of Economic Theory 176, 552-618

[47] Michau, J.B., Ono, Y., and Schlegl, M., 2018. "Wealth preference and rational bubbles." ISER (Institute of Social and Economic Research) Discussion Paper No. 1035, Osaka University.

[48] Olea, J.L.M., and Plagborg-Møller, M. 2021. "Local Projection Inference is Simpler and More Robust Than You Think." Econometrica 89 (4): 1789-1823.

[49] Ono, Y., 2015, "Growth, Secular Stagnation and Wealth Preference." ISER (Institute of Social and Economic Research) Discussion Paper No. 946, Osaka University. 
[50] Ono, Y., and Yamada, K., 2018. "Difference or Ratio: Implications of Status Preference on Stagnation." Australian Economic Papers, forthcoming.

[51] Pan, S., Zhang, M., and Zou, H., 2018. "Status Preference and the Effects of Patent Protection: Theory and Evidence." Macroeconomic Dynamics 22, 837-863.

[52] Romer, C.D., and Romer, D.H., 2004. "A new measure of monetary shocks: Derivation and implications." American Economic Review 94(4), 1055-1084.

[53] Romer, P., 1990. "Endogenous Technological Change." Journal of Political Economy 98, S71-102.

[54] Saez, E., and Stantcheva, S., 2018. "A Simpler Theory of Optimal Capital Taxation." Journal of Public Economics 162, 120-142.

[55] Schumpeter, J.A. 1934. The Theory of Economic Development. Harvard University Press.

[56] Schumpeter, J.A. 1942. Capitalism, Socialism and Democracy. London: Routledge.

[57] Segerstrom, P., 1998. "Endogenous Growth without Scale Effects." American Economic Review, 5, 1290-1310.

[58] Sidrauski, M., 1967. "Rational Choice and Patterns of Growth in a Monetary Economy." American Economic Review 57(2), 534-544.

[59] Smith, W., 1999. "Risk, the Spirit of Capitalism and Growth: The Implications of a Preference for Capital." Journal of Macroeconomics 21(2), 241-262.

[60] Smith, W., 2001. "How Does the Spirit of Capitalism Affect Stock Market Prices?" Review of Financial Studies 14(4), 1215-1232.

[61] Stockman, A., 1981. "Anticipated Inflation and the Capital Stock in a Cash-in-Advance Economy." Journal of Monetary Economics 8, 387-393.

[62] Walsh, C., 2010, "Monetary Theory and Policy (third edition)," Cambridge, MA, the MIT Press.

[63] Weber, M., 1958. The Protestant Ethic and the Spirit of the Capitalism. (1st edition, German, 1904-05). New York, Charles Scribner's Sons.

[64] Wieland, J.F., and Yang, M.J. 2020. "Financial dampening." Journal of Money, Credit and Banking 52(1), 79-113. 
[65] Zou, H.-F., 1994. "The Spirit of Capitalism and Long-run Growth." European Journal of Political Economy 10(2), 279-293.

[66] Zou, H.-F., 1995. "The Spirit of Capitalism and Savings Behavior." Journal of Economic Behavior and Organization 28(1), 131-143. 


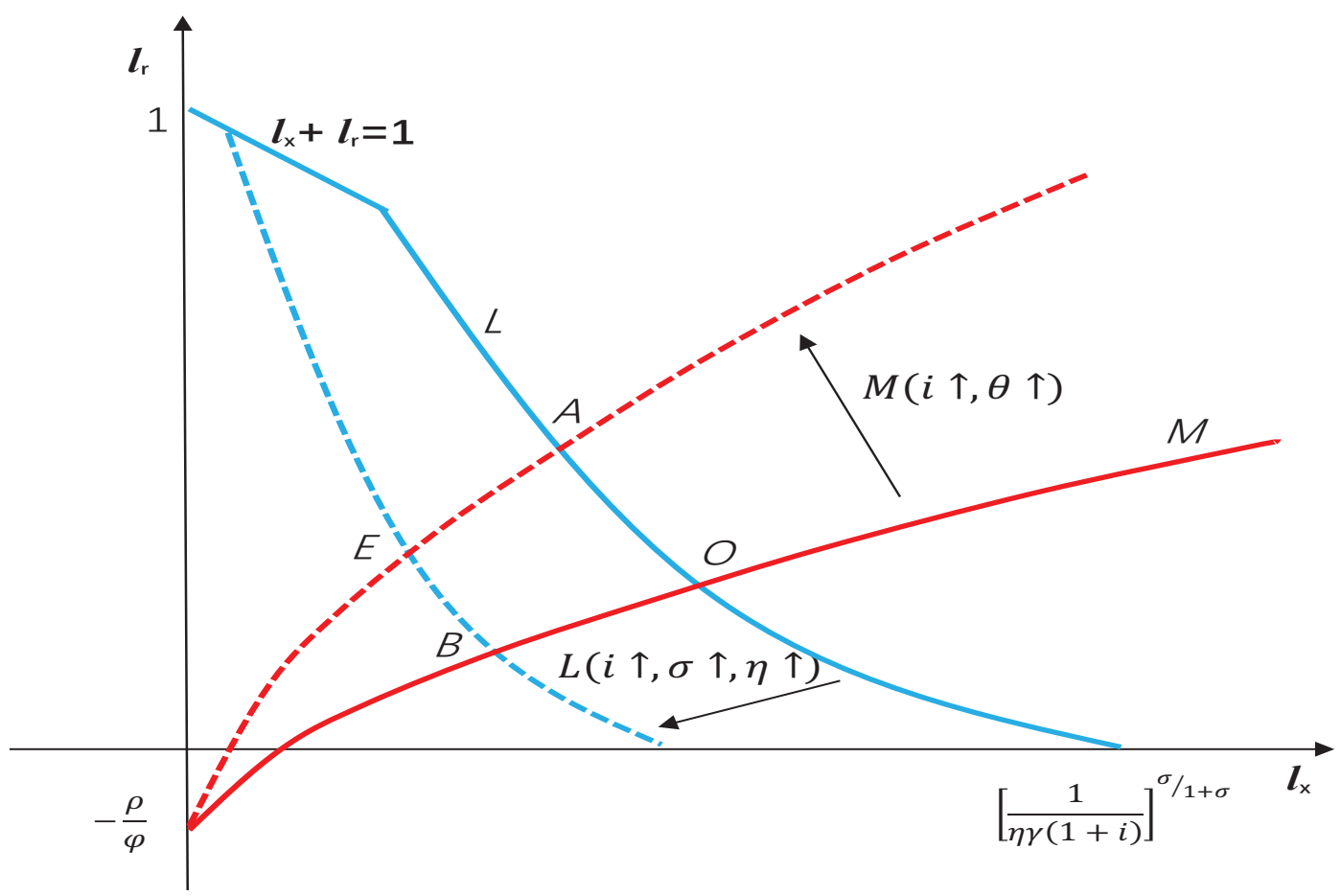

Figure 1: Equilibrium Labor Allocation under a CIA Constraint on Consumption This graph shows the determination of equilibrium labor allocation in the R\&D sector and the production sector. The $L$ is the labor-market clearing condition (equation (22)) and the $M$ curve is the labor mobility condition (equation (23)). 


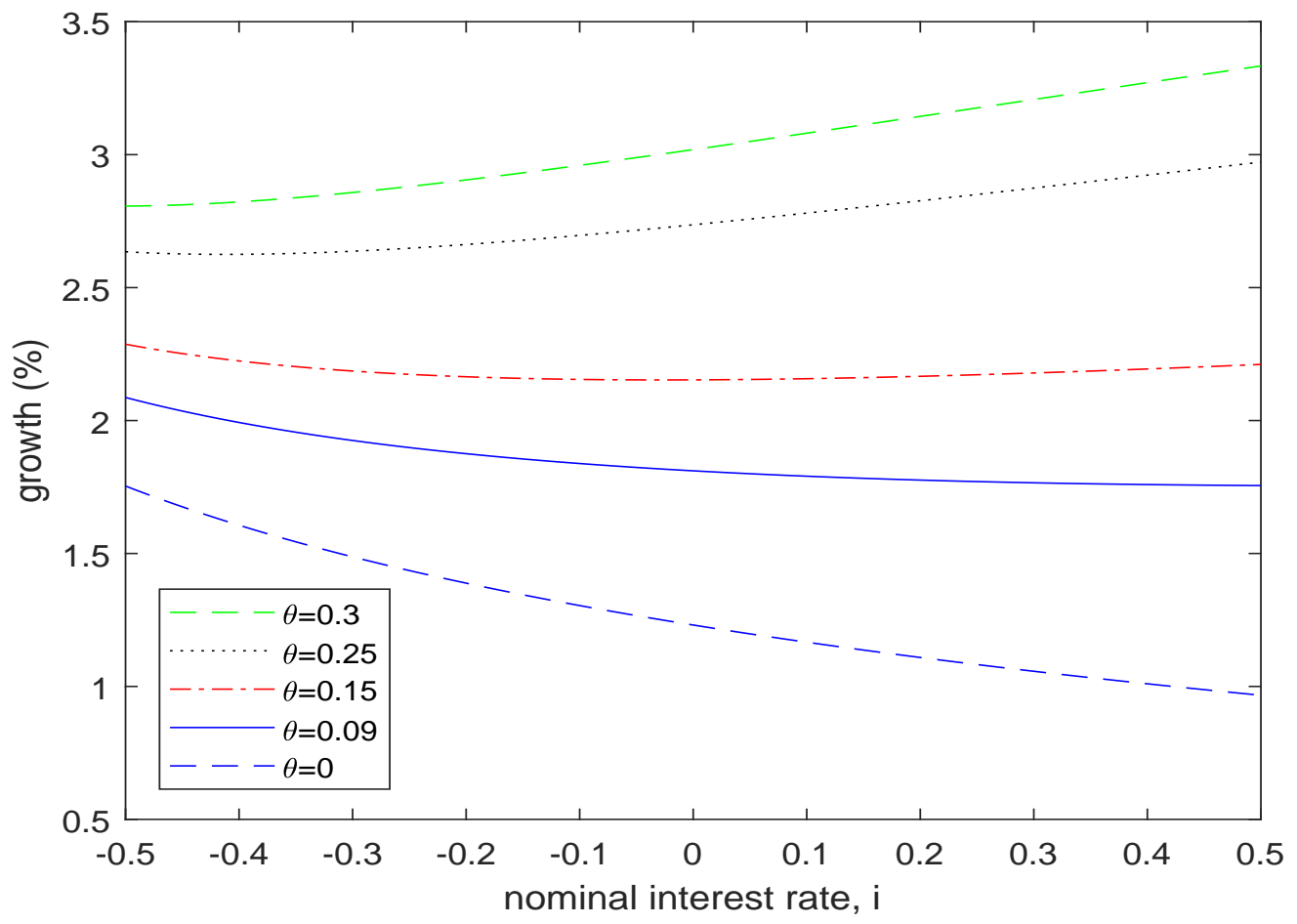

Figure 2: Effect of the Nominal Interest Rate on Growth at Different Degrees of the SOC $(\boldsymbol{\beta}=\mathbf{0 . 0 5})$ The three lines show how long-run growth changes with the nominal interest rate at different degrees of the SOC. The solid line is based on the U.S. calibration. The green dashed line represents a country with a stronger SOC, while the blue dashed line shows the case without the SOC. 

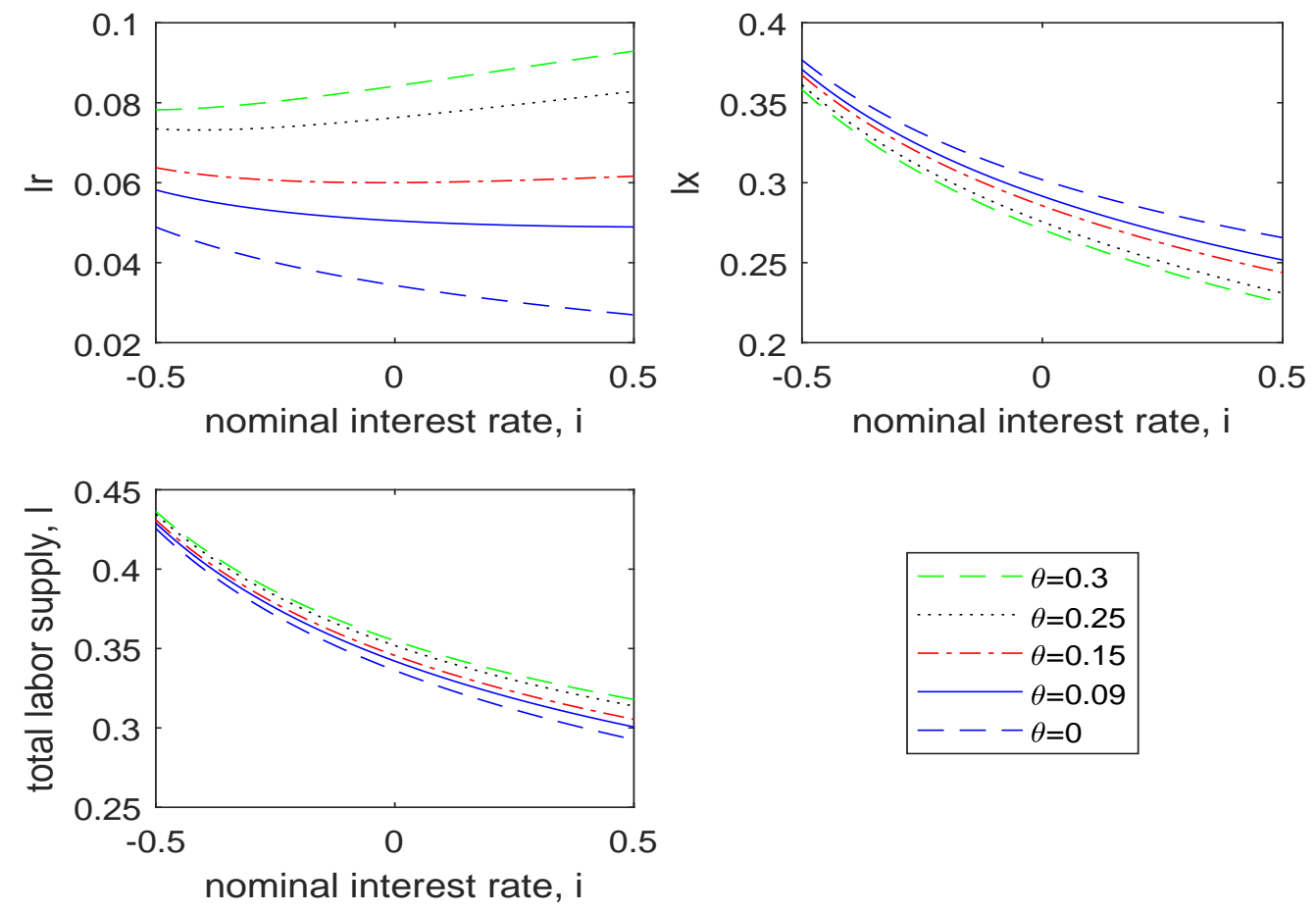

Figure 3: Effect of the Nominal Interest Rate on Labor Allocation at Different Degrees of the SOC $(\boldsymbol{\beta}=\mathbf{0 . 0 5})$ The three lines show how labor input in each sector changes with the nominal interest rate at different degrees of the SOC. The solid line is based on the U.S. calibration. The green dashed line represents a country with a stronger SOC, while the blue dashed line shows the case without the SOC. 


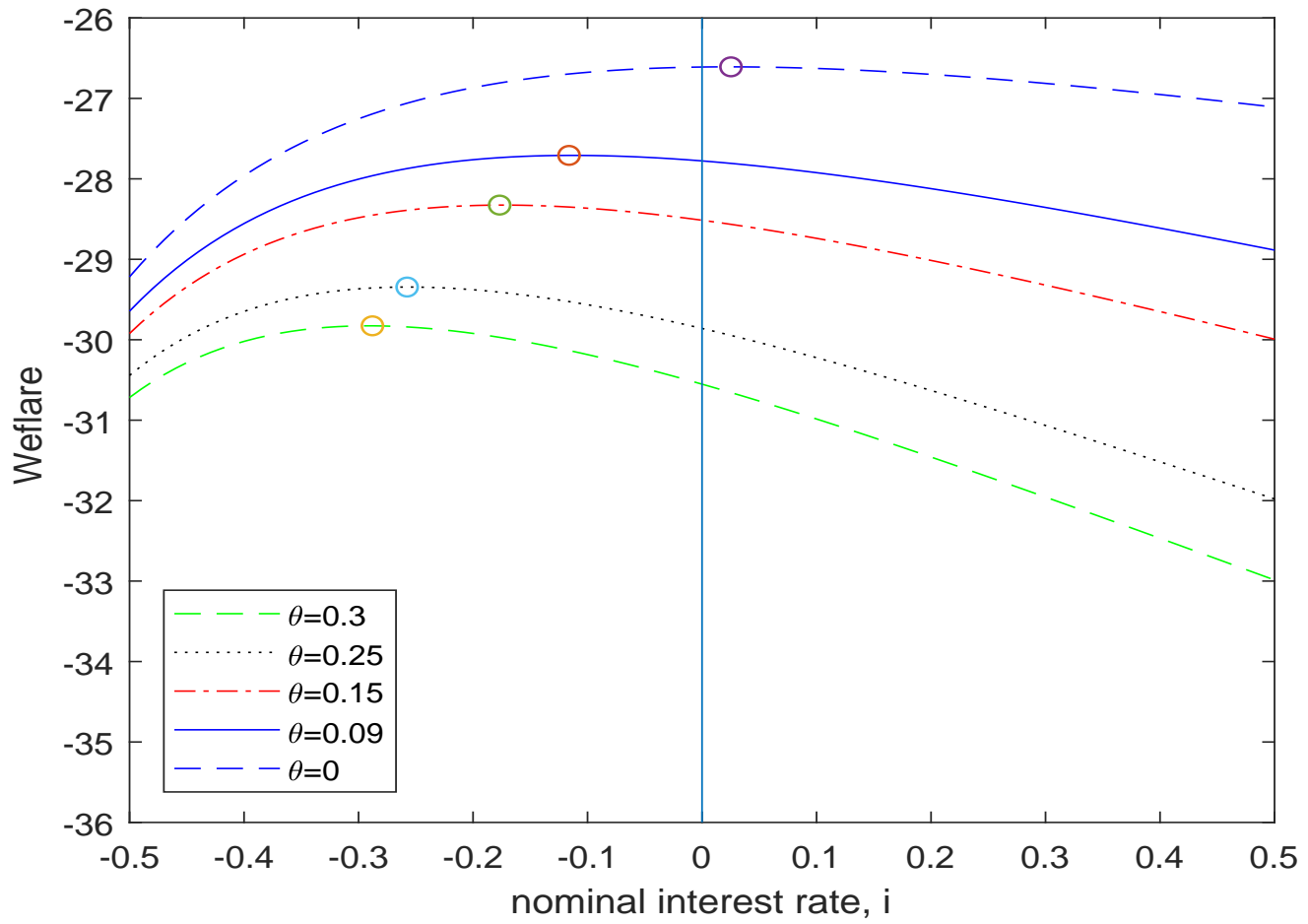

Figure 4: Optimal Nominal Interest Rate at Different Degrees of the SOC $(\boldsymbol{\beta}=\mathbf{0 . 0 5})$ The three lines show how welfare changes with the nominal interest rate at different degrees of the SOC. The circle on each line represents the maximum. The solid line is based on the U.S. calibration. The green dashed line represents a country with a stronger SOC, while the blue dashed line shows the case without the SOC. 


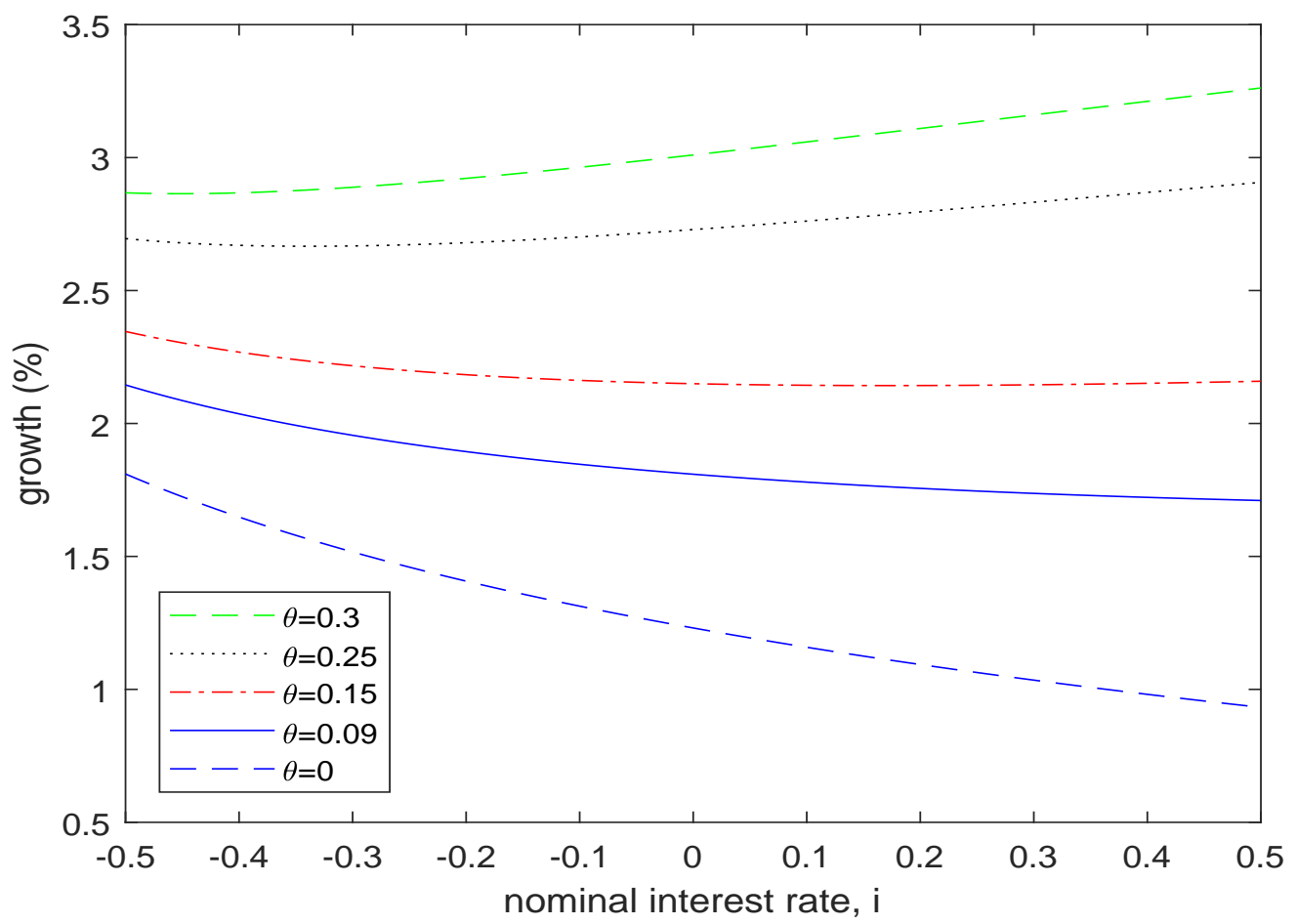

Figure 5: Robustness Check $(\boldsymbol{\beta}=\mathbf{0 . 1})$ : Effect of the Nominal Interest Rate on Growth at Different Degrees of the SOC The three lines show how long-run growth changes with the nominal interest rate at different degrees of the SOC. The solid line is based on the U.S. calibration. The green dashed line represents a country with a stronger SOC, while the blue dashed line shows the case without the SOC. 


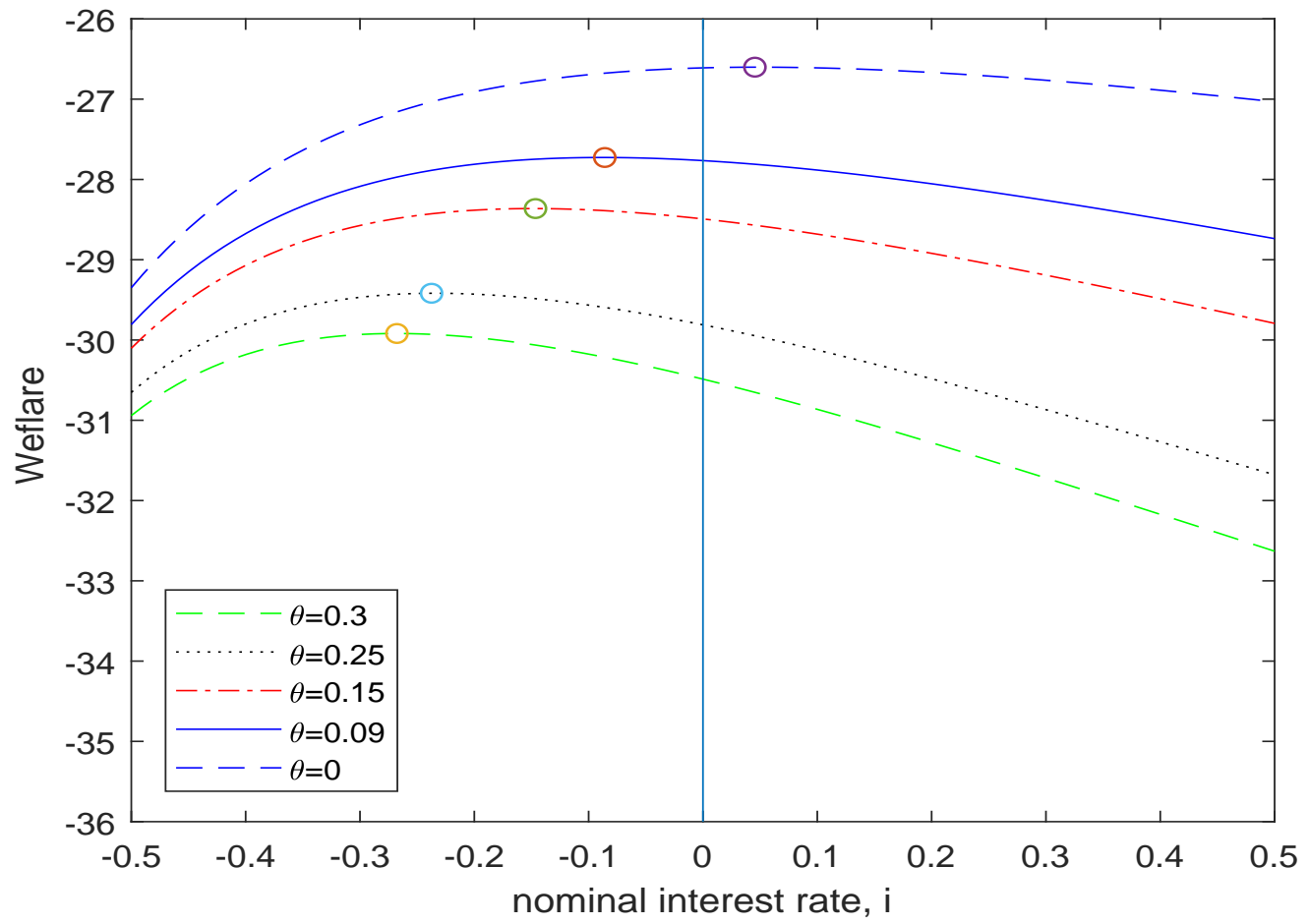

Figure 6: Robustness Check $(\boldsymbol{\beta}=\mathbf{0 . 1})$ : Optimal Nominal Interest Rate at Different Degrees of the SOC The three lines show how welfare changes with the nominal interest rate at different degrees of the SOC. The circle on each line represents the maximum. The solid line is based on the U.S. calibration. The green dashed line represents a country with a stronger SOC, while the blue dashed line shows the case without the SOC. 

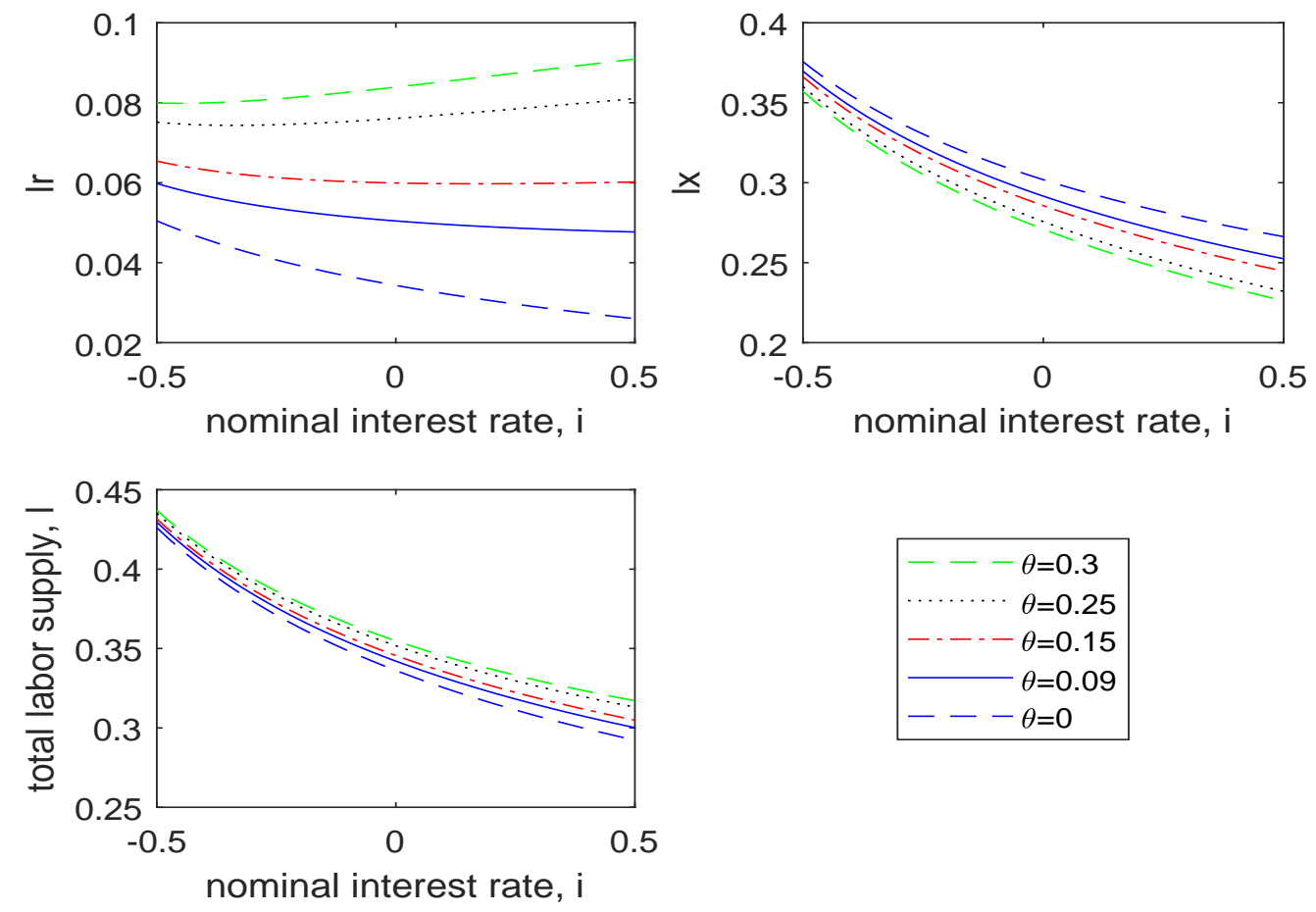

Figure 7: Robustness Check $(\boldsymbol{\beta}=\mathbf{0 . 1})$ : Effect of the Nominal Interest Rate on Labor Allocation at Different Degrees of the SOC The three lines show how labor input in each sector changes with the nominal interest rate at different degrees of the SOC. The solid line is based on the U.S. calibration. The green dashed line represents a country with a stronger SOC, while the blue dashed line shows the case without the SOC. 


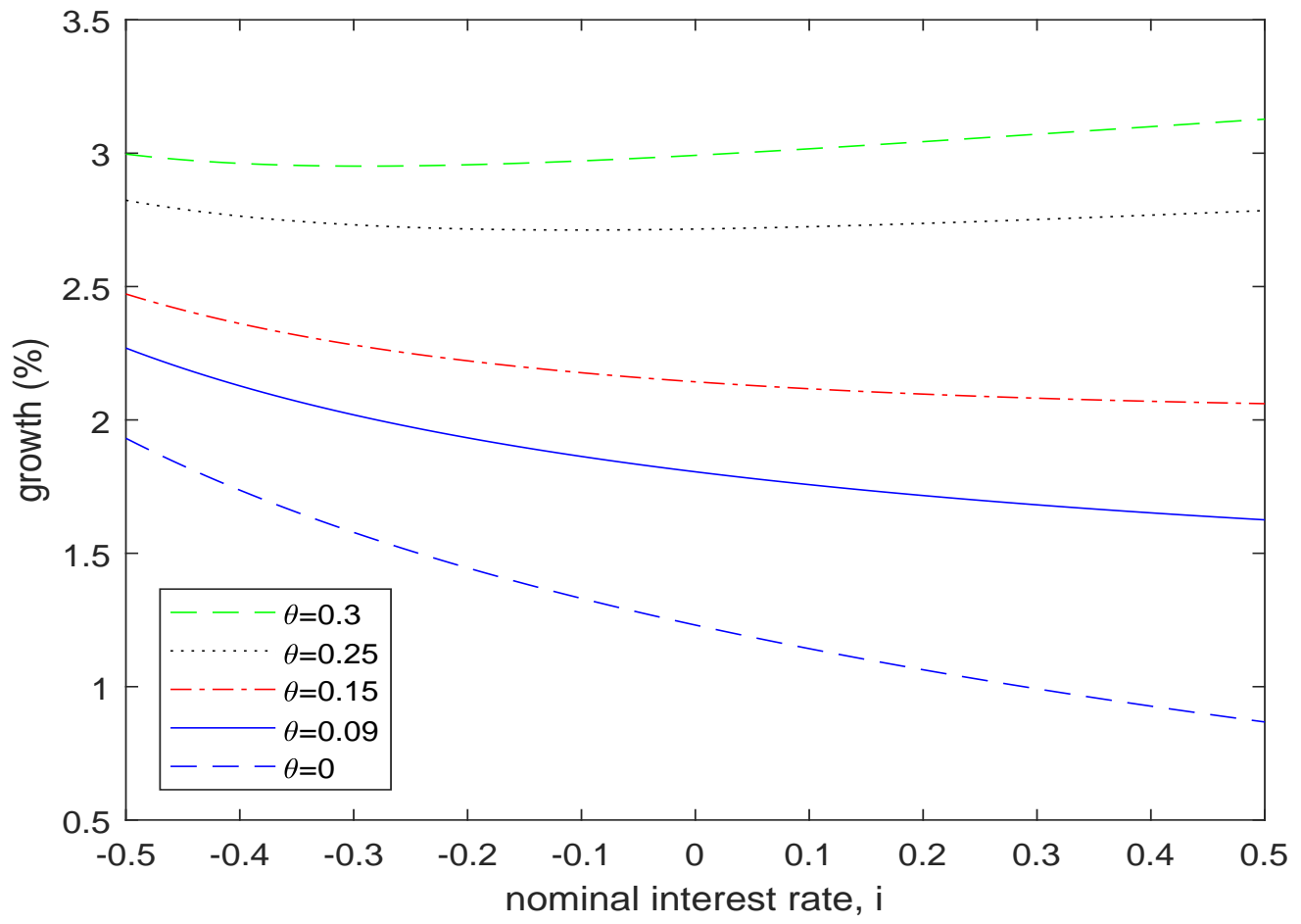

Figure 8: Robustness Check $(\boldsymbol{\beta}=\mathbf{0 . 2})$ : Effect of the Nominal Interest Rate on Growth at Different Degrees of the SOC The three lines show how long-run growth changes with the nominal interest rate at different degrees of the SOC. The solid line is based on the U.S. calibration. The green dashed line represents a country with a stronger SOC, while the blue dashed line shows the case without the SOC. 


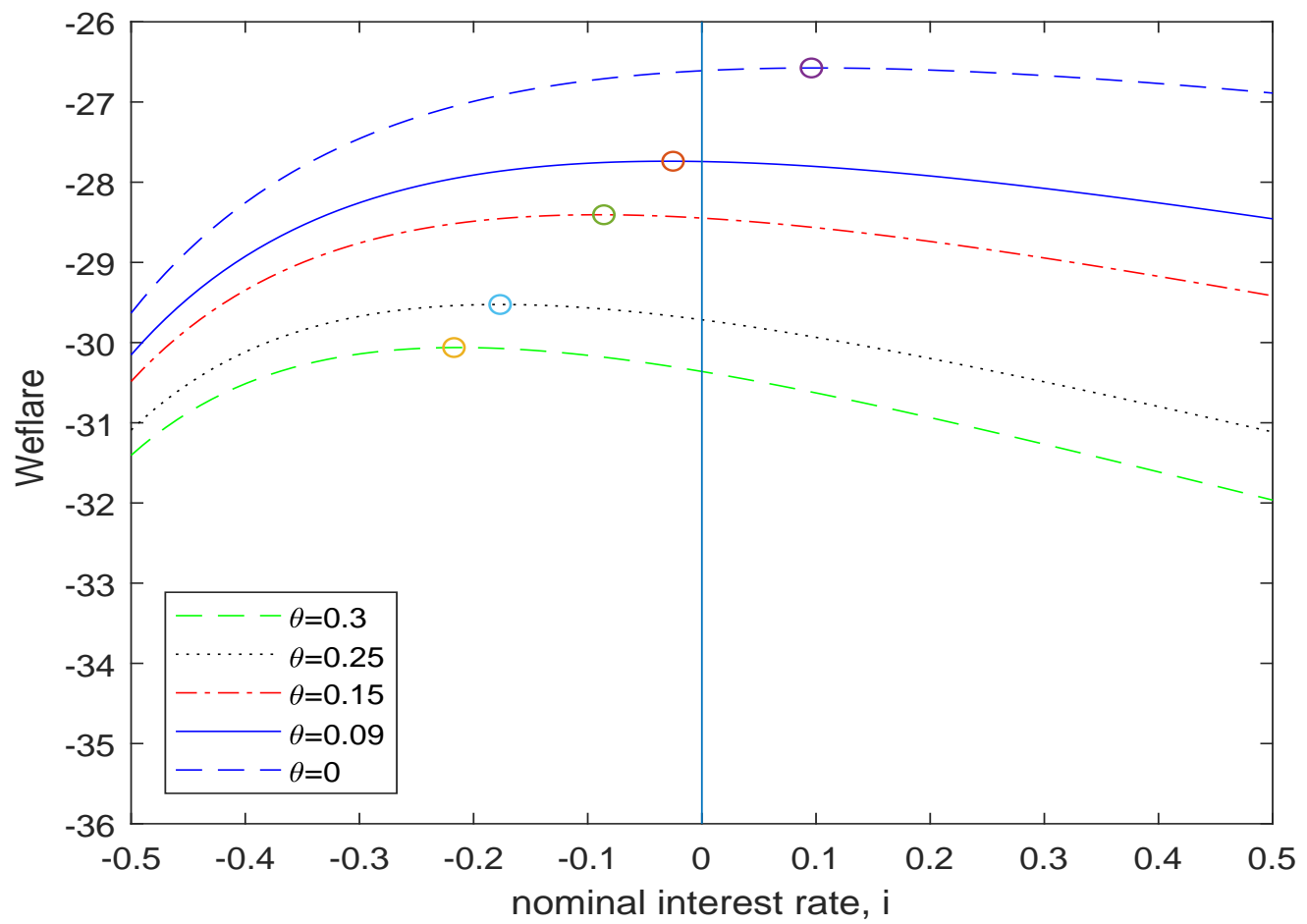

Figure 9: Robustness Check $(\beta=\mathbf{0 . 2})$ : Optimal Nominal Interest Rate at Different Degrees of the SOC The three lines show how welfare changes with the nominal interest rate at different degrees of the SOC. The circle on each line represents the maximum. The solid line is based on the U.S. calibration. The green dashed line represents a country with a stronger SOC, while the blue dashed line shows the case without the SOC. 

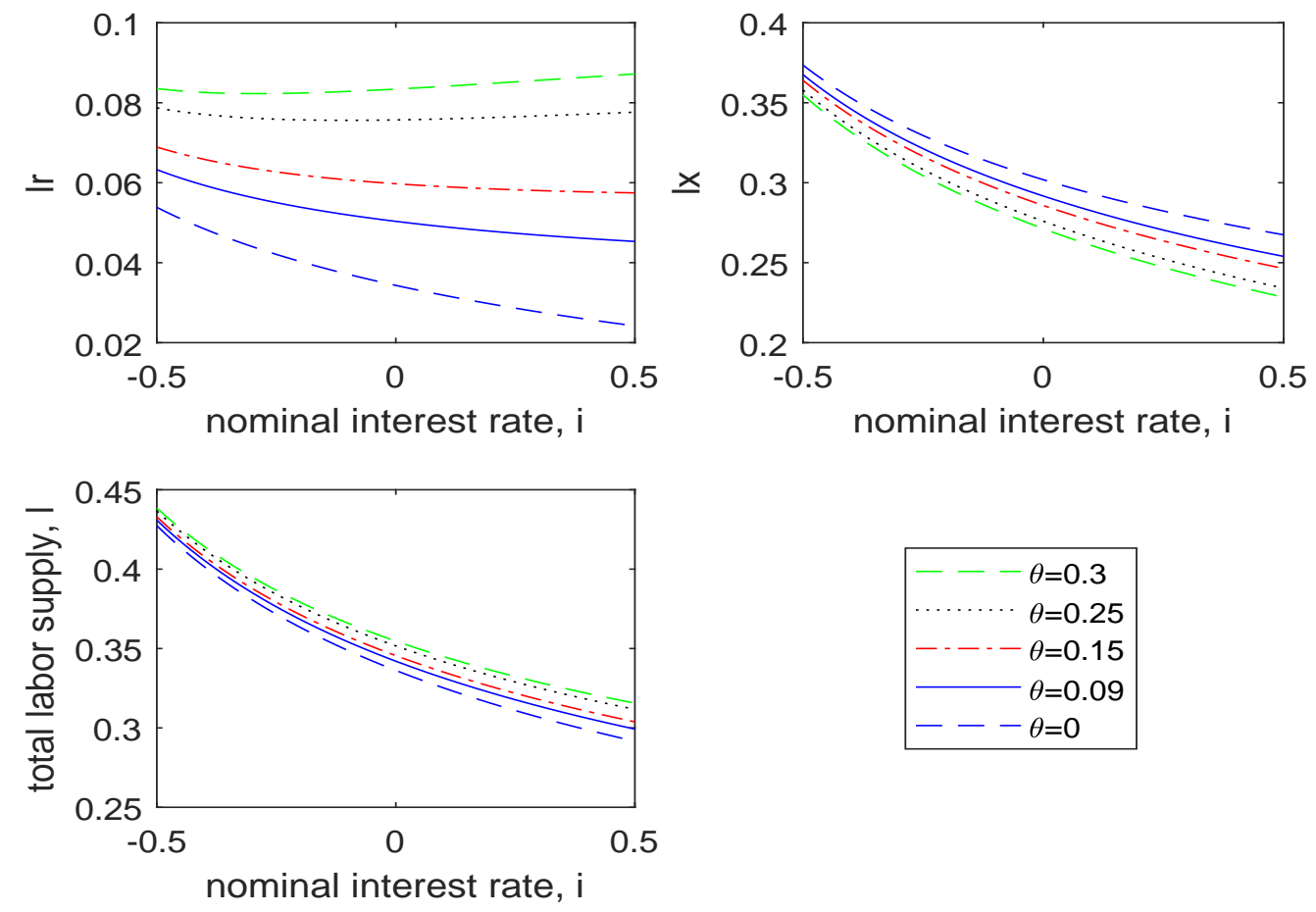

Figure 10: Robustness Check $(\boldsymbol{\beta}=\mathbf{0 . 2})$ : Effect of the Nominal Interest Rate on Labor Allocation at Different Degrees of the SOC The three lines show how labor input in each sector changes with the nominal interest rate at different degrees of the SOC. The solid line is based on the U.S. calibration. The green dashed line represents a country with a stronger SOC, while the blue dashed line shows the case without the SOC. 


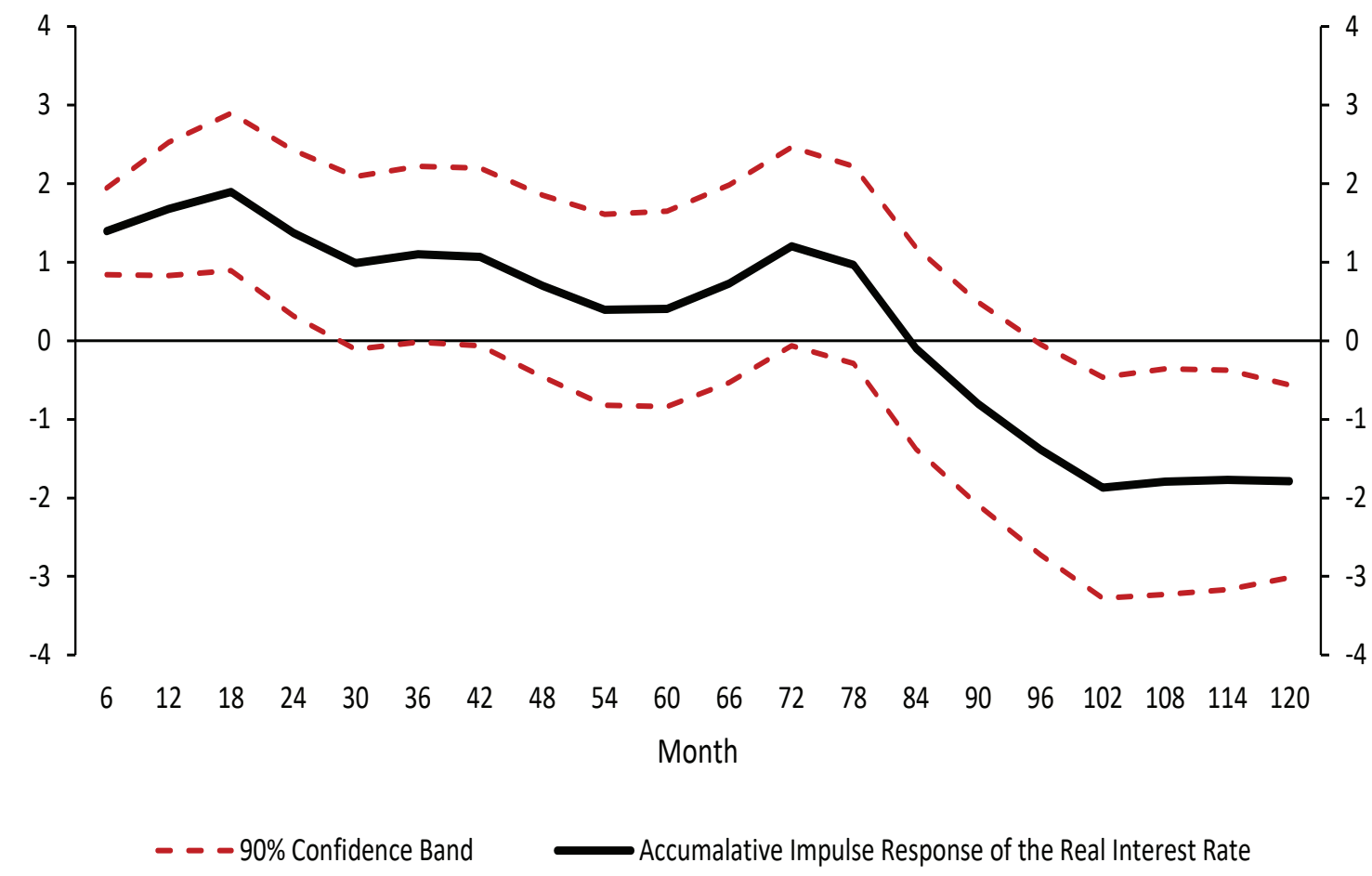

Figure 11: Real Interest Rate's Response to Monetary Policy Shock The solid line shows the accumulative impulse response of the real interest rate to Romer-Romer monetary policy shock. The estimation is based a lag-augmented local projection method using data in 1982-2007. 
Table 1: Parameters and Moments in the Joint Calibration

\begin{tabular}{lcc|lll}
\hline \hline & Parameter & Value & Joint Targets & Data & Model \\
\hline SOC & $\vartheta$ & 0.09 & FOMC long-run projection & $1.8 \%$ & $1.8 \%$ \\
Taste of leisure & $\eta$ & 25 & total labor supply & $1 / 3$ & $1 / 3$ \\
Innovation param. & $\varphi$ & 2.25 & real interest rate & $1.8 \%$ & $1.8 \%$ \\
Innovation param. & $\gamma$ & 1.17 & consumption to wealth ratio & 0.43 & 0.43 \\
\hline
\end{tabular}

Table 2: Effects of SOC on Growth and Labor Allocations

\begin{tabular}{l|cccc}
\hline \hline & long-run growth & labor in R\&D & labor in production & total labor supply \\
& $g$ & $l_{r}$ & $l_{x}$ & $l$ \\
\hline Benchmark Economy & $1.8 \%$ & 0.050 & 0.287 & 0.337 \\
Economy without SOC & $1.2 \%$ & 0.033 & 0.297 & 0.331 \\
\hline Change & -0.6 (ppt.) & $-33.5 \%$ & $3.7 \%$ & $-1.8 \%$ \\
\hline
\end{tabular}




\title{
Online Appendix for "Money, Growth, and Welfare in a Schumpeterian Model with the Spirit of Capitalism" (Not for Publication)*
}

\author{
Qichun $\mathrm{He}^{\dagger} \quad$ Yulei Luo $\quad$ Jun Nie ${ }^{\S} \quad$ Heng-fu Zou $\mathbb{I}$
}

October 23, 2021

\section{Online Appendix A: Inelastic Labor Supply and CIA on R\&D Only}

The inelastic labor supply is captured by $\eta=0$. For simplicity, we assume $\beta=11$ Repeating similar steps as in the main text, we have the free labor mobility condition as:

$$
(\gamma-1) l_{x, t}=(1+i)\left(l_{r, t}+\rho / \varphi-\frac{\theta c_{t}}{\varphi a_{t}}\right)
$$

The CIA constraint binds: $b_{t}=m_{t}$. The output market clearing condition gives $c_{t}=y_{t} / L$. Given $e_{t}=v_{t} / L$, the consumption wealth ratio is:

$$
\frac{c_{t}}{a_{t}}=\frac{y_{t}}{v_{t}+b_{t} L}=\frac{\gamma w_{t} L_{x, t}}{(1+i) w_{t} L_{r, t} / \lambda+w_{t} L_{r, t}}=\frac{\gamma l_{x, t}}{(1+i) / \varphi+l_{r, t}} .
$$

Plugging the labor market clearing condition $l_{r, t}+l_{x, t}=1$ and (2) into (1), we get a univariate quadratic equation for manufacturing labor $l_{x}$ :

$$
\Phi_{1} l_{x}^{2}-\Phi_{2} l_{x}+\Phi_{3}=0
$$

${ }^{*}$ The views expressed here are the opinions of the authors only and do not necessarily represent those of the Federal Reserve Bank of Kansas City or the Federal Reserve System. All remaining errors are our responsibility.

${ }^{\dagger}$ He: China Economics and Management Academy, Central University of Finance and Economics, Beijing, China. Email: qichunhe@gmail.com.

${ }^{\ddagger}$ Luo: Faculty of Business and Economics, University of Hong Kong, Hong Kong. Email: yulei.luo@gmail.com.

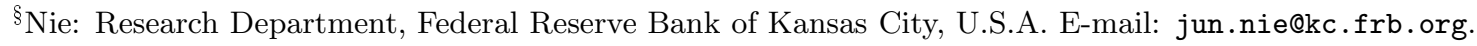

IZou: China Economics and Management Academy, Central University of Finance and Economics, Beijing, China. Email: hzoucema@gmail.com.

${ }^{1}$ We also discuss the case of elastica labor supply and $\beta<1$. 
where $\Phi_{1}=(\gamma+i) \varphi, \Phi_{2}=(1+i)(\varphi+\rho)+(\gamma+i)(1+i+\varphi)+(1+i) \theta \gamma$ and $\Phi_{3}=(1+i)\left(1+\frac{\rho}{\varphi}\right)(1+i+\varphi)$

We can rewrite (3) as

$$
\left(l_{x}-\frac{(1+i)\left(1+\frac{\rho}{\varphi}\right)}{\gamma+i}\right)\left(l_{x}-\frac{\varphi+1+i}{\varphi}\right)=\frac{(1+i) \theta \gamma}{\varphi(\gamma+i)} l_{x}
$$

Proposition 1 Under inelastic labor supply, CIA on R\&D only and $\frac{(1+i)\left(1+\frac{\rho}{\varphi}\right)}{\gamma+i} \leq 1$, the effect of a higher nominal interest rate on growth depends on the degree of the $S O C(\theta)$, whereas it is negative without the SOC. When the growth-enhancing effect of the SOC dominates (more likely with a larger $\theta$ ), a higher nominal interest rate increases growth; when the growth-reducing effect from the CIA on REDD dominates, a higher nominal interest rate reduces growth.

Proof. Using (44), when $\theta=0$, the solutions are two positive numbers, one is smaller than one $\left(\frac{(1+i)\left(1+\frac{\rho}{\varphi}\right)}{\gamma+i} \leq 1\right)$ and the other is larger than one $\left(\frac{\varphi+1+i}{\varphi}>1\right)$. Because manufacturing labor cannot be larger than 1 , the only admissible solution is the smaller positive root $\left.l_{x}\right|_{\theta=0}=$ $\frac{(1+i)\left(1+\frac{\rho}{\varphi}\right)}{\gamma+i}$ (point A in Figure1). When $\theta=0, \frac{\left.\partial l_{x}\right|_{\theta=0}}{\partial i}>0$. That is, when the nominal interest rate increases, point A moves to the right along the horizontal axis to B, yielding a larger manufacturing labor $l_{x}$ and thereby a lower R\&D labor $l_{r}$ (i.e., lower long-run growth).

When $\theta>0$, the solutions to (4) are the intersections of the parabola on the LHS (left-hand side) of (4) and the positively-sloped straightline passing through the origin of coordinates (the RHS (right-hand side) of (4)): the smaller positive root becomes smaller and the larger positive root becomes larger. The admissible solution is the smaller positive root (the equilibrium is point $\mathrm{C}$ in Figure 1).

When the nominal interest rate increases, the parabola on the LHS of (44) shifts to the right. Meanwhile, the straightline on the RHS of (4) rotates counter-clockwise. The new equilibrium will be point D. Obviously, whether point $\mathrm{D}$ is to the left or right of point $\mathrm{C}$ depends on the size of $\theta$. Therefore, whether a higher nominal interest rate increases/decreases manufacturing labor $l_{x}$ depends on the size of $\theta$.

When labor supply is elastic and $\beta<1$, the proof can be shown similarly using the two conditions that pin down the equilibrium labor allocation: the labor market clearing condition and the free labor mobility condition (as in our proof of Proposition 2 in the main text).

In this case, the labor market clearing condition becomes

$$
l_{r, t}+l_{x, t}=\left(\frac{1}{\eta \gamma l_{x, t}}\right)^{\sigma} .
$$

Graphically, the $L$ curve remains the same as in Figure 1 in the main text. 
Figure 1: Equilibrium Labor Allocation under CIA on R\&D and Inelastic Labor Supply

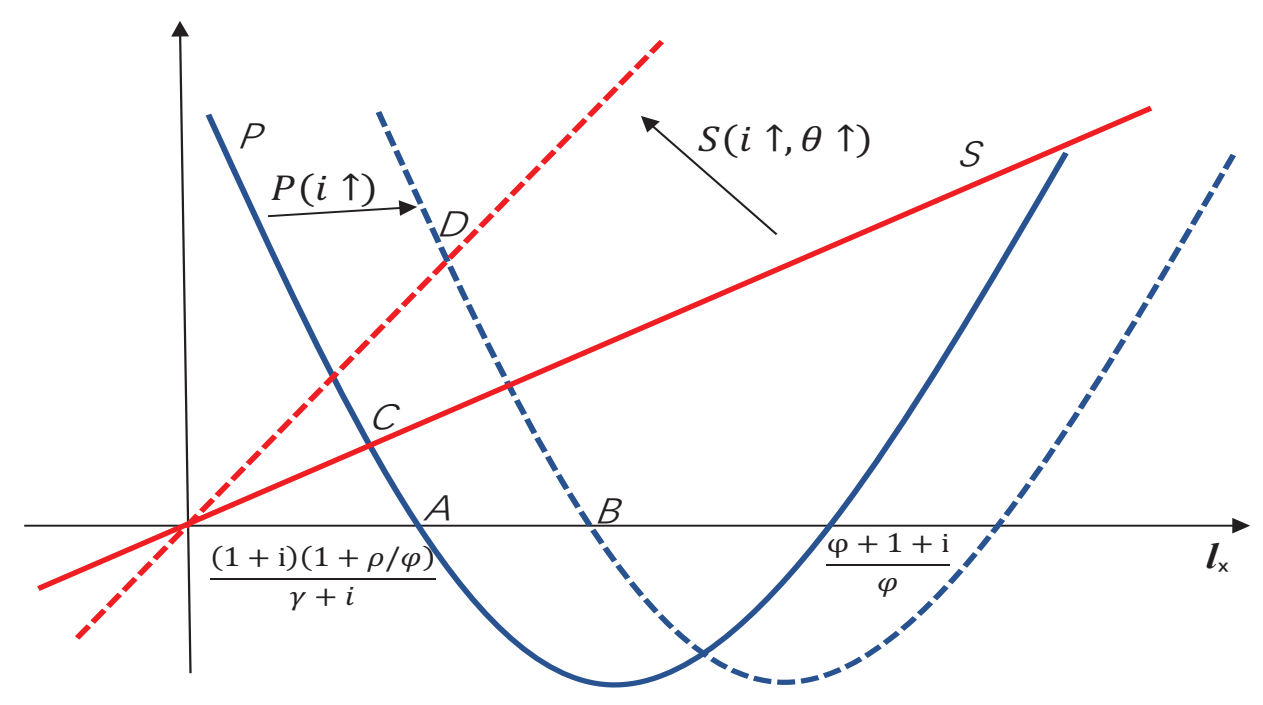

Repeating similar steps, the free labor mobility condition becomes

$$
(\gamma-1) l_{x, t}=(1+\beta i)\left(l_{r, t}+\rho / \varphi-\frac{\theta c_{t}}{\varphi a_{t}}\right) .
$$

We now have $\frac{c_{t}}{a_{t}}=\frac{\gamma l_{x, t}}{(1+\beta i) / \varphi+\beta l_{r, t}}$. Taken together, the free labor mobility condition becomes

$$
(\gamma-1) l_{x, t}=(1+\beta i)\left(l_{r, t}+\rho / \varphi-\frac{\theta \gamma l_{x, t}}{(1+\beta i)+\beta \varphi l_{r, t}}\right)
$$

which gives the upward-sloping $M$ curve as in Figure 1 in the main text.

Observing (5), an increase in the nominal interest rate will not shift the $L$ curve in Figure 1 in the main text. That is, the nominal interest rate has no effect on the consumption-leisure choice and thereby labor supply when the CIA on consumption is absent. By contrast, given a change in the nominal interest rate, both the SOC and the CIA on R\&D will affect growth through the free labor mobility condition (i.e., through shifting the $M$ curve).

On the one hand, under the CIA on R\&D, an increase in the nominal interest rate raises the borrowing cost of entrepreneurs, shifting labor away from R\&D to manufacturing. This effect comes from the $(1+\beta i)$ term in the first bracket on the RHS of (7). Graphically, an increase in the nominal interest rate leads to a rightward shift in the $M$ curve and the magnitude of the shift increases with the strength of the CIA on $\mathrm{R} \& \mathrm{D} \beta$ (using Figure 1 in the main text), thereby decreasing R\&D labor $l_{r}$ and increasing manufacturing labor $l_{x}$, all else equal.

On the other hand, due to the existence of the SOC, an increase in the nominal interest rate leads to a leftward shift in the $M$ curve in the Figure 1 in the main text), thereby increasing 
R\&D labor $l_{r}$ and decreasing manufacturing labor $l_{x}$, all else equal. This effect comes from the $\frac{(1+\beta i) \theta c_{t}}{\varphi a_{t}}$ term on the RHS of (6)), which is the $\frac{(1+\beta i) \theta \gamma l_{x, t}}{(1+\beta i)+\beta \varphi l_{r, t}}$ term on the RHS of (7). This term is increasing in the nominal interest rate because $\frac{(1+\beta i) \theta \gamma l_{x, t}}{(1+\beta i)+\beta \varphi l_{r, t}}=\frac{\theta \gamma l_{x, t}}{1+\beta \varphi l_{r, t} /(1+\beta i)}$ when the CIA on R\&D decreases R\&D labor $l_{r}$ and increases manufacturing labor $l_{x}$, all else equal, following an increase in the nominal interest rate (shown above). Given the same increase in the nominal interest rate, a higher degree of the SOC $\theta$ leads to a larger leftward shift in the $M$ curve in Figure 1 in the main text, thereby increasing R\&D labor $l_{r}$ and decreasing manufacturing labor $l_{x}$, all else equal.

Therefore, the total effect of the nominal interest rate on $\mathrm{R} \& \mathrm{D}$ labor (and thereby long-run growth) depends on the relative magnitude of the degree of the SOC $\theta$ versus the strength of the CIA on R\&D (i.e., $\beta$ ). Without the SOC, the effect of a higher nominal interest rate on $R \& D$ labor is negative. When the SOC is strong enough, the overall effect could be positive. 


\section{Online Appendix B: Inelastic Labor Supply and CIA on Consumption Only}

In this section, inelastic labor supply is captured by $\eta=0$, which yields $l_{r, t}+l_{x, t}=1$. The CIA constraint becomes $c_{t} \leq m_{t}$.

Proposition 2 Under inelastic labor supply and CIA on consumption, the steady state growth increases with the nominal interest rate $i$ as long as $\theta>0$ and $\frac{1+\rho / \varphi}{\gamma} \leq 1$. Moreover, the higher the degree of the SOC (i.e., a larger $\theta$ ), the larger the effect of the nominal interest rate on growth, all else equal.

Proof. Using $l_{r, t}+l_{x, t}=1$, imposing $\beta=0$ and repeating similar steps, we end up with a univariate quadratic equation for manufacturing labor $l_{x}$ :

$$
\gamma^{2} \varphi l_{x}^{2}+\Lambda_{2}^{1} l_{x}-\Lambda_{3}=0
$$

where $\Lambda_{2}^{1}=\gamma[1-(\varphi+\rho)+\theta(1+i)]$ and $\Lambda_{3}=1+\rho / \varphi$. Because $\gamma^{2} \varphi>0$ and $\Lambda_{3}>0$, (8) always has one negative root and one positive root. Because manufacturing labor cannot be negative, the only admissible solution is the positive root.

When $\theta=0$ (i.e., there is no SOC), using (8), we have the standard Schumpeterian model with the CIA constraint on consumption. $l_{x}$ is determined by

$$
\left(\gamma l_{x}-\Lambda_{3}\right)\left(\gamma \varphi l_{x}+1\right)=0
$$

where the two roots are $\left.l_{x}\right|_{\theta=0}=\frac{\Lambda_{3}}{\gamma}=\frac{1+\rho / \varphi}{\gamma}$ and $\left.l_{x}\right|_{\theta=0}=-\frac{1}{\gamma \varphi}$. The only admissible solution is the positive root $\left.l_{x}\right|_{\theta=0}=\frac{\Lambda_{3}}{\gamma}=\frac{1+\rho / \varphi}{\gamma}$. Therefore, we assume $\frac{1+\rho / \varphi}{\gamma} \leq 1$ to ensure $l_{x} \leq 1$.

When the nominal interest rate increases, the y-intercept of the quadratic function in (8) $-\Lambda_{3}$ remains constant, so does the coefficient of the quadratic term $\gamma^{2} \varphi$ (i.e., the shape of the parabola remains unchanged). The axis of symmetry of the quadratic function in (8) is $-\frac{\Lambda_{2}^{1}}{2 \gamma^{2} \varphi}$, which shifts to the left as the nominal interest rate increases. Taken together, the graph of the quadratic function in (8) (i.e., the parabola) remains unchanged and wholly shifts to the left as the nominal interest rate increases. Therefore, the positive root of the quadratic equation (i.e., manufacturing labor $l_{x}$ ) decreases. As a result, $\mathrm{R} \& \mathrm{D}$ labor $l_{r}$ and thereby long-run growth would increase as the nominal interest rate $i$ increases. One can observe from (8) that the increase in $\theta$ and that in $i$ tend to impact $l_{x}$ similarly, which proves the second part of the Proposition.

When $\theta=0$ (i.e., there is no SOC), $l_{r}$ and $l_{x}$ (thereby growth and welfare) are independent of the nominal interest rate under inelastic labor supply and CIA on consumption.

The intuition is as follows. Under inelastic labor supply, the effect of the nominal interest rate on labor supply through the consumption-leisure choice is absent. Without the SOC, the free 
labor mobility condition is not affected by the nominal interest rate under the CIA constraint on consumption. Therefore, without the SOC, both the R\&D labor $l_{r}$ and manufacturing labor $l_{x}$ (thereby growth and welfare) are not functions of the nominal interest rate (i.e., money is superneutral). By contrast, the existence of the SOC will yield the same labor reallocation effect that shifts labor away from manufacturing to $R \& D$ when the nominal interest rate increases. As a result, long-run growth increases and a higher degree of the SOC increases the effect of the nominal interest rate on growth.

Under inelastic labor supply and CIA on consumption, Corollary 1 still holds. Concerning welfare, imposing $\eta=0$ yields

$$
U=\frac{1}{\rho}\left[\ln \left(l_{x, 0}\right)+\theta \ln \left(\frac{1}{\varphi}+\gamma l_{x, 0}\right)+\frac{(1+\theta) g}{\rho}+\Omega\right],
$$

where $\Omega$ is a constant.

Proposition 3 Under inelastic labor supply and CIA on consumption, the steady state welfare increases with the nominal interest rate $i$ when $\theta \in(0, \underline{\theta})$ and $\frac{\rho}{\varphi \ln \gamma}<\frac{1+\rho / \varphi}{\gamma} \leq 1$, and it decreases with $i$ when $\theta \in(\bar{\theta}, \infty)$ and $\rho>\frac{\ln \gamma}{\gamma}$.

Proof. Taking derivative of $U$ in (10) with respect to $i$, using $\partial l_{x, 0} / \partial i=-\partial l_{r, 0} / \partial i$ under inelastic labor supply and $\partial g / \partial i=\varphi \ln \gamma \partial l_{r, 0} / \partial i$, we have

$$
\frac{\partial U}{\partial i}=\frac{\partial U}{\partial l_{x, 0}} \frac{\partial l_{x, 0}}{\partial i}+\frac{\partial U}{\partial g} \frac{\partial g}{\partial i}=\frac{1}{\rho}\left[\frac{1}{l_{x, 0}}+\frac{\varphi \gamma \theta}{1+\varphi \gamma l_{x, 0}}-\frac{(1+\theta) \varphi \ln \gamma}{\rho}\right] \frac{\partial l_{x, 0}}{\underset{(-)}{\partial i}}
$$

where $\partial l_{x, 0} / \partial i<0$ when $\theta>0$, according to the previous Proposition. Therefore, sign $\left(\frac{\partial U}{\partial i}\right)>0$ if $\left[\frac{1}{l_{x, 0}}+\frac{\varphi \gamma \theta}{1+\varphi \gamma l_{x, 0}}-\frac{(1+\theta) \varphi \ln \gamma}{\rho}\right]<0$. We have

$$
\begin{gathered}
{\left[\frac{1}{l_{x, 0}}+\frac{\varphi \gamma \theta}{1+\varphi \gamma l_{x, 0}}-\frac{(1+\theta) \varphi \ln \gamma}{\rho}\right]<\left[\frac{1}{l_{x, 0}}+\frac{\varphi \gamma \theta}{\varphi \gamma l_{x, 0}}-\frac{(1+\theta) \varphi \ln \gamma}{\rho}\right]} \\
=(1+\theta)\left[\frac{1}{l_{x, 0}}-\frac{\varphi \ln \gamma}{\rho}\right] .
\end{gathered}
$$

According to the previous Proposition, we have proved that $\left.l_{x}\right|_{\theta=0}=\frac{1+\rho / \varphi}{\gamma} \leq 1$ for any $i$ under inelastic labor supply. Therefore, we first need $\frac{1}{\left.l_{x}\right|_{\theta=0}}<\frac{\varphi \ln \gamma}{\rho}$, which is equivalent to $\frac{\rho}{\varphi \ln \gamma}<\frac{1+\rho / \varphi}{\gamma}$. Moreover, the previous Proposition shows that $l_{x, 0}$ is decreasing in both $\theta$ and $i$. Therefore, for a given $i$, when $\theta$ increases from zero, $l_{x, 0}$ decreases from $\frac{1+\rho / \varphi}{\gamma}$. Therefore, as long as $\theta<\underline{\theta}$ $\left(\underline{\theta}\right.$ is pinned down by $\left.l_{x, 0}(\underline{\theta})=\frac{\rho}{\varphi \ln \gamma}\right)$, we have $\operatorname{sign}\left(\frac{\partial U}{\partial i}\right)>0$. However, when $\theta$ continues to increase, it is possible that $\left[\frac{1}{l_{x, 0}}+\frac{\varphi \gamma \theta}{1+\varphi \gamma l_{x, 0}}-\frac{(1+\theta) \varphi \ln \gamma}{\rho}\right]>0$. We can find the $\bar{\theta}>\underline{\theta}$ by solving $\left[\frac{1}{l_{x, 0}}+\frac{\varphi \gamma \theta}{1+\varphi \gamma l_{x, 0}}-\frac{(1+\theta) \varphi \ln \gamma}{\rho}\right]=0\left(l_{x, 0}\right.$ is a function of $\left.\theta\right)$. If $\rho>\frac{\ln \gamma}{\gamma}$, the middle term in the square 
bracket increases at a rate of $\varphi \gamma \theta$ as $\theta$ approaches infinity, whereas the third term increases at a rate of $\frac{\theta \varphi \ln \gamma}{\rho}$. The middle term increases faster if $\rho>\frac{\ln \gamma}{\gamma}$, and $\operatorname{sign}\left(\frac{\partial U}{\partial i}\right)<0$ when $\theta \in(\bar{\theta}, \infty)$.

The intuition is as follows. According to (10), an increase in the nominal interest rate has two opposing effects on the welfare: (1) it reduces welfare by decreasing manufacturing labor $l_{x, 0}$ (thereby initial consumption and wealth) and (2) it increases welfare through raising the growth rate $g$. When the nominal interest rate increases, the SOC (i.e., households enjoy direct utility from holding wealth) makes households change their consumption-portfolio choice by reducing initial consumption: substituting consumption with more savings in the form of equity shares. The value of innovations increases due to lower borrowing costs, which generates the labor reallocation effect that increases R\&D labor and thereby growth. When $\theta$ is below a threshold, the welfare gain from higher future consumption and wealth dominates the welfare loss from lower initial consumption and wealth, and total welfare increases with the nominal interest rate. However, when $\theta$ is beyond a threshold, the welfare loss from lower initial consumption and wealth dominates the welfare gain from higher future consumption and wealth, and total welfare decreases with the nominal interest rate.

The reason to impose $\frac{\rho}{\varphi \ln \gamma}<\frac{1+\rho / \varphi}{\gamma} \leq 1$ is as follows. For instance, when $\gamma=1$, we have $\operatorname{sign}\left(\frac{\partial U}{\partial i}\right) \leq 0$. That is, in an economy without growth (when the step-size of innovation is 1 ), welfare cannot be increasing in the nominal interest rate even when $\theta>0$. This is understandable because the trade-off between lower initial consumption and wealth and higher future consumption and wealth is possible only when there is growth. When $\rho>\frac{\ln \gamma}{\gamma}$ (a larger $\rho$ means households are more impatient and discount future consumption more heavily), it is more likely that the welfare loss from lower initial consumption/wealth dominates the welfare gain from higher future consumption/wealth.

Under inelastic labor supply and CIA on consumption, we show that higher nominal interest rates always increase growth when $\theta>0$. By contrast, our results also indicate that higher nominal interest rates increase welfare when $\theta>0$ and $\theta$ is below a threshold; beyond a threshold, the effect of a higher nominal interest rate on welfare depends on structural parameters. Therefore, concerning optimal monetary policy, the Friedman rule (Friedman, 1969) of keeping the nominal interest rate at zero is suboptimal when $\theta>0$ and $\theta$ is below a threshold; the Friedman may be optimal when $\theta$ is above a threshold (this is possible in theory, but in real world situations, $\theta$ may not be that large). We summarize this point in the following Corollary.

Corollary 2 Under inelastic labor supply and CIA on consumption, the Friedman rule is suboptimal when $\theta>0$ and $\theta$ is below a threshold; depending on structural parameters, the Friedman may be optimal when $\theta$ is above the threshold. 


\section{Online Appendix C: Money Supply and Nominal Interest Rate}

In this online appendix, we show that under our calibrated parameter values, an increase in money supply also leads to an increase in the nominal interest rate based on the following equation:

$$
\frac{\dot{M}_{t}}{M_{t}}=i_{t}-\rho+\theta\left(1+i_{t}\right) \frac{c_{t}}{a_{t}} .
$$

The existence of the SOC slightly complicates the relationship between the nominal interest rate $i_{t}$ and the money supply growth rate $M_{t} / M_{t}$ by introducing an extra term on the right side of (14). However, as Figure 2 shows, the positive relationship is well maintained under the calibrate parameter values and different values of $\beta$ (the tightness of the CIA constraint on $R \& D$ ).

Figure 2: Relationship between Money Supply and Nominal Interest Rate

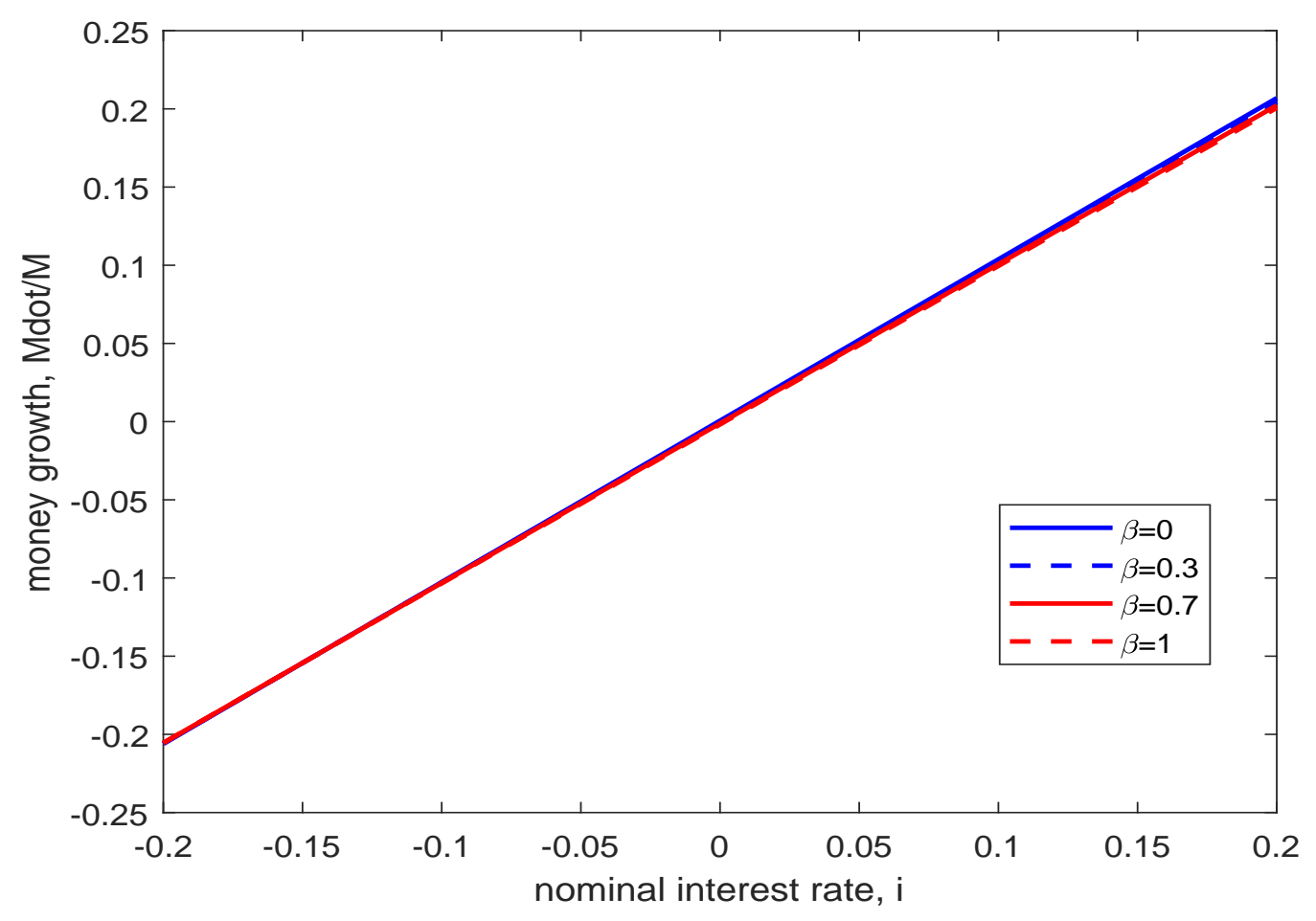




\section{Online Appendix D: A Non-monetary Schumpeterian Model with the SOC}

Without money, the new asset-accumulation equation becomes

$$
\dot{e}_{t}=r_{t} e_{t}+w_{t} l_{t}-c_{t}
$$

Per capita wealth $a_{t}$ becomes $a_{t}=e_{t}$. The optimal condition for labor supply can thus be written as:

$$
l_{t}=\left(\frac{w_{t}}{\eta c_{t}}\right)^{\sigma}
$$

The Euler equation is

$$
-\frac{\dot{\mu_{t}}}{\mu_{t}}=r_{t}-\rho+\frac{\theta}{\mu_{t} a_{t}}=r_{t}-\rho+\frac{\theta c_{t}}{a_{t}} .
$$

The dynamics of the model remain the same: it immediately jumps to the (saddle-point stable) balanced growth path on which the labor allocations are stationary and unique.

Now the labor market clearing condition becomes

$$
l_{r, t}=\left(\frac{1}{\eta \gamma}\right)^{\sigma} l_{x, t}^{-\sigma}-l_{x, t}
$$

The final goods market clearing condition gives $c_{t}=y_{t} / L$. We have $e_{t}=v_{t} / L$. Therefore, the consumption wealth ratio is

$$
\frac{c_{t}}{a_{t}}=\frac{y_{t}}{v_{t}}=\frac{\gamma w_{t} L_{x, t}}{w_{t} L_{r, t} / \lambda}=\varphi \gamma l_{x, t} .
$$

The free labor mobility condition is $(\gamma-1) l_{x, t}=l_{r, t}+\rho / \varphi-\theta c_{t} /\left(\varphi a_{t}\right)$. Combining with (19) yields

$$
l_{r, t}=(\gamma-1) l_{x, t}-\rho / \varphi+\theta \gamma l_{x, t} .
$$

Proposition 4 Given $(\eta \gamma)^{-\sigma /(1+\sigma)} \leq 1$, the steady state growth increases with $\theta$ (the degree of the $S O C)$, all else equal.

Proof. For the labor market clearing condition, we still have: $\frac{\partial l_{r, t}}{\partial l_{x, t}}<0$ and $\frac{\partial^{2} l_{r, t}}{\partial l_{x, t}^{2}}>0$. Given $\lim _{l_{x, t} \rightarrow 0} l_{r, t}=\infty$, the labor market clearing condition becomes $l_{r, t}+l_{x, t}=1$ when $l_{x, t}$ is below a threshold. We assume $\left.l_{x, t}\right|_{l_{r}=0}=\left(\frac{1}{\eta \gamma}\right)^{\sigma /(1+\sigma)} \leq 1$. Therefore, the labor market clearing condition is described by the $L$ curve in Figure 3. Using the free labor mobility condition, we have $\frac{\partial l_{r, t}}{\partial l_{x, t}}=(\gamma-1)+\theta \gamma>0$ and $\frac{\partial^{2} l_{r, t}}{\partial l_{x, t}^{2}}=0$. Therefore, the $M$ curve for the free labor mobility condition is a straight upward-sloping line. Using Figure 3, an increase in $\theta$ does not shift the $L$ curve, but it does rotate the $M$ curve counter-clockwise around $(0,-\rho / \varphi)$ (i.e., the equilibrium would move from $O$ to $E$ ), thereby increasing R\&D labor $l_{r}$ and decreasing manufacturing labor $l_{x}$, all else equal. 


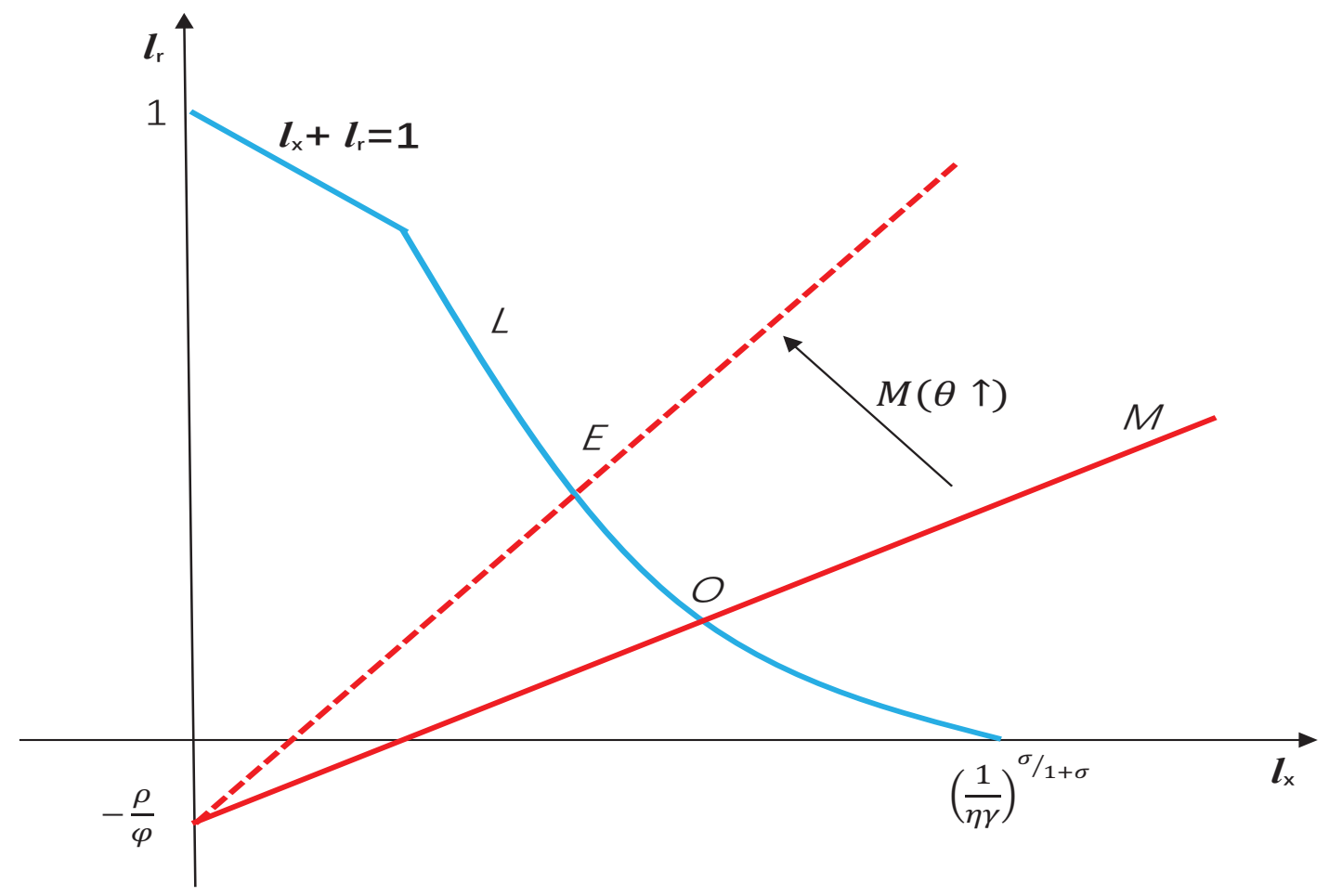

Figure 3: Effect of the SOC on Labor Allocation in a Non-monetary Schumpeterian

Model This graph shows the determination of equilibrium labor allocation in the R\&D sector and the production sector in a Schumpeterian model without money. The $L$ is the labor-market clearing condition and the $M$ curve is the labor mobility condition.

The intuition behind this Proposition can be explained in a similar way. With the SOC, the savings decision will depend on $\theta c_{t} / a_{t}+r_{t}-\rho$. An increase in $\theta$ raises the marginal benefit of saving through the direct preference for wealth. This would lead people to substitute more consumption with savings, which drives down the real interest rate and the borrowing cost of entrepreneurs. This increases the return to entrepreneurial investment and attracts more labor into R\&D (causing labor reallocation from manufacturing to $\mathrm{R} \& \mathrm{D})$. However, an increase in $\theta$ would not affect the labor supply choice, leaving total labor supply unchanged (i.e., the consumption-leisure choice effect is absent). The larger labor reallocation effect due to a higher $\theta$ results in larger R\&D labor and thereby higher long-run growth.

This result echoes the finding in the literature that the existence of the SOC promotes growth in the Ramsey-Cass-Koopmans capital accumulation models, the AK model (see Zou, 1994), the Romer's expanding-varieties model (Pan et al., 2018), and Romer's expanding-varieties model 
with capital accumulation (Hof and Prettner, 2019). 


\section{Online Appendix E: Comparison with a Monetary AK Model with the SOC}

In this section, we replace the Schumpterian growth model with an AK growth model. To introduce money into the growth model, we continue to assume a CIA constraint on consumption. The utility function remains the same. Each individual is endowed with one unit of labor. There is no population growth and total population is fixed at $L$. Each household maximizes its lifetime utility (the same as the benchmark model) subject to the asset-accumulation equation:

$$
\dot{k}_{t}+\dot{m}_{t}=A k-c_{t}-\pi_{t} m_{t}+\tau_{t}
$$

where $k_{t}$ is the real value of capital stock held by each person, and $A$ is the level of technology; the other variables remain the same as before. Here the per capita wealth is $a_{t}=k_{t}+m_{t}$. The CIA constraint is still $c_{t} \leq m_{t}$.

Proposition 5 In the AK model with the SOC and a CIA constraint on consumption, growth in the steady state increases with the nominal interest rate (i.e., money is not superneutral). Without the SOC, money is superneutral.

Proof. Household's Hamiltonian function in this AK model is given by

$$
H_{t}=\ln c_{t}+\theta \ln \left(a_{t}\right)+\mu_{t}\left(A k_{t}-c_{t}-\pi_{t} m_{t}+\tau_{t}\right)+\xi_{t}\left(m_{t}-c_{t}\right)
$$

where $\mu_{t}$ is the co-state variable; $\xi_{t}$ is the Lagrangian multiplier for the CIA constraint; $a_{t}=$ $k_{t}+m_{t}$.

The corresponding first-order conditions are given by:

$$
\begin{aligned}
& \frac{\partial H_{t}}{\partial c_{t}}=\frac{1}{c_{t}}-\mu_{t}-\xi_{t}=0, \\
& \frac{\partial H_{t}}{\partial k_{t}}=\frac{\theta}{a_{t}}+A \mu_{t}=\rho \mu_{t}-\dot{\mu}_{t}, \\
& \frac{\partial H_{t}}{\partial m_{t}}=\frac{\theta}{a_{t}}-\mu_{t} \pi_{t}+\xi_{t}=\rho \mu_{t}-\dot{\mu}_{t} .
\end{aligned}
$$

On the balanced growth path, we have $\dot{c}_{t} / c_{t}=\dot{k}_{t} / k_{t}=g_{a k}$. Using the resource constraint, we have $\dot{k}_{t}=A k_{t}-c_{t}$, which gives

$$
\frac{c_{t}}{k_{t}}=A-g_{a k}
$$

Combining (23) and (24) yields $\xi_{t}=\left(A+\pi_{t}\right) \mu_{t}$. We have $\dot{m}_{t}=M_{t} /\left(P_{t} L\right)$, which yields $\dot{m}_{t} / m_{t}=$ $\dot{M}_{t} / M_{t}-\pi_{t}$. The binding CIA constraint yields $\dot{c}_{t} / c_{t}=\dot{m}_{t} / m_{t}=g_{a k}$. Taken together, we have

$$
\xi_{t}=\left(A+\frac{\dot{M_{t}}}{M_{t}}-g_{a k}\right) \mu_{t} .
$$


Using the Fisher equation $i_{t}=\pi_{t}+r_{t}$, we have $i_{t}=\dot{M}_{t} / M_{t}-\dot{m}_{t} / m_{t}+A$, where we have used $r_{t}=A$ in the AK model. Therefore, we have $i_{t}=M_{t} / M_{t}-g_{a k}+A$, and combining with (26) yields $\xi_{t}=i_{t} \mu_{t}$. Plugging this condition into (22) yields

$$
\frac{1}{c_{t}}=\mu_{t}\left(1+i_{t}\right)
$$

which shows that, given $i_{t}=i$, on the balanced growth path, $\dot{c}_{t} / c_{t}=-\dot{\mu}_{t} / \mu_{t}=g_{a k}$.

Using (23), we have

$$
-\frac{\dot{\mu_{t}}}{\mu_{t}}=A-\rho+\frac{\theta}{\mu_{t} a_{t}}
$$

Plugging (27) into (28), we have the Euler equation

$$
-\frac{\dot{\mu_{t}}}{\mu_{t}}=g_{a k}=A-\rho+\frac{\theta c_{t}(1+i)}{a_{t}} .
$$

In equilibrium, the CIA constraint binds, which gives $c_{t}=m_{t}$. Using (25), we can rewrite (29) as

$$
g_{a k}=A-\rho+\frac{\theta(1+i)}{1+\frac{1}{A-g_{a k}}} .
$$

Rewriting (30), we have the univariate quadratic equation for $g_{a k}$ :

$$
g_{a k}^{2}-\Omega_{1} g_{a k}+\Omega_{2}=0
$$

where $\Omega_{1}=\theta(1+i)+(A+1)+(A-\rho)$ and $\Omega_{2}=\theta A(1+i)+(A+1)(A-\rho)$.

When $i \geq-1$, we have $\Omega_{1}>0$ and $\Omega_{2}>0$. Therefore, the quadratic equation (31) has two positive roots when $\Delta=\Omega_{1}^{2}-4 \Omega_{2}>0$ and no solution (in real numbers) when $\Delta<0$. We assume $\Delta>0$ because $\left.\Delta\right|_{\theta=0}>0$.

When $\theta=0$ (i.e., there is no SOC), we have

$$
g_{a k}^{2}-[(A+1)+(A-\rho)] g_{a k}+(A+1)(A-\rho)=0,
$$

where the two roots are $\left.g_{a k}\right|_{\theta=0}=A+1$ and $\left.g_{a k}\right|_{\theta=0}=A-\rho$. The only admissible solution is the smaller root $\left.g_{a k}\right|_{\theta=0}=A-\rho$. That is, money is superneutral in the AK model with a CIA constraint on consumption (see also Dotsey and Sarte, 2000).

Therefore, when $\theta>0$, focusing on the unique perfect-foresight equilibrium, the only admissible solution is the smaller root of (31). Thus, the balanced growth rate is

$$
g_{a k}=\frac{\Omega_{1}-\sqrt{\Omega_{1}^{2}-4 \Omega_{2}}}{2} .
$$


When the nominal interest rate $i$ increases, the y-intercept $\Omega_{2}$ of the quadratic function increases, and its axis of symmetry $\frac{\Omega_{1}}{2}$ shifts to the right. Therefore, the smaller positive root of the quadratic function (i.e., the balanced growth rate) increases.

The intuition behind this proposition is similar to that provided in Proposition 2. It is worth noting that Sidrauski (1967) proves the superneutrality of money in a qualitatively equivalent approach which assumes money enters the utility function 2 As explained by Sidrauski (1967, p. 544), "In the short run, an increase in the rate of monetary expansion is equivalent to a rise in government transfers to the private sector. It therefore results in an increase in consumption and a fall in the rate of capital accumulation." In addition, monetary expansion pushes people to substitute real balance with capital holdings (the Mundell-Tobin portfolio-shift effect that refers to shifts between assets related to inflation changes, see Mundell, 1965; Tobin, 1965), which tends to reduce consumption under the CIA constraint on consumption. The two opposing effects (the positive Sidrauski government transfer effect and the negative Mundell-Tobin portfolio-shift effect) offset each other, leaving the steady state consumption, savings and capital stock unchanged in Ramsey models and the saving rate and thereby long-run growth unchanged in the AK model (see e.g., Dotsey and Sarte, 2000). In other words, with a CIA constraint on consumption, long-run growth in capital accumulation models depends solely on the real return to capital accumulation $r_{t}$ (i.e., not on labor supply $l_{t}$ ) that is independent of monetary policy because the nominal interest rate does not alter the saving behavior of households nor the marginal productivity of capital.

To recap, in the AK model with the CIA constraint on consumption, money is superneutral without the SOC because the aforementioned two opposing effects (the positive Sidrauski government transfer effect and the negative Mundell-Tobin portfolio-shift effect) on consumption still offset each other, leaving the saving rate and thereby long-run growth unchanged. By contrast, in the presence of the SOC, a higher nominal interest rate yields a larger consumption-portfolio effect that decreases the marginal propensity to consume due to stronger saving motivation. In the AK model, labor supply has no effect on long-run growth (i.e., the negative consumption-leisure choice effect is absent). Taken together, long-run growth is an increasing function of the nominal interest rate.

There is one important difference between our Schumpeterian model and the AK model. That is, a higher nominal interest rate always increases growth in the AK model, while it possibly decreases growth in our Schumpeterian model. The reason is as follows. In the Schumpeterian model with the SOC and elastic labor supply, there exists the consumption-leisure choice channel from a higher nominal interest rate. This consumption-leisure choice effect through decreasing

\footnotetext{
${ }^{2}$ This is an equivalent way, as using a CIA constraint, to introduce money into growth models.
} 
market size tends to reduce growth when the nominal interest rate increases. When this effect dominates the labor reallocation effect, a higher nominal interest rate reduces long-run growth. However, this consumption-leisure choice effect is absent in the AK model and thus growth always increases with the nominal interest rate in the AK model. 


\section{Online Appendix F: Alternative Utility Function Nesting Chu and Cozzi (2014)}

Maintaining the utility function in Chu and Cozzi (2014) helps identify the driving force of our main results from a comparative perspective. To do so, we use the following utility function 3

$$
U=\int_{0}^{\infty} e^{-\rho t}\left[\ln \left(c_{t}\right)+\theta \ln \left(a_{t}\right)+\eta \frac{\left(1-l_{t}\right)^{1-\sigma}}{1-\sigma}\right] d t
$$

where $c_{t}$ is per capita real consumption of final goods, $a_{t}$ is per capita wealth, and $l_{t}$ is per capita labor supply at time $t$. $\rho$ is the rate of time preference; $\theta \geqslant 0$ captures the preference for wealth (i.e., the degree of the SOC, and a larger $\theta$ means a higher degree of the SOC); $\eta \geqslant 0$ is still the taste for leisure as in Doepke and Zilibotti (2008); $\sigma>0$ determines the elasticity of labor supply.

This new utility specification has the advantage of nesting the Chu and Cozzi's (2014) log-log utility as a special case with $\sigma=1$.

Unlike the Chu-Cozzi specification, both the new utility specification and the one used in our main text allow us to separate the elasticity of labor supply versus the taste for leisure. Both parameters are important in the macroeconomic literature (e.g., the taste for leisure is highlighted in Doepke and Zilibotti, 2008, as one fundamental parameter of the SOC, whereas the elasticity of labor supply is highlighted in Aghion, Akcigit and Fernández-Villaverde, 2013, for the optimal labor versus capital taxes in Schumpeterian models).

For the Chu-Cozzi utility specification, we have the following

$$
\frac{1}{c_{t}}=\mu_{t}\left(1+i_{t}\right) \text { and } \frac{\eta}{1-l_{t}}=w_{t} \mu_{t}
$$

which gives

$$
\frac{\eta c_{t}}{1-l_{t}}=\frac{w_{t}}{1+i_{t}}
$$

Given $\eta$ and holding $c_{t}$ and $i_{t}$ fixed, the elasticity of leisure with respect to the wage rate is defined as:

$$
\frac{d \ln \left(1-l_{t}\right)}{d \ln \left(w_{t}\right)}=-1
$$

To compute the elasticity of labor supply with respect to the wage rate, we approximate $\ln \left(1-l_{t}\right)$ around the steady state $\bar{l}$ as follows:

$$
\ln \left(1-l_{t}\right)=\ln \left(1-\exp \left(l_{t}\right)\right) \cong \ln (1-\bar{l})-\frac{\bar{l}}{1-\bar{l}} \ln \left(l_{t}-\bar{l}\right)=-1,
$$

which means that

$$
\frac{d \ln \left(l_{t}\right)}{d \ln \left(w_{t}\right)}=\frac{1-\bar{l}}{\bar{l}} .
$$

\footnotetext{
${ }^{3}$ We thank Angus Chu for helpful discussion.
} 
In other words, in the Chu and Cozzi (2014) setting, the elasticity of labor supply with respect to the wage rate is $\frac{1-\bar{l}}{\bar{l}}$, not 1 or $\eta$.

As a comparison, in our alternative additively separable utility function $\ln \left(c_{t}\right)+\theta \ln \left(a_{t}\right)-$ $\eta \frac{l_{t}^{1+1 / \sigma}}{1+1 / \sigma}$, combining the two FOCs yields

$$
\frac{1}{c_{t}}=\mu_{t}\left(1+i_{t}\right) \text { and } \eta l_{t}^{1 / \sigma}=w_{t} \mu_{t}
$$

which obtains

$$
\eta c_{t} l_{t}^{1 / \sigma}=\frac{w_{t}}{1+i_{t}}
$$

Given $\eta$ and holding $c_{t}$ and $i_{t}$ fixed, the Frisch elasticity of labor supply with respect to the wage rate is defined as:

$$
\frac{d \ln \left(l_{t}\right)}{d \ln \left(w_{t}\right)}=\sigma
$$

Separating these two parameters will not change our main predictions, but it does allow us to evaluate the separate roles of the taste for leisure $(\eta)$ and the Frisch elasticity of labor supply $(\sigma)$. Our model yields testable predictions concerning the two important macroeconomic parameters.

For our new utility specification that nests the Chu and Cozzi's (2014) log-log utility as a special case with $\sigma=1$, repeating similar steps, we can calculate the elasticity of labor supply as $\frac{1}{\sigma} \frac{1-\bar{l}}{\bar{l}}$, which means the elasticity of labor supply is proportional to $\frac{1}{\sigma}$ (similar to the intertemporal elasticity of substitution for CRRA utility function). Therefore, the new utility function still allows us to separate and isolate the roles of the elasticity of labor supply versus the taste for leisure in the effect of monetary policy on long-run growth and welfare.

\section{F.1. Solving the Model}

In this alternative model, we still use the CIA constraint $c_{t} \leq m_{t}$.

Using Hamiltonian, we can derive the optimality condition for consumption

$$
\frac{1}{c_{t}}=\mu_{t}\left(1+i_{t}\right)
$$

where $\mu_{t}$ is the Hamiltonian co-state variable, and $i_{t}=\pi_{t}+r_{t}$ (the Fisher equation) is the nominal interest rate.

The optimal condition for labor supply is

$$
\eta\left(1-l_{t}\right)^{-\sigma}=w_{t} \mu_{t}
$$

Using (40), we rewrite the optimal condition for labor supply as

$$
l_{t}=1-\left[\frac{\eta c_{t}\left(1+i_{t}\right)}{w_{t}}\right]^{\frac{1}{\sigma}} .
$$


Equations (41) and (42) show that a higher nominal interest rate reduces labor supply through the consumption-leisure choice (i.e., the negative consumption-leisure choice effect is still present).

The Euler equation is

$$
-\frac{\dot{\mu_{t}}}{\mu_{t}}=r_{t}-\rho+\frac{\theta}{\mu_{t} a_{t}}=r_{t}-\rho+\frac{\theta\left(1+i_{t}\right) c_{t}}{a_{t}}
$$

where the last equality uses (40). When $\theta=0$, we will have the monetary Schumpeterian model without the SOC. $\theta>0$ will yield the positive labor reallocation effect.

Repeating similar steps, we have the free labor mobility condition as

$$
(\gamma-1) l_{x, t}=l_{r, t}+\rho / \varphi-\frac{\theta(1+i) c_{t}}{\varphi a_{t}}
$$

We have $a_{t}=e_{t}+m_{t}$. The CIA constraint binds: $c_{t}=m_{t}$. The output market clearing condition gives $c_{t}=y_{t} / L$. We have $e_{t}=v_{t} / L$. Therefore, the consumption wealth ratio is

$$
\frac{c_{t}}{a_{t}}=\frac{y_{t}}{v_{t}+y_{t}}=\frac{\gamma w_{t} L_{x, t}}{w_{t} L_{r, t} / \lambda+\gamma w_{t} L_{x, t}}=\frac{\gamma l_{x, t}}{1 / \varphi+\gamma l_{x, t}} .
$$

Plugging (45) into (44), we have the free labor mobility condition as

$$
(\gamma-1) l_{x}=l_{r}+\rho / \varphi-\frac{\theta(1+i) \gamma l_{x}}{1+\varphi \gamma l_{x}}
$$

Using the output market clearing condition $c_{t}=y_{t} / L$ and $y_{t}=\gamma w_{t} L_{x, t}$, the labor market clearing condition (42) becomes

$$
l_{r, t}+l_{x, t}=l_{t}=1-\left[\eta \gamma\left(1+i_{t}\right) l_{x, t}\right]^{1 / \sigma} .
$$

The above two conditions pin down the equilibrium labor allocation.

Below we will show Proposition 2 (our key results in the paper) holds for $\sigma=1$ (Chu and Cozzi 2014) and $\sigma \neq 1$.

We rewrite the labor market clearing condition (47) as

$$
l_{r, t}=1-\left[\eta \gamma\left(1+i_{t}\right) l_{x, t}\right]^{1 / \sigma}-l_{x, t} .
$$

Using (48), we have

$$
\begin{aligned}
\frac{\partial l_{r, t}}{\partial l_{x, t}} & =-\frac{1}{\sigma}\left[\eta \gamma\left(1+i_{t}\right)\right]^{1 / \sigma} l_{x, t}^{1 / \sigma-1}-1<0, \\
\frac{\partial^{2} l_{r, t}}{\partial l_{x, t}^{2}} & =-\frac{1}{\sigma}\left(\frac{1}{\sigma}-1\right)\left[\eta \gamma\left(1+i_{t}\right)\right]^{1 / \sigma} l_{x, t}^{1 / \sigma-2} \gtrless 0 .
\end{aligned}
$$


As discussed above, $\frac{1}{\sigma}$ captures the elasticity of labor supply (a smaller $\sigma$ means a higher elasticity of labor supply). It's easy to see $\frac{\partial^{2} l_{r, t}}{\partial l_{x, t}^{2}}<0$ when $\sigma \in(0,1), \frac{\partial^{2} l_{r, t}}{\partial l_{x, t}^{2}}>0$ when $\sigma \in(1, \infty)$, and $\frac{\partial^{2} l_{r, t}}{\partial l_{x, t}^{2}}=0$ when $\sigma=1$.

Therefore, the labor market clearing condition shows that, with manufacturing labor $\left(l_{x, t}\right)$ on the horizontal axis, R\&D labor share $\left(l_{r, t}\right)$ is a downward-sloping concave (convex) function of $l_{x, t}$ when $\sigma \in(0,1)$ (when $\sigma \in(1, \infty)$ ). It is a downward-sloping linear function when $\sigma=1$ (the case for Chu and Cozzi 2014). We denote this curve as the $L$ curve in Figure 4 A higher elasticity of labor supply (a smaller $\sigma$ ) shifts the $L$ curve leftward.

The free labor mobility condition is unchanged from our paper which is an upward-sloping concave function of manufacturing labor $l_{x, t}$ (with $l_{x, t}$ on the horizontal axis). We denote this curve as the $M$ curve in Figure 4 .

Figure 4: Alternative Figure 1 (in the Paper) under the New Utility Function

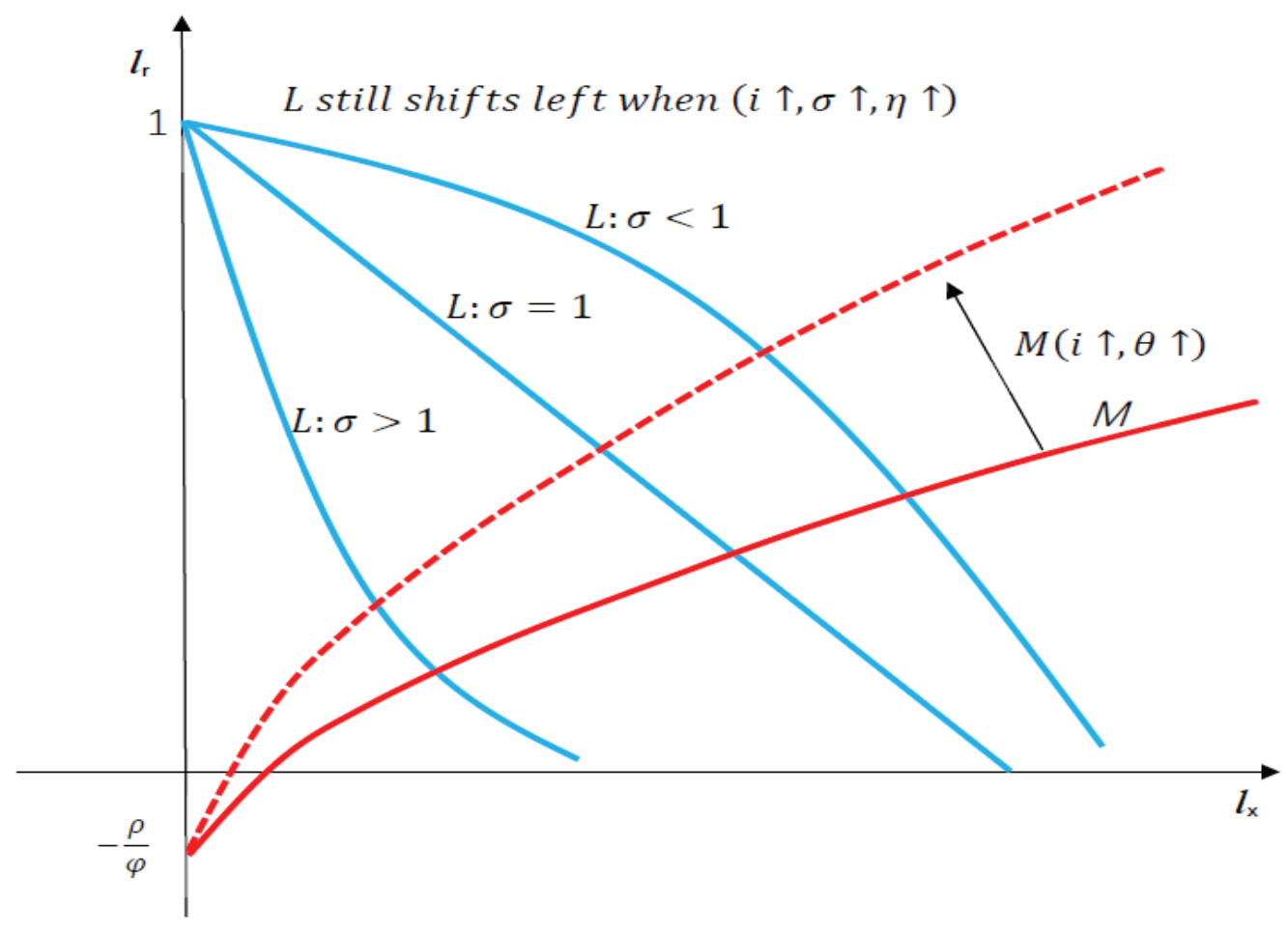

Figure 4 helps illustrate why the key mechanism is robust to $\sigma>1, \sigma<1$, and $\sigma=1$. Our key mechanism is that an increase in the nominal interest rate $(i)$ will shift the $M$ curve to the left (or rotate it counterclockwise) while a stronger SOC $(\theta)$ amplifies this effect. For the $L$ curve, an increase in the nominal interest rate shifts it to the left (or rotate it clockwise), for all values 
of $\sigma$ ). Therefore, for any value of $\sigma$, the equilibrium labor in the R\&D sector $\left(l_{r}\right)$ could rise if the $M$ curve shifts to the left enough, leading to a higher long-run growth rate. In other words, as $\sigma$ only matters for the shape of the $L$ curve but does not influence the $M$ curve, the key mechanism holds generally at different values of $\sigma$.

To briefly summarize, the consumption-leisure choice effect will always decrease labor supply with a higher nominal interest rate, the magnitude of the effect depends on the labor supply parameter $\sigma$. However, the growth-promoting effect of the SOC with a higher nominal interest rate does not hinge on the specific value of the labor-supply elasticity.

\section{F.2. Further Discussions}

It is worth noting that there exists a minimum level of $\theta$ under which our main predictionwith the SOC, higher nominal interest rates may promote log-run economic growth (a finding that was not found in the previous literature) — holds true. When $\eta=0$ (i.e., inelastic labor supply), as long as $\theta>0$, higher nominal interest rate would promote long-run economic growth. This is because the negative consumption-leisure choice effect is absent under inelastic labor supply, while the labor reallocation effect is positive when $\theta>0$. When $\eta>0$, however, this minimum level of $\theta$ obviously depends on other structural parameters, especially the taste for leisure $\eta$. When $\eta>0$, for a given nominal interest rate level, an increase in the nominal interest rate will shift the $M$ curve upwardly and the $L$ curve leftward. So we need to find out the threshold $\underline{\theta}$ such that an upward shift in the $M$ curve will offset the leftward shift of the $L$ in keeping the equilibrium labor in the R\&D sector $\left(l_{r}\right)$ unchanged. However, even under the case $\sigma=1$ which corresponds to Chu and Cozzi's (2014) log-log utility specification, plugging $l_{r, t}+l_{x, t}=1-\eta \gamma\left(1+i_{t}\right) l_{x, t}$ into (46) to substitute out $l_{x}$ leaves $l_{r}$ as a non-linear function of $i$ and $\theta$, which is why an analytical solution for $\underline{\theta}$ is unavailable even for the case of $\sigma=1$. However, we have quantitatively shown by figure in the paper that when $\theta$ increases from 0 to 0.3 , the correlation between the nominal interest rate and growth changes from negative to positive.

Moreover, we can see the advantage of using the two utility functions (the one used in our main text and the new one that nests the Chu-Cozzi log-log utility as a special case with $\sigma=1$ ): they both allow us to study the separate roles of the taste for leisure $(\eta)$ and the elasticity of labor supply in the effect of higher nominal interest rate on long-run growth. For instance, in our main text model, when $\eta>0$, labor supply is still inelastic when $\sigma$ approaches zero. Although both cases ( $\sigma$ approaches zero and $\eta=0$ ) correspond to inelastic labor supply (i.e., households spend all of time working, $l=1$ ), the mechanism is different.

$\eta=0$ means people love work (a low taste for leisure means a higher degree of the SOC as highlighted Doepke and Zilibotti, 2008). According to Doepke and Zilibotti (2008), an upper 
class imbued with disdain for work cultivate a refined taste for leisure, whereas a hard-working and frugal middle class develop patience and work ethics: "These class-specific attitudes, which are rooted in the nature of pre-industrial professions, become key determinants of success once industrialization transforms the economic landscape."

By contrast, even with $\eta>0$, labor supply could also be inelastic when $\sigma$ approaches zero in our main text model. The elasticity of labor supply measures the responsiveness of households' labor supply with respect to the changes in the wage rate, whereas the taste for leisure has nothing to do the responsiveness of the households' labor supply with respect to the changes in the wage rate. We can separatedly discuss the effect of the Frisch elasticity of labor supply, as shown in the following figure. Obviously, this change in labor supply is totally due to the change in elasticity of labor supply (for any given $\eta>0$ ).

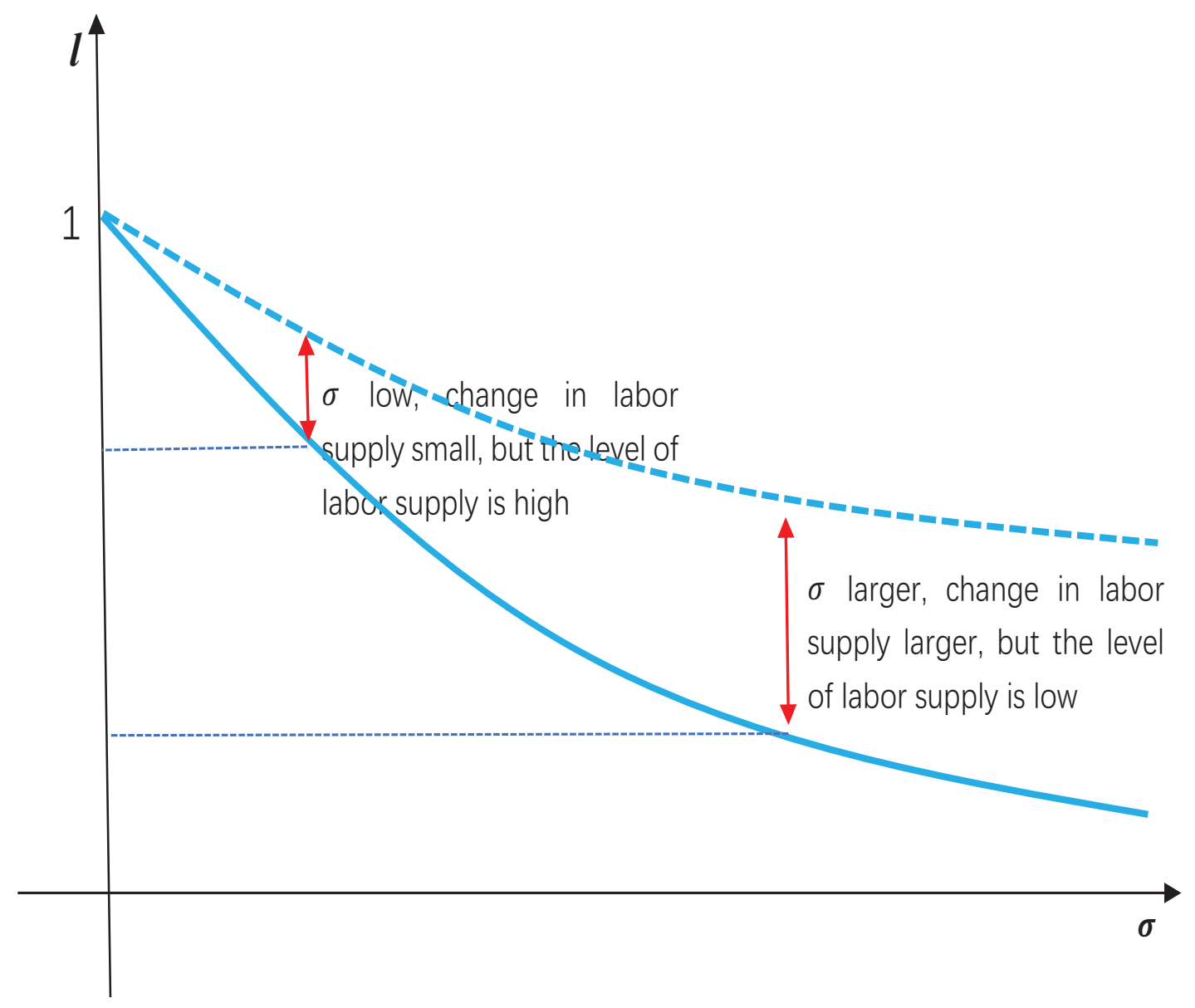




\section{Online Appendix G: Introducing Money through Money in the Utility Function}

In the following we will show that the same positive effect of a higher nominal interest on savings due to the existence of the SOC still exists if we use the MIUF (money-in-the-utility-function) approach, which indicates that our mechanism is quite robust as long as fiat money enters the households' problem.

At time $t$, the population size of each household is fixed at $L$. There is a unit continuum of identical households, which have a lifetime utility function as

$$
U=\int_{0}^{\infty} e^{-\rho t}\left[\ln \left(c_{t}\right)+\theta \ln \left(a_{t}\right)+\xi \ln \left(m_{t}\right)\right] d t
$$

where $m_{t}$ is per capita real balance and the other variables remain the same.

Each household maximizes its lifetime utility given in equation (51) subject to the assetaccumulation equation given by

$$
\dot{e}_{t}+\dot{m}_{t}=r_{t} e_{t}+w_{t}-c_{t}-\pi_{t} m_{t}+\tau_{t}
$$

where the variables remain the same as in the main text.

Given the budget constraint, per capita wealth $a_{t}$ is defined as $a_{t}=e_{t}+m_{t}$. The no-arbitrage condition is $i_{t}=\pi_{t}+r_{t}$, where $i_{t}$ is also the nominal interest rate. Household's Hamiltonian function is

$$
H_{t}=\ln c_{t}+\theta \ln \left(a_{t}\right)+\xi \ln \left(m_{t}\right)+\mu_{t}\left(r_{t} e_{t}+w_{t}-c_{t}-\pi_{t} m_{t}+\tau_{t}\right),
$$

where $\mu_{t}$ is the co-state variable on (152).

The first-order conditions include:

$$
\begin{aligned}
& \frac{\partial H_{t}}{\partial c_{t}}=\frac{1}{c_{t}}-\mu_{t}=0, \\
& \frac{\partial H_{t}}{\partial e_{t}}=\frac{\theta}{a_{t}}+\mu_{t} r_{t}=\rho \mu_{t}-\dot{\mu}_{t}, \\
& \frac{\partial H_{t}}{\partial m_{t}}=\frac{\theta}{a_{t}}+\frac{\xi}{m_{t}}-\mu_{t} \pi_{t}=\rho \mu_{t}-\dot{\mu}_{t} .
\end{aligned}
$$

Combining (54) and (55) yields

$$
\frac{\xi}{m_{t}}=\mu_{t}\left(r_{t}+\pi_{t}\right)=\mu_{t} i_{t} .
$$

The Euler equation is

$$
-\frac{\dot{\mu_{t}}}{\mu_{t}}=r_{t}-\rho+\frac{\theta}{\mu_{t} a_{t}} .
$$


Using (53), (57) and (56), the consumption Euler equation is

$$
\frac{\dot{c_{t}}}{c_{t}}=r_{t}-\rho+\theta \frac{i_{t} m_{t}}{\xi a_{t}}
$$

This consumption Euler equation points to the same mechanism as we highlight under the CIA constraint on consumption. When $\theta=0$ (i.e., without the SOC), the households' problem shows that the nominal interest rate has no direct effect on the real interest rate and thereby the consumption/savings decision of the households. The result is expected because the cross partial derivatives of the utility function are zeros (i.e., there is neither substitutability nor complementarity between consumption, real balance and leisure). Under inelastic labor supply, money is superneutral under this special MIUF model.

By contrast, when $\theta>0$ (i.e., with the SOC), the preference for wealth accumulation tends to lower consumption by introducing a third term on the right side of equation (58). In general, this equation shows that, when people have the SOC, consumption-savings choices depend not only on the real return on wealth, $r_{t}-\rho$, but also on the marginal rate of substitution between wealth and real balance. In other words, as Michaillat and Saez (2019) also point out, people become less forward-looking and future interest rates have less impact on today's consumption than in the standard model. The modification of the Euler equation due to wealth in the utility in equation (58) still reveals that a higher nominal interest rate tends to increase the marginal rate of substitution between wealth and real balance. This makes households even less forward-looking, thereby increasing households' saving.

A couple of results follow. First of all, higher money growth reduces the demand for real balance because the opportunity cost of holding real balance is the foregone nominal interest rate. This is seen by combining (54) and (55) to get (56). That is, the left-hand-side of (56) is the additional marginal benefit of holding real balance, whereas the right-hand-side of (56) is opportunity cost of holding real balance. Therefore, higher money growth reduces the demand for real balance, which tends to generate the Mundell-Tobin effect because households would substitute their money holding with real asset, all else equal.

In addition, the consumption Euler equation indicates that a higher nominal interest rate would generate the consumption-portfolio effect by discouraging consumption and increasing savings. The reason is due to the increased marginal rate of substitution between wealth and real balance, the third term in (58). 


\section{References}

[1] Aghion, P., Akcigit, U. and Fernández-Villaverde, J. 2013. "Optimal Capital versus Labor Taxation with Innovation-Led Growth.” NBER Working Paper No. 19086.

[2] Chu, A., and Cozzi, G., 2014. "R\&D and Economic Growth in a Cash-in-Advance Economy." International Economic Review, 55: 507-524.

[3] Doepke, M., and Zilibotti, F., 2008. "Occupational Choice and the Spirit of Capitalism." The Quarterly Journal of Economics 123(2), 747-793.

[4] Dotsey, M., and Sarte, P., 2000. "Inflation Uncertainty and Growth in a Cash-in-Advance Economy." Journal of Monetary Economics 45, 631-655.

[5] Friedman, M., 1969. The Optimum Quantity of Money. Macmillan.

[6] Hof, F.X., and Prettner, K., 2019. "The Quest for Status and R\&D-based Growth." Journal of Economic Behavior and Organization 162(C), 290-307.

[7] Michaillat, P., and Saez, E., 2019. "Resolving New Keynesian Anomalies with Wealth in the Utility Function." Review of Economics and Statistics (forthcoming).

[8] Mundell, R., 1965. "Growth, Stability and Inflationary Finance." Journal of Political Economy 73, 97-109.

[9] Pan, S., Zhang, M., and Zou, H., 2018. "Status Preference and the Effects of Patent Protection: Theory and Evidence." Macroeconomic Dynamics 22, 837-863.

[10] Sidrauski, M., 1967. "Rational Choice and Patterns of Growth in a Monetary Economy." American Economic Review 57(2), 534-544.

[11] Tobin, J., 1965. "Money and Economic Growth." Econometrica 33: 671-684.

[12] Zou, H.-F., 1994. "The Spirit of Capitalism and Long-run Growth." European Journal of Political Economy 10(2), 279-293. 